\title{
VIBRATION HEALTH MONITORING OF GEARS
}

\author{
A Thesis \\ Presented to \\ the Faculty of California Polytechnic State University, San Luis Obispo, and \\ the Faculty of Karlsruhe University of Applied Sciences
}

\author{
In Partial Fulfillment \\ of the Requirements for the Degree \\ Master of Science in Mechanical Engineering
}

by

Markus Scherer

June 27, 2012 
(C) 2012

Markus Scherer

ALL RIGHTS RESERVED 
COMMITTEE MEMBERSHIP

TITLE:

VIBRATION HEALTH MONITORING OF GEARS

AUTHOR:

Markus Scherer

DATE SUBMITTED:

June 27, 2012

COMMITTEE CHAIR:

Dr. Jim Meagher

Mechanical Engineering Professor, Cal Poly

COMMITTEE MEMBER: Dr. Mase

Mechanical Engineering Professor, Cal Poly

COMMITTEE MEMBER: Dr. Wolf-Immo Jutzler

Karlsruhe University of Applied Sciences

COMMITTEE MEMBER: Dr. Frank Pöhler

Karlsruhe University of Applied Sciences 


\section{ABSTRACT}

VIBRATION HEALTH MONITORING OF GEARS

Markus Scherer

Monitoring the health of vibrating gears is important to ensure proper operation especially in potentially life-threatening structures, such as helicopters, nuclear power plants, and uninterruptible power supply transitions in hospitals. The most common monitoring technique is casing mounted accelerometers to measure vibration. In contrast, during the last few years acoustic monitoring techniques have also provided a few diagnostic methods for gear failure. Current diagnostic methods to indicate improper gear behavior use either existing vibration data, recorded from defective gear systems, or modern dynamic models predicting gear failure behavior.

This thesis uses dynamic models to indicate, predict, and diagnose healthy and unhealthy gear systems. Influence of Tip Relief on contact forces are introduced for a decent understanding of gear dynamics followed by evaluation of common gear failure mechanisms. Two software systems were used to model gear failure: Adams $\AA_{\text {, a }}$ vibration based software that uses a rigid-elastic model for multi-body dynamics, and LSDYNA®, a transient dynamic finite element solver, capable of solving acoustic problems with the boundary element method.

Results describe tooth loads along the line of contact with respect to different Tip Reliefs and contact ratios. Gear failure is examined using a Fast Fourier Transformation to characterize patterns that can be used to diagnose unhealthy gear systems. Agreement of experimental results validates theoretical predictions of analytical and numerical solutions of gear failure especially of tooth breakage. 


\section{Table of Content}

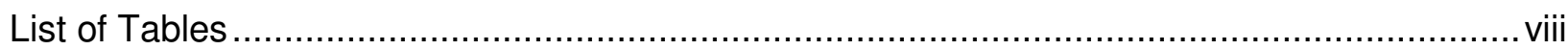

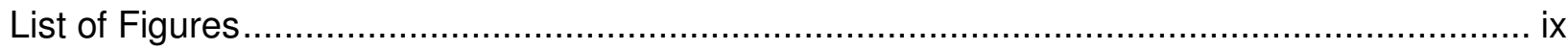

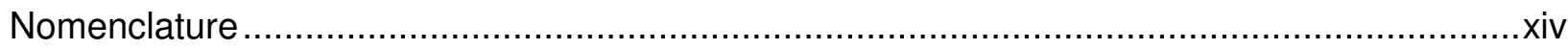

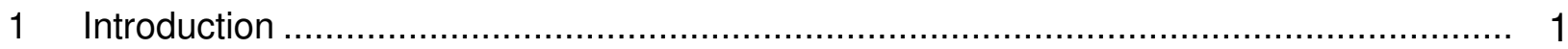

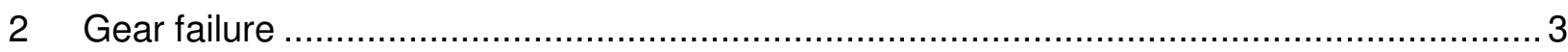

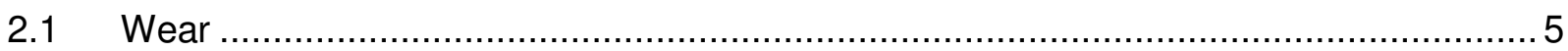

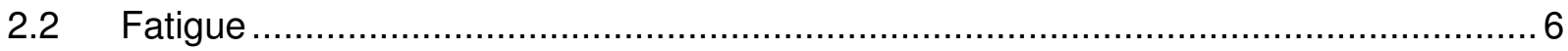

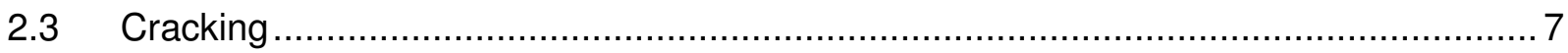

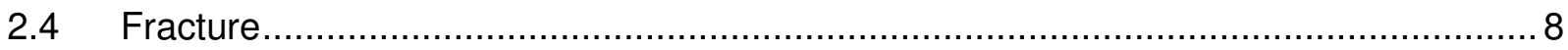

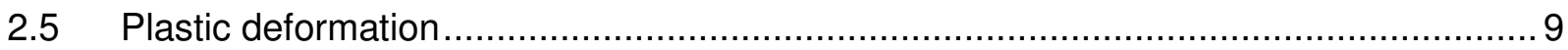

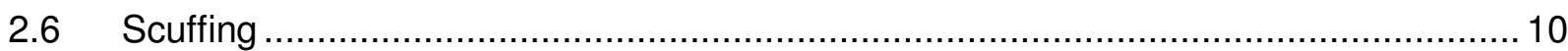

2.7 Current techniques of health monitoring gears .............................................. 11

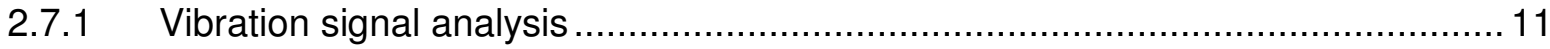

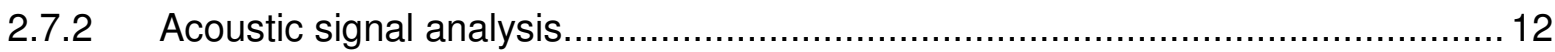

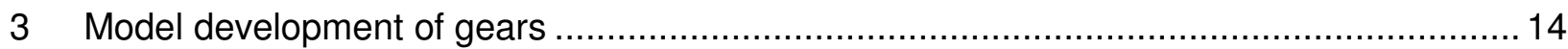

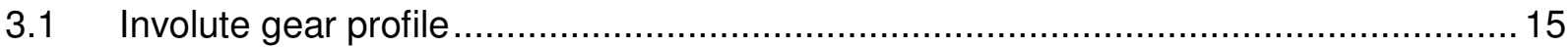

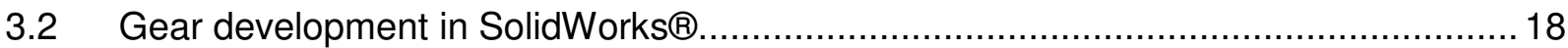

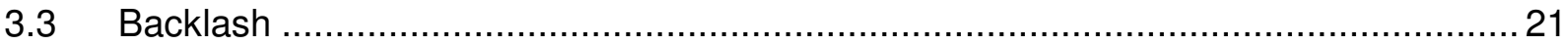

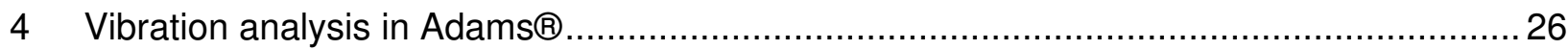

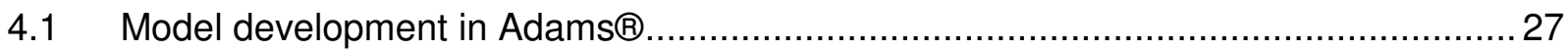

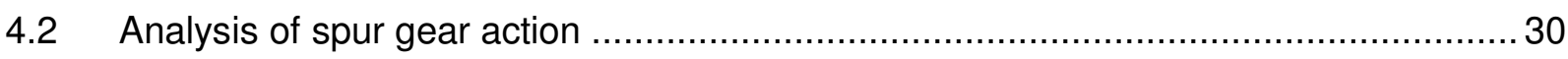

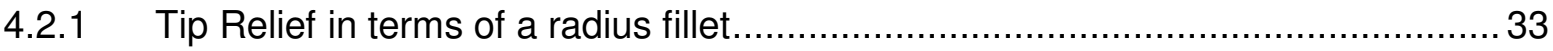

4.2.2 Tip Relief related to Rothe Erde .................................................... 35

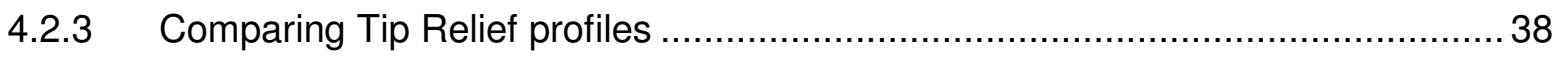




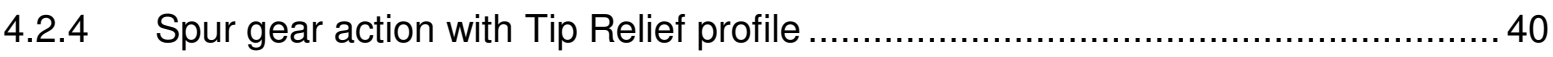

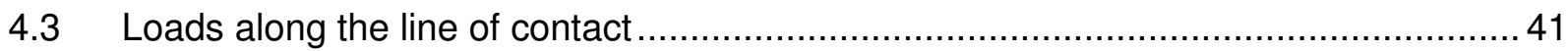

4.3.1 Single contact forces with a split gear pair............................................ 43

4.3.2 Single contact forces with a divided gear pair ........................................ 45

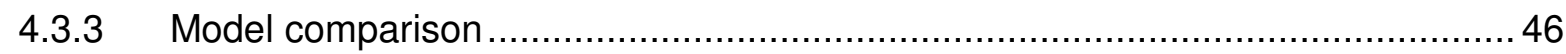

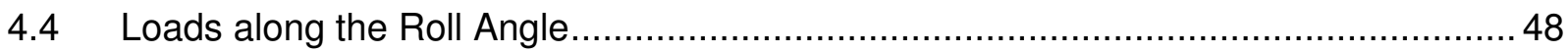

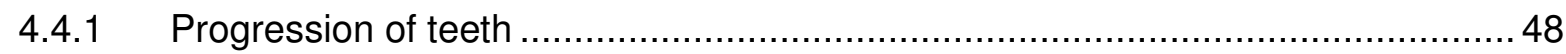

4.4.2 Experimental estimation of loads along the Roll Angle ................................ 50

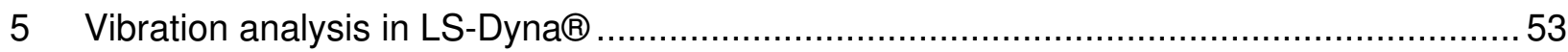

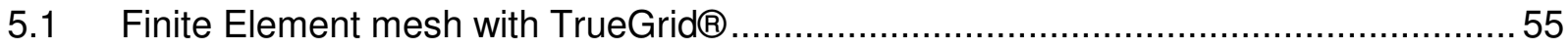

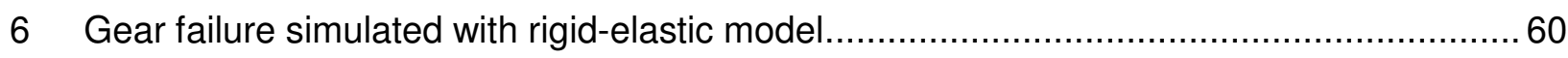

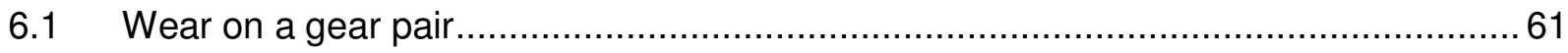

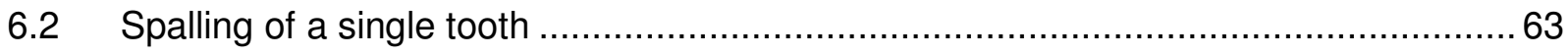

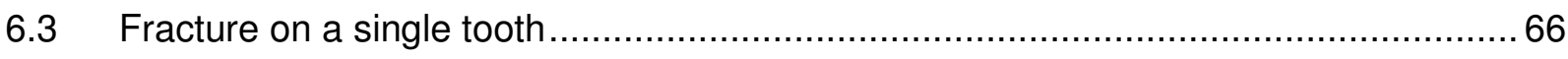

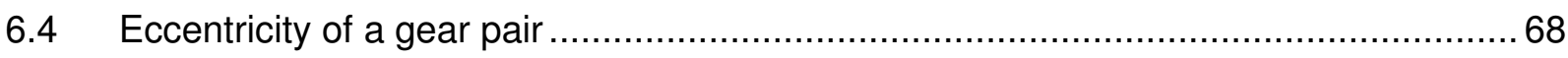

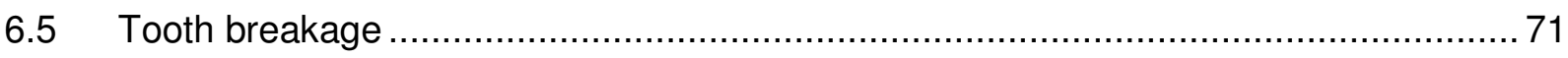

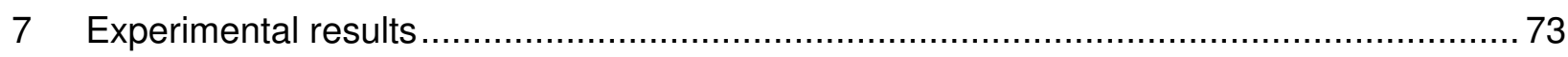

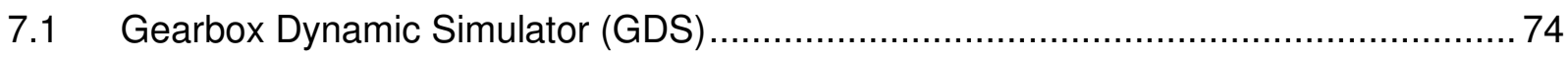

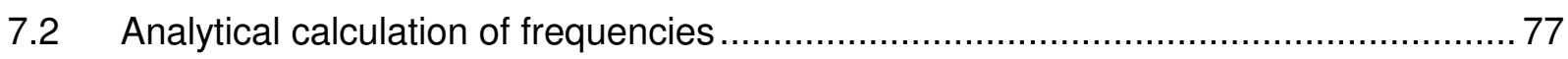

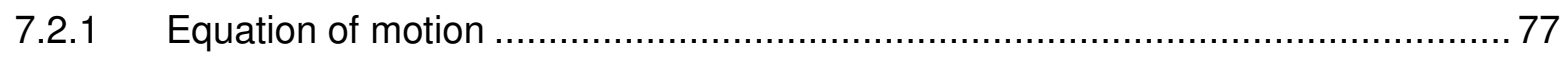

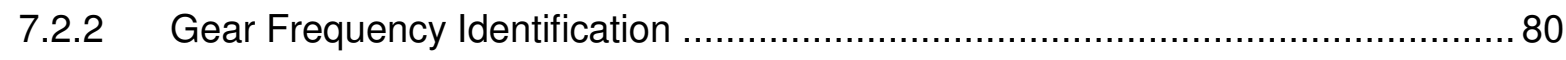

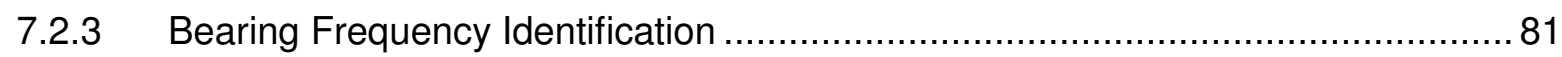

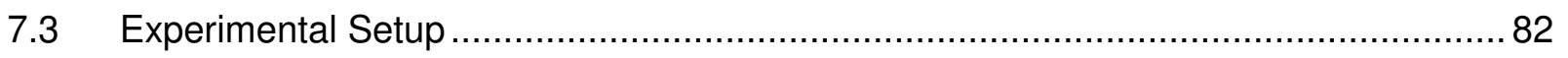

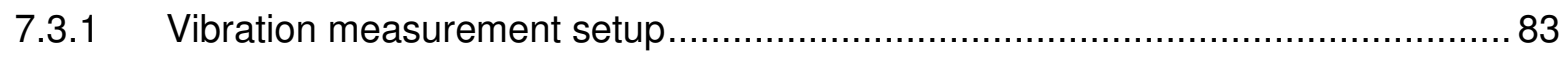

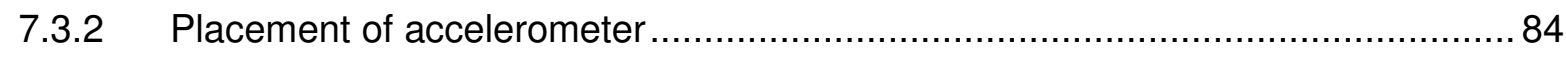

7.3.3 Acoustic measurement setup …................................................................. 85 


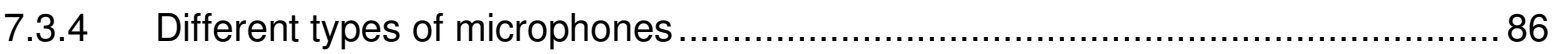

7.4 Data Acquisition of physical experimental results ......................................... 88

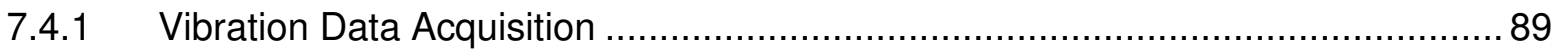

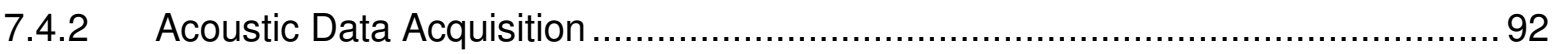

7.4.3 Experimental and Analytical result comparison ...................................... 95

7.4.4 Comparison between Adams ${ }^{\circledR}$ results and experimental results .....................97

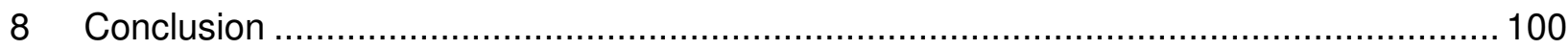

8.1 Force distribution along the line of contact..................................................... 100

8.2 Gear action with acoustic and rigid-elastic modeling ................................... 101

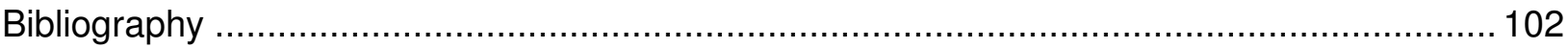




\section{List of Tables}

Table 1. Geometry of gear set of Figure 9

Table 2. Backlash values

Table 3. Values and names of the generating process of a gear model in Adams ${ }^{\circledR}$......27

Table 4. Equivalent moment of inertia for a split gear pair

Table 5. Contact ratio and Roll Angle for the first gear pair, determined with Adams $\AA$..49

Table 6. Convert rotational angle with Roll Angle .51

Table 7. Geometry of dummy model in TrueGrid .56

Table 8. Wear modification values of Figure 43 .61

Table 9. Spalling modification values of Figure 46 .63

Table 10. Fracture modifications values of Figure 50 66

Table 11. Eccentricity modification of Figure 53 68

Table 12. Current range for different voltages. 76

Table 13. Analytical Model Parameters 79

Table 14. Precision condenser Microphone (model 378B20) [28].... .87

Table 15. Calculated Frequencies compared with Experimental Results of the gear .....95

Table 16. Calculated Frequencies compared with Experimental Results of bearings.....96 


\section{List of Figures}

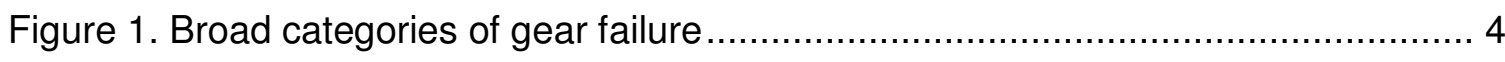

Figure 2. Gearbox Dynamic Simulator (GDS) ………….................................14

Figure 3. Process flow to develop Gearbox Dynamic Simulator (GDS) .......................14

Figure 4. Physical and mathematical model of involute gear theory ............................15

Figure 5. Inner triangle rotating along the base circle ............................................16

Figure 6. Outer triangle rotating along the involute profile....................................16

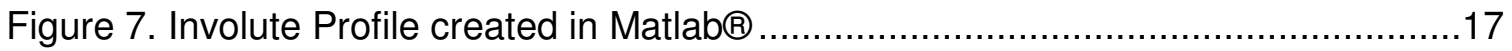

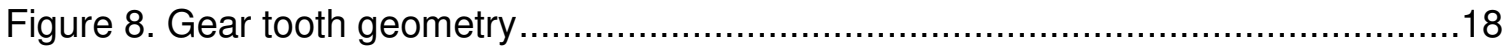

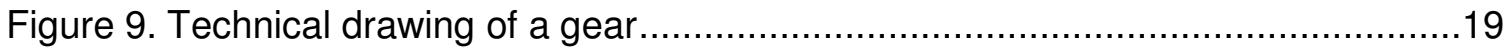

Figure 10. Backlash / clearance on spur gears ……......................................................

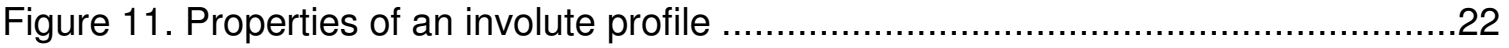

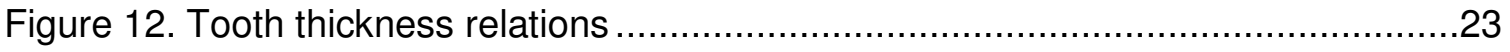

Figure 13. Increased shaft distance vs. backlash of first gear pair ..............................25

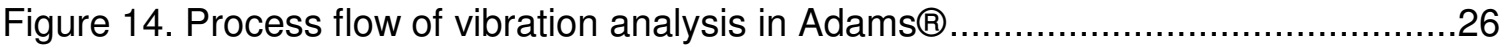

Figure 15. Impact contact condition using a spring-damper-system.............................28

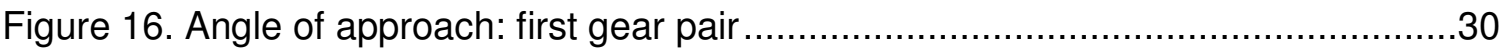


Figure 17. Angle of recess: first gear pair

Figure 18. Normalized fillet radii on gear teeth.......................................................33

Figure 19. Different tooth tip radius fillet of the first gear pair .....................................34

Figure 20. Tip Relief profile according to Rothe Erde GmbH ......................................35

Figure 21. Tip Relief with respect to an ellipse angle .................................................36

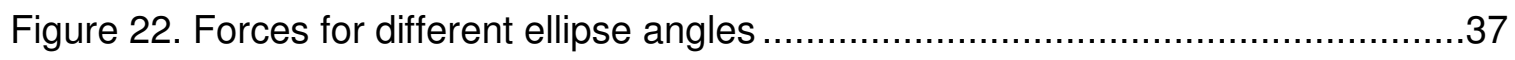

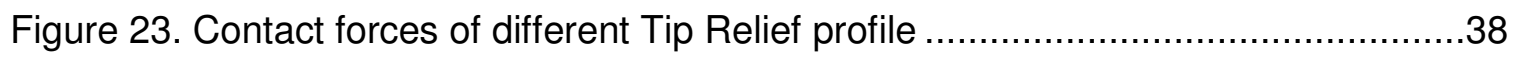

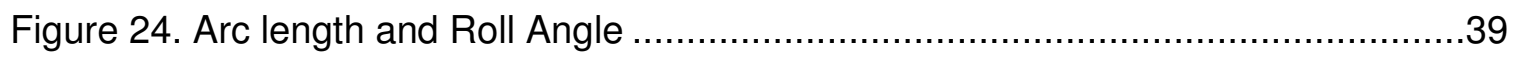

Figure 25. Tip Relief profile in terms of Roll Angle and fillet depth of PinionS1224 .......39

Figure 26. Angle of approach: first gear pair with elliptical Tip Relief ..........................40

Figure 27. Angle of recess: first gear pair with elliptical Tip Relief..............................40

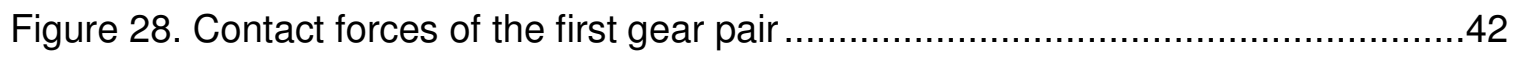

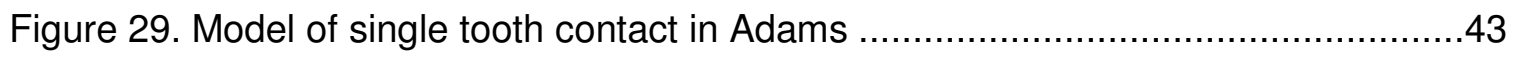

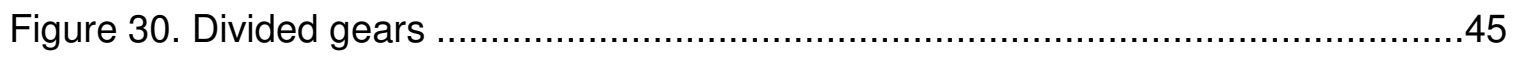

Figure 31. Comparison of split and divided gears to analyze single tooth forces ...........46

Figure 32. Single tooth contact forces of divided gear set..........................................47

Figure 33. Theoretical progression of teeth of a perfect gear set ................................48 
Figure 34. Contact forces and rotational angle of divided gear set.

Figure 35. Contact forces along Roll Angle derived by a divided gear set.

Figure 36. Graphic of tooth force along the tooth profile. .52

Figure 37. "Dummy" model and block mesh model in TrueGrid® .55

Figure 38. Computational Window and Physical Window of uncut elements .57

Figure 39. Computational Window and Physical Window of cut elements .57

Figure 40. Project lines of a one tooth block mesh model to the outer surface. .58

Figure 41. Projection areas. .59

Figure 42. Whole meshed perfect gear. .59

Figure 43. Model of wear on all teeth of PinionS1224 61

Figure 44. Time response plots of different wear cases 62

Figure 45. Frequency response plots of different wear cases 62

Figure 46. Model of spalling on one tooth of PinionS1224 .63

Figure 47. Time response plots of different spalling cases. .64

Figure 48. Frequency response plots of different spalling cases. .64

Figure 49. ${ }^{\star}$ GMF and $2^{\star} \mathrm{GMF}$ of spalling. Legend follows Figure 48. .65

Figure 50. Model of fracture of all influenced teeth of PinionS1224 and GearS1260.....66 
Figure 51. Time response plots of different fractures

Figure 52. Frequency response plots of different fractures .....................................67

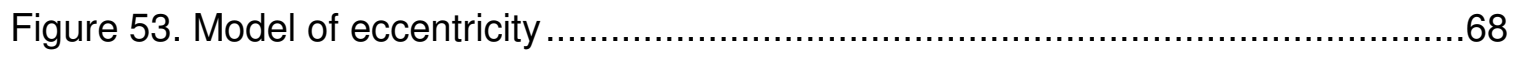

Figure 54. Time response plots of different eccentricity cases ....................................69

Figure 55. Frequency response plots of different eccentricity cases ............................69

Figure 56. $1^{*} \mathrm{GMF}$ and $2^{*} \mathrm{GMF}$ of eccentricity. Legend follows Figure $55 \ldots \ldots \ldots \ldots \ldots \ldots \ldots . . .70$

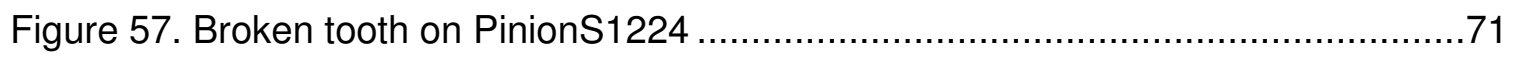

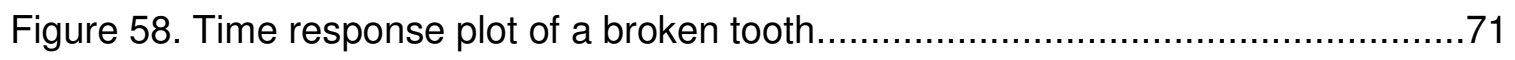

Figure 59. Frequency response plot of broken tooth..............................................72

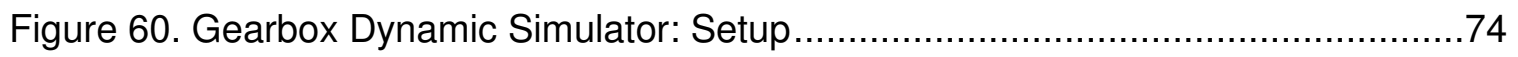

Figure 61. Two stage spur gears system on three parallel shafts .............................75

Figure 62. Magnetic particle BRAKE B220: brake performance characteristics ............76

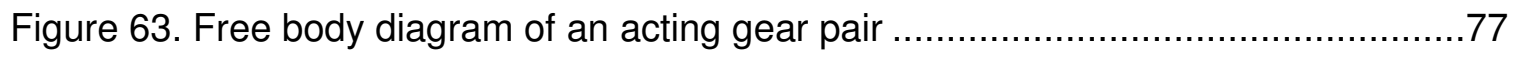

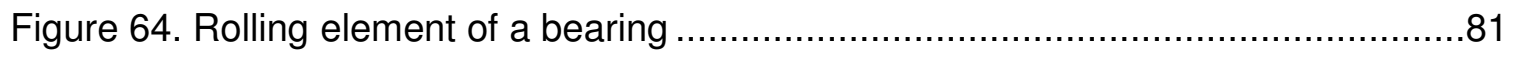

Figure 65. Set up of gear system with acoustic and vibration measurenment devices ...82

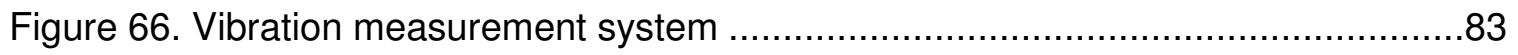

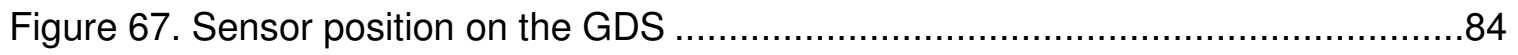


Figure 68. Acoustic measurement system

Figure 69. Free field .86

Figure 70. Pressure field .86

Figure 71. Random incidence noise .86

Figure 72. Tooth breakage of PinionS1224 .89

Figure 73. Time domain of GDS of accelerometer 89

Figure 74. Frequency domain with Hanning Window of GDS with accelerometer........ .90

Figure 75. Evidence of tooth breakage .91

Figure 76. Time domain of GDS with microphone .92

Figure 77. Frequency domain with Hanning Window of GDS with a microphone .93

Figure 78. Sidebands between Gear Mesh Frequency and first superharmonic .94

Figure 79. Frequency domain of experimental results and rigid-elastic results .97

Figure 80. First superharmonic of Figure 79. Legend follows Figure 79. .98

Figure 81. Second superharmonic of Figure 79. Legend follows Figure 79. .99

Figure 82. Contact forces along the Roll Angle with a rigid-elastic model in Adams $\AA_{\text {...100 }}$

Figure 83. Contact forces in Adams ${ }^{\circledR}$ and experimental data of an eccentric gear 101 


\section{Nomenclature}

\begin{tabular}{|c|c|}
\hline$\left(x_{c}, y_{c}\right)$ & Point on base circle in terms of Roll Angle $\theta$ \\
\hline$\left(x_{c}^{\prime}, y_{c}^{\prime}\right)$ & Point on the involute gear profile in terms of Roll Angle $\theta$ \\
\hline$B_{L}$ & Backlash \\
\hline$J_{P}, J_{G}$ & Moment of inertia: Pinion and Gear \\
\hline$R_{b}$ & Radius to a certain point at the involute profile \\
\hline$R_{i}$ & Radius to a specific point of the of the involute profile \\
\hline$T_{i}$ & Tooth thickness from at a certain point of the of the involute profile \\
\hline$c_{m}$ & Linear tooth mesh damping \\
\hline$d_{a}$ & Diameter of addendum circle \\
\hline$d_{b}$ & Diameter of base circle \\
\hline$d_{d}$ & Diameter of dedendum circle \\
\hline$k_{m}$ & Linear tooth mesh stiffness \\
\hline$r_{P}, r_{G}$ & Pinion and Gear Radius: with respect to the point of action \\
\hline$r_{b}$ & Radius of base circle \\
\hline$s_{a}$ & Arc length \\
\hline$t_{d_{b}}$ & Tooth thickness \\
\hline$\beta_{G_{\text {approach }}}$ & Angle of recess of gear \\
\hline$\beta_{G_{\text {recess }}}$ & Angle of approach of gear \\
\hline$\beta_{P_{\text {approach }}}$ & Angle of approach of Pinion \\
\hline$\beta_{P_{\text {recess }}}$ & Angle of recess of Pinion \\
\hline$\theta_{G}, \dot{\theta}_{G}, \ddot{\theta}_{G}$ & Angular displacement / velocity / acceleration of Gear \\
\hline$\theta_{P}, \dot{\theta}_{P}, \ddot{\theta}_{P}$ & Angular displacement / velocity / acceleration of Pinion \\
\hline. IGES & Initial Graphics Exchange Specification \\
\hline
\end{tabular}




\begin{tabular}{|c|c|}
\hline BEM & Boundary Element Method \\
\hline $\mathrm{C}$ & Gear Mesh Damping coefficient \\
\hline CAD & Computer-Aided Design \\
\hline e & Nonlinear Force exponent \\
\hline GUI & Graphical User Interface \\
\hline$h$ & Rothe Erde: Tip Relief depth on addendum circle \\
\hline $\mathrm{k}$ & Gear Mesh Stiffness coefficient \\
\hline$\delta$ & Penetration Depth Tolerance after a recalculation \\
\hline$\Delta \beta_{c}$ & Angle of tooth contact between pinion and gear. \\
\hline$\Delta \theta_{p}$ & Angular pitch of a gear \\
\hline$B$ & Bore diameter \\
\hline$H$ & Diameter of Hub \\
\hline$P$ & Projection of Hub \\
\hline$T$ & Input torque \\
\hline$c$ & Rothe Erde: Tip Relief depth on the outer surface \\
\hline$d$ & Pitch circle diameter \\
\hline$m$ & Modulus of a gear \\
\hline$p$ & Rothe Erde: Radius on Tip Relief \\
\hline$z$ & Number of gear teeth \\
\hline$\gamma$ & Rotation angle to displace an involute profile \\
\hline$\theta$ & Roll Angle of an involute gear profile \\
\hline$\varphi$ & Pressure angle \\
\hline S & Shaft speed \\
\hline$\theta_{1}$ & Roll Angle of displaced involute profile \\
\hline$\alpha_{1}$ & Angle between the beginning and a certain point of involute profile \\
\hline
\end{tabular}


$\rho_{1} \quad$ Arc length of a displaced involute profile

$\varphi_{1} \quad$ Angle between Roll Angle and a certain point at the involute profile 


\section{Introduction}

This thesis represents the last part of a Master's double degree program between Cal Poly and Karlsruhe, located in Germany. One program goal is for exchange students to experience and explore their major discipline in a foreign country. During a thesis, students can apply their skills and engineering techniques they have learned during their theoretical studies. The topic of this thesis is "Vibration Health Monitoring of Gears".

Vibration and noise are excited by errors in gears, process of manufacture, advancing local faults, and changing gear mesh stiffness. It is also known that errors on gear teeth cause impacts. These impacts cause oscillations and can be observed with acoustic and vibration signals.

"Fix it when it breaks," is still the most common repair strategy. However, an unscheduled total breakage of a gear system is a major concern and has sometimes serious consequences with high costs as a result. To recognize an early stage of gear failure is motivation of monitoring vibrating gears. This process involves observing a system over time using dynamic response measurements from accelerometers to measure vibration or microphones to measure sound. A prognosis to predict future health states of gears is difficult and numerous modeling techniques have been researched. One method to predict gear failure is to implement preliminary stages of gear failure in gears to characterize them. These characteristics can be used to compare a spectrum of a gear system with a reference spectrum of gear failure and their typical characteristics. With modern numerical software products it is also possible to simulate an implementation of preliminary stages of gear failure to characterize them. 
One such numeric tool is Adams ${ }^{\circledR}$. It uses rigid-elastic elements to model multibodydynamics. This Rigid-elastic model assumes rigid bodies with elastic contact conditions which involves stiffness, force exponent, damping, and penetration depth. An almost real body interaction can be simulated and solved in a short time, which makes it a powerful solver. LS-Dyna® is a solver that uses dynamic finite element models. More realistic dynamic results can be determined and the surface dynamics of gears are accurate enough to convert surface vibration to acoustic signals. Generated LS-Dyna® results can be compared to experimental results. Both programs reduce the complexity of reality, but provide powerful results to model certain types of gear failure mechanism. 


\section{Gear failure}

There are many possibilities to describe, classify and evaluate gear failure. Several authors have studied gear failure and defined different ways to classify them:

- An accepted way to describe gear failure is associated with the definition: "A gear has failed when it can no longer do efficiently the job for which it was defined" [1, p 85].

- Gear failure can be separated into lubricated-related failure, like overload bending and fatigue and nonlubricated-related failure, like Hertzian fatigue (pitting wear and scuffing). These classifications are described in Erricho. [5]

- Gear failure can be divided into gear tooth flank failure like pitting, scuffing, and wear or failure modes on gear root fillets, like bending, fatigue, and impact. [7]

- In 1973 Shipley divided gear failure in their frequency of occurrence. [6] He divided it into:

○ Fatigue: Tooth bending, surface contact (pitting or spalling), rolling contact, thermal fatigue

- Impact: Tooth bending, tooth shear, tooth chipping, case crushing, torsion shear

- Wear: Abrasive, adhesive

- Stress rupture: Internal, external

- The American Gear Manufacturers Association (AGMA) has classified 36 modes of gear failure which are described in the AGMA gear failure nomenclature. It is organized into broad categories of wear, scuffing, plastic deformation, contact fatigue, cracking, fracture and bending fatigue. [8] 
These methods define gear failures and their importance is based on a certain time period. One method to evaluate important and current gear failure is the number of scientific articles and patents to accurately define gear failure over a certain time. Google scholar is a platform, where articles and patents can be found. The number of results correlates with the current importance. The American Gear Manufacturers Association (AGMA), which is the trade group of some companies in manufacturing gears and gearing, provides names and definitions of gear failures. Figure 1 shows broad categories of gear failure. It is ordered in the decreasing frequency of all mechanisms. Wear, for instance, has more than 50,000 published papers and patents and is currently the most critical gear failure mechanism.

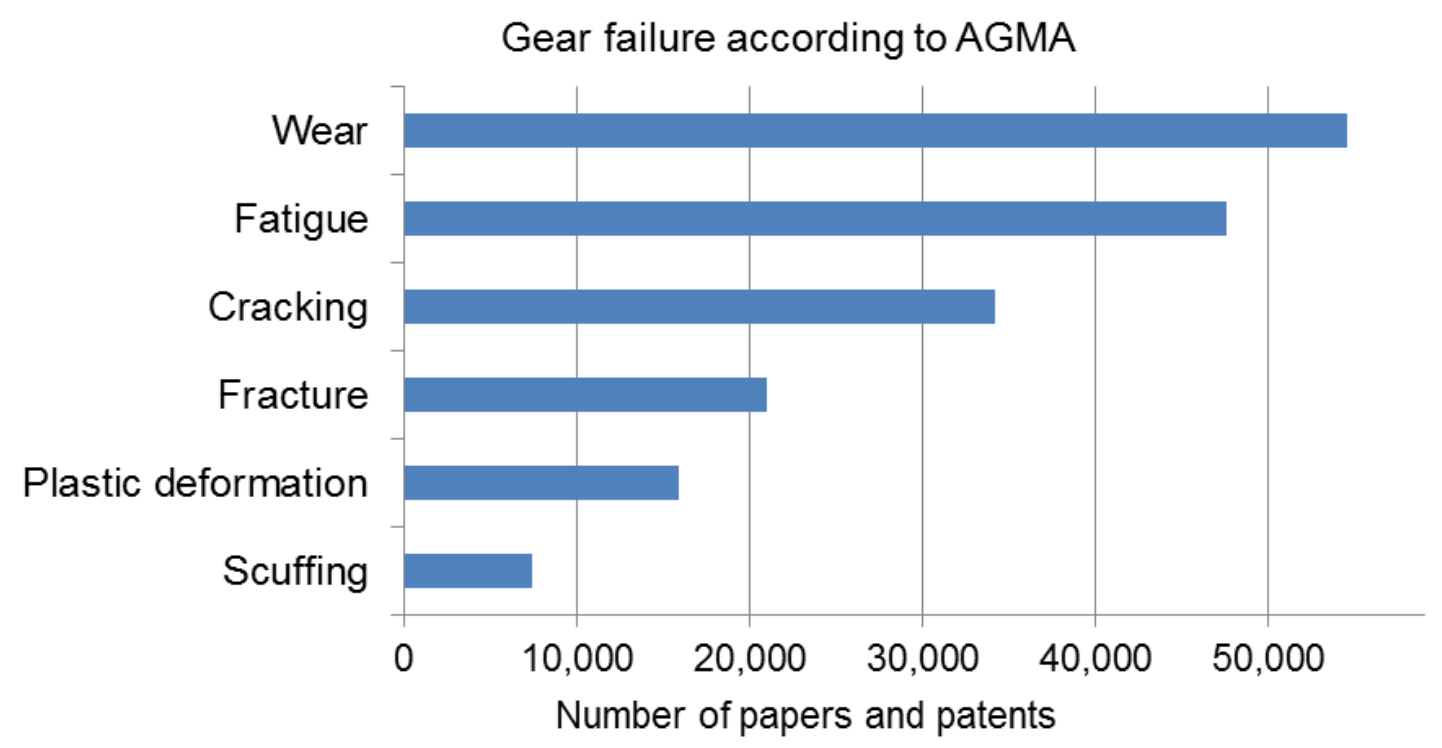

Figure 1. Broad categories of gear failure

This chapter describes broad categories of gear failure with all their subcategories. 


\subsection{Wear}

Definition: Wear describes a loss or removal of material of gear flanks. In terms of gear failure, it is more a deterioration of a gear profile, for instance, a damage of a tooth layer. Adhesive and abrasive wear are important modes of wear. Abrasive wear occurs when a surface is cut away by abrasive particles. These particles must be washed away to avoid these particles destroying the tooth surface. This primary failure can lead to adhesive wear, which is an unwanted displacement and attachment on a gear profile. Particles in lubrication, for example, can be welded on a tooth surface under high pressure. Material transfer from one tooth surface to another can further displace gear material.

Subcategories of wear: Scaling, Electrical discharge, Polishing, Corrosion, Erosion, Rippling, Adhesion, Abrasion, Cavitation, and Fretting corrosion. [8]

Hints to avoid wear: Wear and an increase in vibration decreases if loads along the line of contact are continuous without erratic load changes. A clean lubricant without any contaminants and with a correct viscosity is necessary to keep wear low. Therefore, it is necessary to filter lubrication to avoid a continuous supply of abrasive material. Wear also causes other forms of gear failure and is quite often the beginning of gear failure. It is very important to avoid the first step of deconstruction. 


\subsection{Fatigue}

Definition: Fatigue occurs under repeated stresses which are lower than ultimate tensile strength and higher than "fatigue limit". Pitting is the most common mode of fatigue and a particular form of it is spalling.

A typical fatigue failure is divided in three different parts. First, fatigue starts at a particular defect point of the gear mainly in flank areas. It normally has pits less than $1 \mathrm{~mm}$ diameter and it is called initial pitting. This particular part progresses its pits successively under cycles of loading and is called progressive pitting or macropitting. In this part the direction of progression of fatigue can be seen and at the end a crack might result from shear or tension.

Subcategories of fatigue: Pitting, Low-cycle fatigue, High-cycle fatigue, Micropitting, and Subcase fatigue. [8]

Hints to avoid fatigue: The more number of cycles a gear has, the more likely fatigue will occur. Therefore, a replacement after a dangerous number of gear cycles might be necessary. If stress amplitudes are under the fatigue limit, no fatigue will occur. This gear failure is highly attracted to grooves, notches or imperfections on the tooth surface. The goal is to avoid imperfections to stop the first step of fatigue. 


\subsection{Cracking}

Definition: Cracking starts with small stress raisers quite often in the root of a gear. This causes unsuspected overloads with a tooth breakage as a result. Cracking is also associated with a high sliding speed which raises the temperature of the hardened case. Cold lubrication and hot gears lead to thermal fatigue cracks or hardening cracks associated with heat treated gears. Grinding cracks are also a result of localized overheating but it occurs on the tooth surface after the tooth finished grinding on the gear tooth pair.

Subcategories of Cracking: Grinding cracks, Hardening cracks, Fatigue cracks, Rim and web cracks, and Case/core separation. [8]

Hints to avoid Cracking: A difficult part of designing gears is to dimension a part. Especially unpredictable dynamic loadings could make troubles. Therefore, it might be helpful to increase tooth strength by increasing the modulus, face width, or diameter to reduce loading and mechanical stresses. To reduce thermal stress, it is helpful to choose the appropriate lubrication. 


\subsection{Fracture}

Definition: Fracture is also called tooth breakage or rupture. It is one of the most dangerous gear failures because the whole gear could be damaged or it might destroy other components like shafts or bearings. Brittle fracture is a rapid crack with less deformation while ductile fracture has a deformation before a part of a gear breaks. $\mathrm{A}$ combination of brittle and ductile fracture is called mixed mode fracture. Shear fracture is caused by an overload of a single tooth. It starts with a weak point within a gear which builds up higher stresses than the strength of material allows. Therefore, a small crack can grow and a tooth might break off.

Subcategories of Fracture: Tooth shear, brittle Fracture, mixed mode Fracture, Fracture after plastic deformation, and ductile Fracture. [8]

Hints to avoid Fracture: The crack origin is identified beneath the hardened layer. It is difficult to detect and identify them and no standards or methods for prediction exist. A tooth fracture is caused by high overloads. Cracking starts quite often with fatigue, small grooves, or notches that could lead to repeated overloads on a certain point on the gear. Avoiding the first step of gear failure is imperative. 


\subsection{Plastic deformation}

Definition: Plastic deformation might occur if softer gear materials are subjected to heavy loads. However, deformation could be beneficial to correct minor errors but as soon as the deformation is too high the gear has to be replaced before it gets cracked. Hot flow occurs due to a temperature higher than the recrystallization temperature associated with insufficient lubrication. Cold flow occurs at a temperature below the recrystallization temperature. Ridging occurs when gears are exposed to reversal of directions. Due to the direction of friction, a groove is formed along the pitch line. Ridging are grooves on active flanks of gears while rippling is more a wave deformation at right angles to the direction of sliding. The most common plastic deformation is rolling, which occurs due to high contact stresses on acting gears. This kind of material displacement can be observed on the pitchline.

Subcategories of plastic deformation: Rolling, Cold flow, Hot flow, Tooth hammer, Rippling, Ridging, Indentation, Burr, Root fillet yielding, and Tip-to-root interference. [8]

Hints to avoid plastic deformation: Overheating gears are quite often associated with insufficient lubrication. A higher viscosity of lubricant helps to avoid ridging or grooving. If another choice of lubricant doesn't help it is necessary to use material with a higher strength or more hardened gear surface. 


\subsection{Scuffing}

Definition: Scuffing is also called scoring. It occurs when there is no oil film between two acting gears. This might happen if the gear speed is too slow or the temperature of the oil is too hot to keep the teeth surfaces apart. If the pressure is very high, and depending on the heat, local welding and tearing can occur. As soon as deterioration starts it is difficult to stop scuffing because the surface becomes rough and reestablishing an oil film is more difficult. Scuffing can be divided into severe, moderate, and mild scuffing. Mild scuffing is the first step of scuffing and occurs to small areas with small effects of welding and tearing. If nothing changes, a progressive scuffing is expected and is called moderate scuffing. The last stage is severe scuffing on significant portions, like addendum or dedendum, so that the gear cannot efficiently do the job for which it is designed. When scuffing continues and increases, scoring is a result. It is predominant over the pitch line region.

Subcategories of Scuffing: severe Scuffing, mild Scuffing, and moderate Scuffing. [8]

Hints to avoid Scuffing: The right lubricant is important to avoid metal to metal contact and to avoid scuffing. Increasing the oil viscosity helps to get a thicker oil film. Decreasing the oil viscosity helps to reduce heat generation and lower friction. Using light loads and slow speeds keeps both gears apart. 


\subsection{Current techniques of health monitoring gears}

There are currently three approaches to detect gear failure in geared systems:

- Vibration signal analysis

- Acoustic signal analysis

- Debris monitoring

Vibration signal analysis is the most common and oldest health monitoring technique. Acoustic signal analysis has developed during the last years dramatically and is becoming more important. Both monitoring techniques are explained below.

\subsubsection{Vibration signal analysis}

Vibration signal analysis is the most popular health monitoring technique. Three of the most common vibration-based monitoring techniques are classified as frequency/cepstrum analysis, time statistical analysis, and time-frequency analysis. A brief description is given below.

Frequency/Cepstrum analysis is the most common gear diagnostic technique. It is a spectral analysis method comparing a spectrum of a gear system with a reference spectrum of gear failure. It could be possible to identify some gear failure. Cepstrum uses the inverse of the Fourier transformation. Gear failure with its periodicity in the spectrum is highlighted. This is a powerful tool especially for a few pairs of gears. However, the more gear pairs are acting the more difficult is it to recognize gear failure. [26]

Time/Statistical analysis is an averaging process of gear cycles. Time synchronous average (TSA) averages a large number of gear cycles synchronous with the shaft 
speed. The advantage of synchronization is that all non-synchronous periodic events can be removed. This is a reliable method to identify advanced gear tooth damage. [26]

Time-Frequency analysis uses a time-frequency analysis techniques like short-time Fourier transform (STFT) to diagnose gear failure. The energy distribution of the timefrequency domain is a successful method to detect gear failure. Wavelet transform (WT) is also a time-frequency based method to detect cracked and chipped gear failure. [26]

\subsubsection{Acoustic signal analysis}

Acoustic condition monitoring contributes only a little towards health monitoring of gears. Vibration signals are better understood with their dynamic characteristics of gear failure. Background noise and the motor, for example, disturb acoustic measurements. One advantage of acoustic health monitoring is that no vibration sensors are necessary. Measuring gear noise from a certain distance is also safe and independent from the temperature of the gearbox. Further, acoustic signals can be recorded at a distance without touching the gear system.

Naim Bzydar and Andrew Ball [13] demonstrated acoustic condition monitoring of local faults with time-frequency analysis representations like Wigner-Ville distribution (WVD), pseudo-Wigner-Ville distribution (SPWVD), and wavelet transform (WT). According to their research early faults and progressing faults can be affective detected by acoustic signals.

Tim Toutountzakis and David Mba [27] contributed also towards health diagnostics of gear failure. Acoustic emission (AE) occurs by rapid release of elastic energy. Elastic 
waves spread out in all directions and provide useful information about gear failure. Acoustic emission occurs also from non-rotating elements like gear housing. To know about the acoustic emission, piezoelectric sensors can be attached on the housing. According to his research, acoustic emissions correlate with speed and progression of gear defect. Gear failure can be indicated from the bearing housing.

Hints to identify health of gears in order to reduce noise

- According to G. Niemann and H. Winter [5] gear noise occurs due to surface roughness, impact of tooth and sliding and rolling friction, and at the contact point due to error in the gear profile.

- Prof. K.Gopinath \& Prof. M.M.Mayuram [14] suggest methods of combating noise, like improving the tooth finishing operations, modifying the profile by flanking, increasing the contact ratio, equalizing the load along the face width of the tooth rim, using crowned gears, and improving the design of the covers and housings.

- P. S. Houghton [3] determined important design and manufacture hints in order to minimize noise like choose the right clearance to reduce harsh backlash, use gear materials with a high damping ability to avoid noise, the casing should muffle any noise, and lubrication reduces heat and wear but also noise. 


\section{Model development of gears}

A Gearbox Dynamic Simulator (GDS) is used to simulate gear failure. In order to compare numerical results with physical results, the exact geometry must be described with CAD software. This chapter introduces the development of the gear system. SolidWorks ${ }^{\circledR}$ is used to create, modify, analyze, and optimize this gear set, shown in Figure 2.

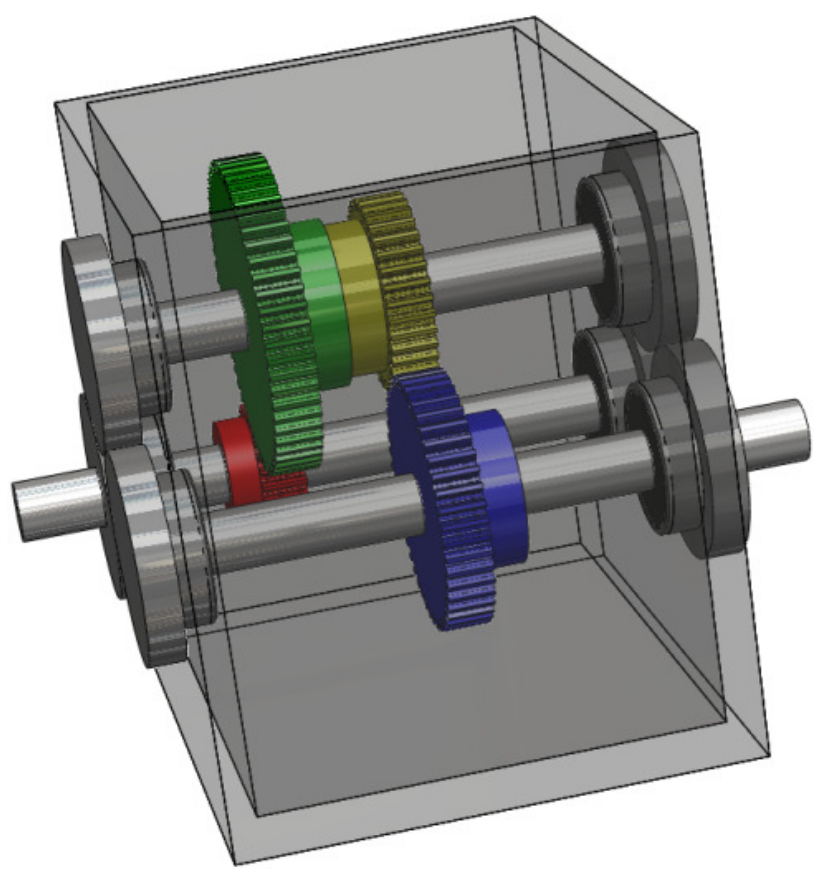

Figure 2. Gearbox Dynamic Simulator (GDS)

To develop the gear system, Matlab® is used to create the tooth profile of spur gears as well as to calculate backlash. The procedure to design a gear is shown in Figure 3.

Involute gear profile
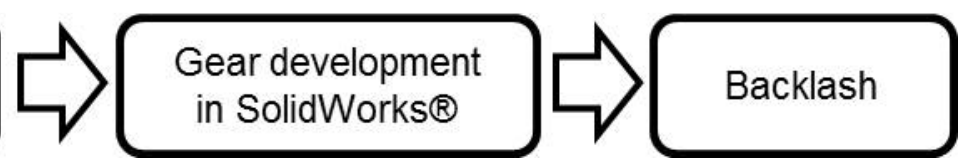

Figure 3. Process flow to develop Gearbox Dynamic Simulator (GDS) 


\subsection{Involute gear profile}

Involute gear profile describes the geometry of gear teeth. Matlab®, a numerical computing environment from MathWorks $\AA$, is used to calculate it. This is a programming environment to develop and visualize algorithms and designed for solving technical computing problems.

Involute gear profile is the most common tooth profile in gearing systems, which means that the profile of teeth is an involute of a circle. A physical way to create an involute profile is to unwrap a string from a cylinder, shown in Figure 4. The advantage of an involute profile is that gear teeth contact occurs at a single instantaneous point at a certain angle to both gear axes respectively.
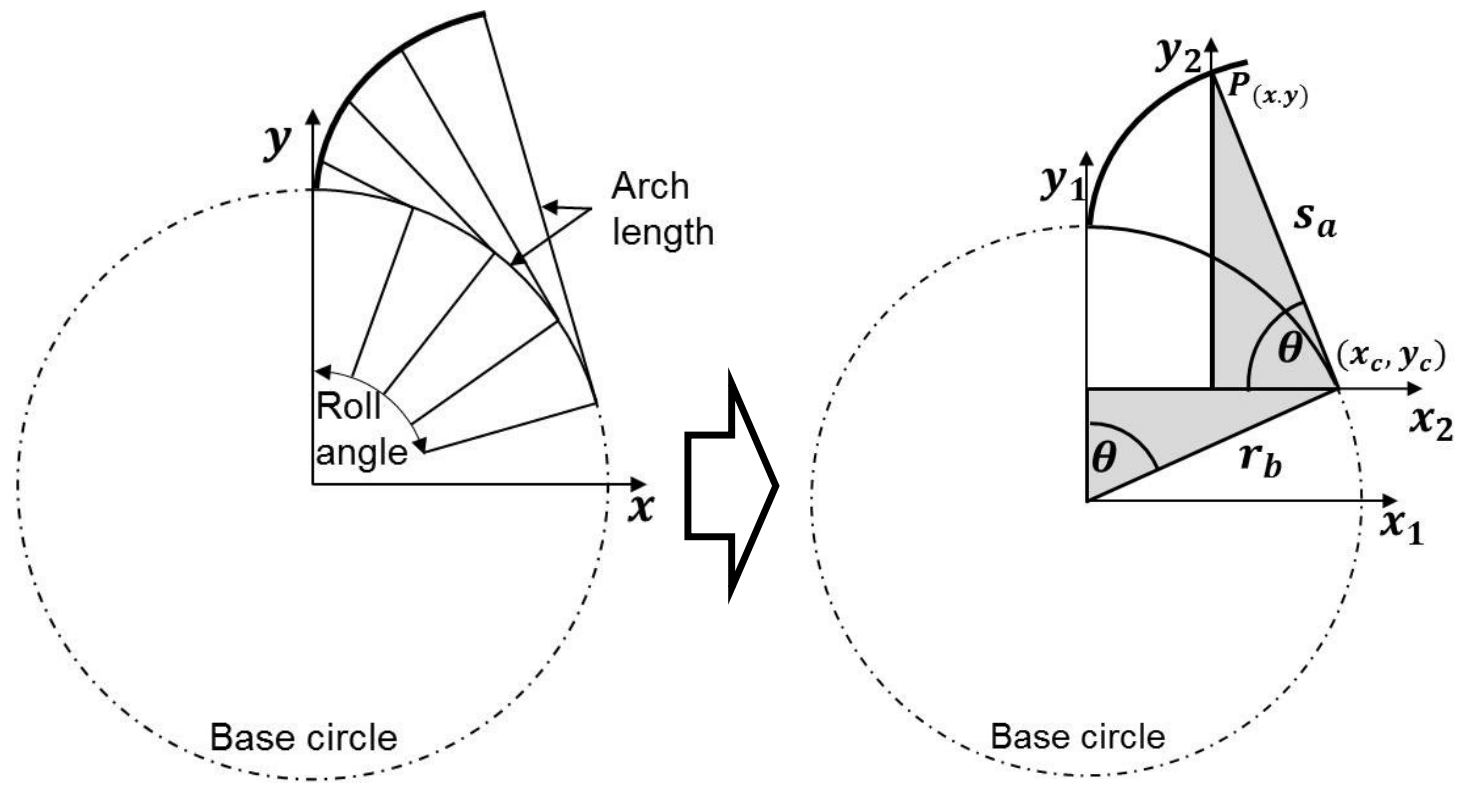

Figure 4. Physical and mathematical model of involute gear theory 
The mathematical model in Figure 4 can be divided into two single triangles which are similar to each other. The first triangle, shown in Figure 5, is rotating along the base circle. The second triangle, shown in Figure 6, rotates along the involute profile and determines single points of the involute profile. First $x_{c}$ and $y_{c}$ of the inner triangle are determined to calculate single points on the gear surface $x_{c}{ }^{\prime}$ and $y_{c}{ }^{\prime}$ of the outer triangle.

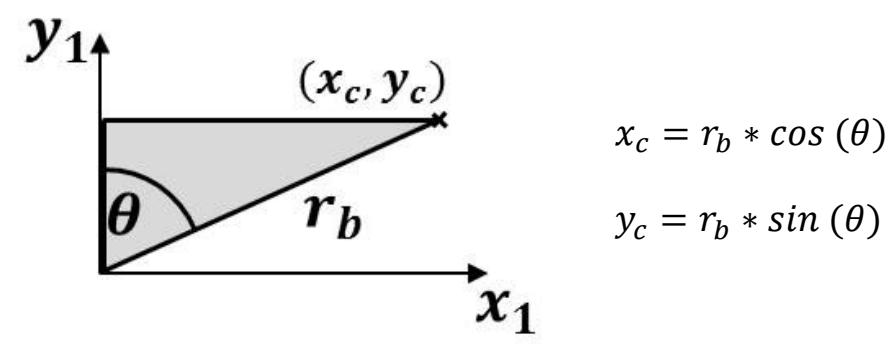

Figure 5. Inner triangle rotating along the base circle

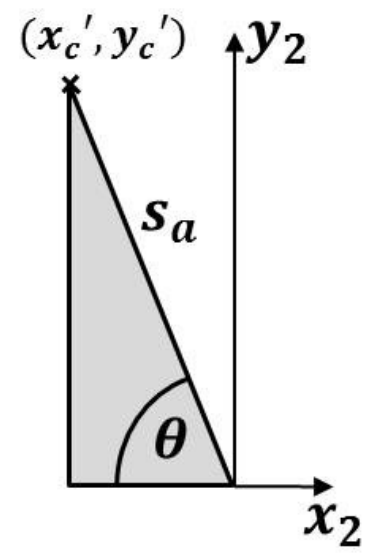

$$
\begin{aligned}
& x_{c}{ }^{\prime}=s_{a} * \cos (\theta) \\
& y_{c}{ }^{\prime}=s_{a} * \sin (\theta) \\
& \text { Using: } s_{a}=r_{b} * \theta \\
& -x_{c}{ }^{\prime}=r_{b} * \theta * \cos (\theta) \\
& -y_{c}{ }^{\prime}=r_{b} * \theta * \sin (\theta)
\end{aligned}
$$

Figure 6. Outer triangle rotating along the involute profile

Line " $r_{b}$ " and line " $s_{a}$ " are perpendicular to each other since " $\mathrm{s}$ " is tangent to the base circle. Therefore, both triangles are similar and the angles $\theta$ in both triangles are the same. 
Coordinates of $P_{(x, y)}$ can be described with:

$$
\begin{aligned}
& x=x_{c}-x_{c}^{\prime}=r_{b} * \sin (\theta)-r_{b} * \theta * \cos (\theta) \\
& y=y_{c}+y_{c}^{\prime}=r_{b} * \cos (\theta)+r_{b} * \theta * \sin (\theta)
\end{aligned}
$$

Sixty three single points along the curve are created to design a tooth in SolidWorks®. Each single point of one gear is shown in Figure 7.

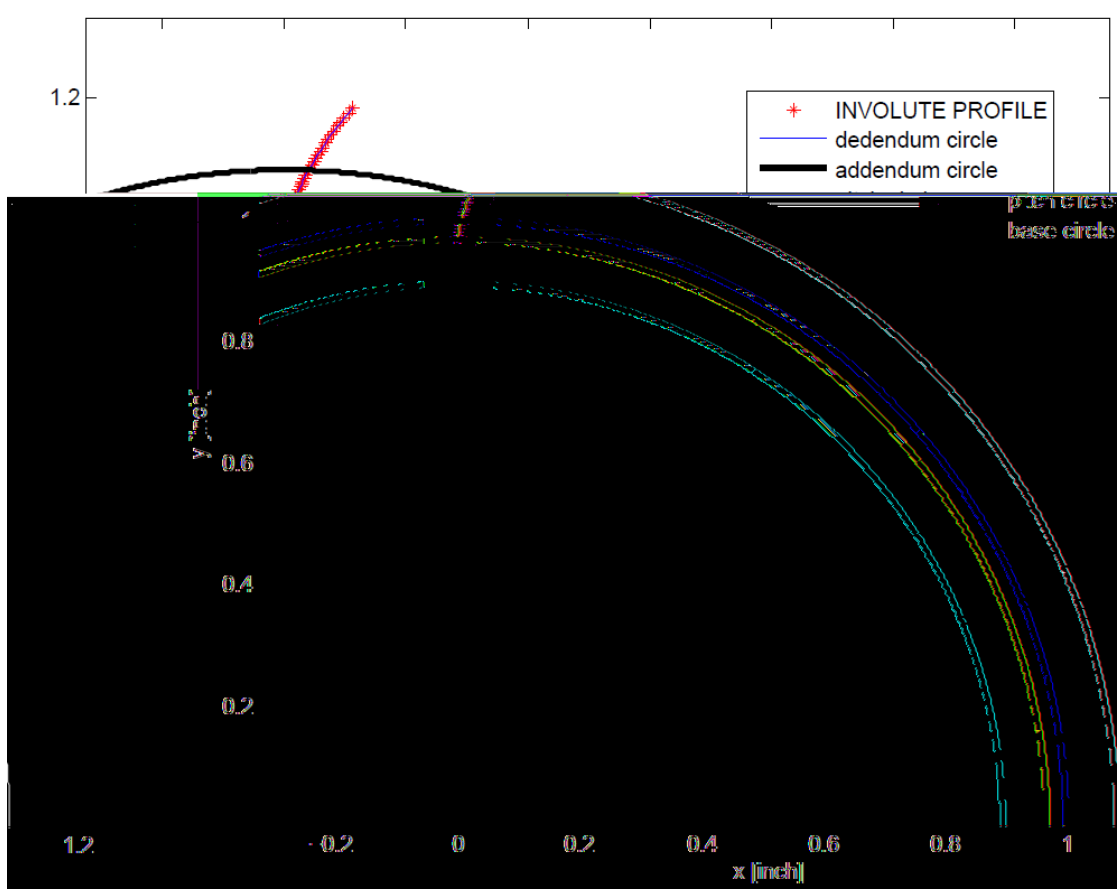

Figure 7. Involute Profile created in Matlab ${ }^{\circledR}$ 


\subsection{Gear development in SolidWorks $\AA$}

To design a gear, SolidWorks $\AA$, a product of "DassaultSystème®," is used. Besides 3D design and simulation tools, SolidWorks ${ }^{\circledR}$ also provides a product data management system.

SolidWorks ${ }^{\circledR}$ offers several interfaces to import points of the involute profile. One possibility is to create a curve through points. The number of points defines the order of curve. The more points are imported, the more precise and accurate the curve is. Matlab $\AA$ creates 63 points along the involute gear profile within $36^{\circ}$ radius of curvature. Figure 8 shows a typical single tooth profile.

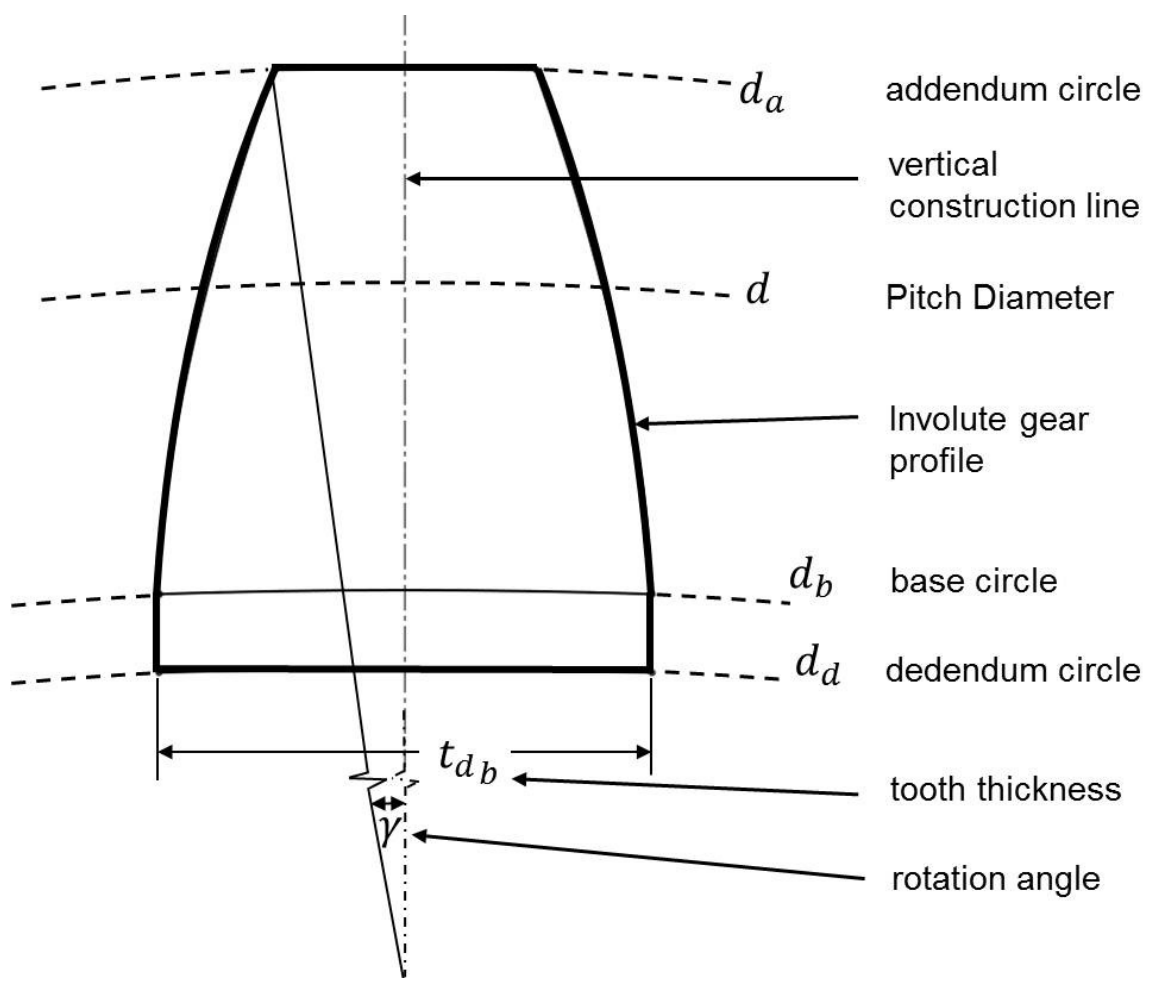

Figure 8. Gear tooth geometry 
Figure 9, shows a drawing of spur gears. Table 1 includes all their values.

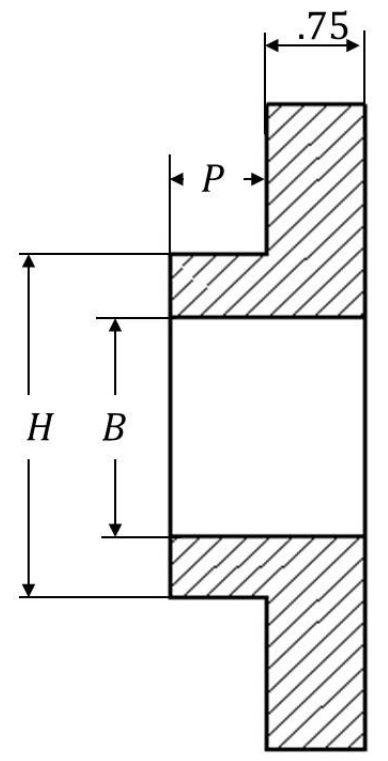

Section $A-A$

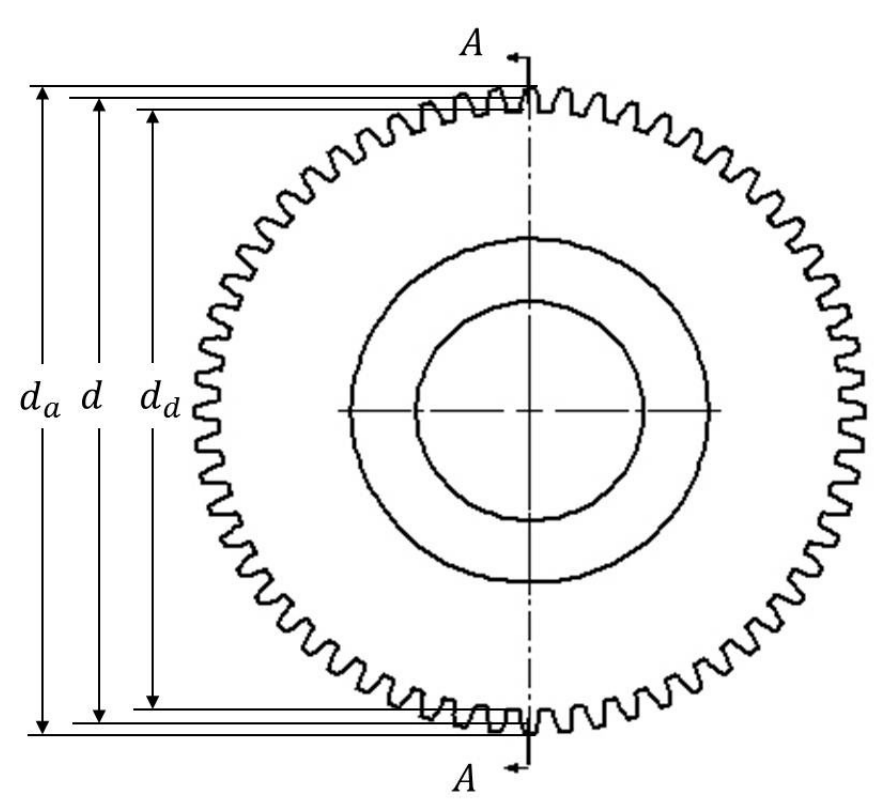

Figure 9. Technical drawing of a gear 
Table 1. Geometry of gear set of Figure 9

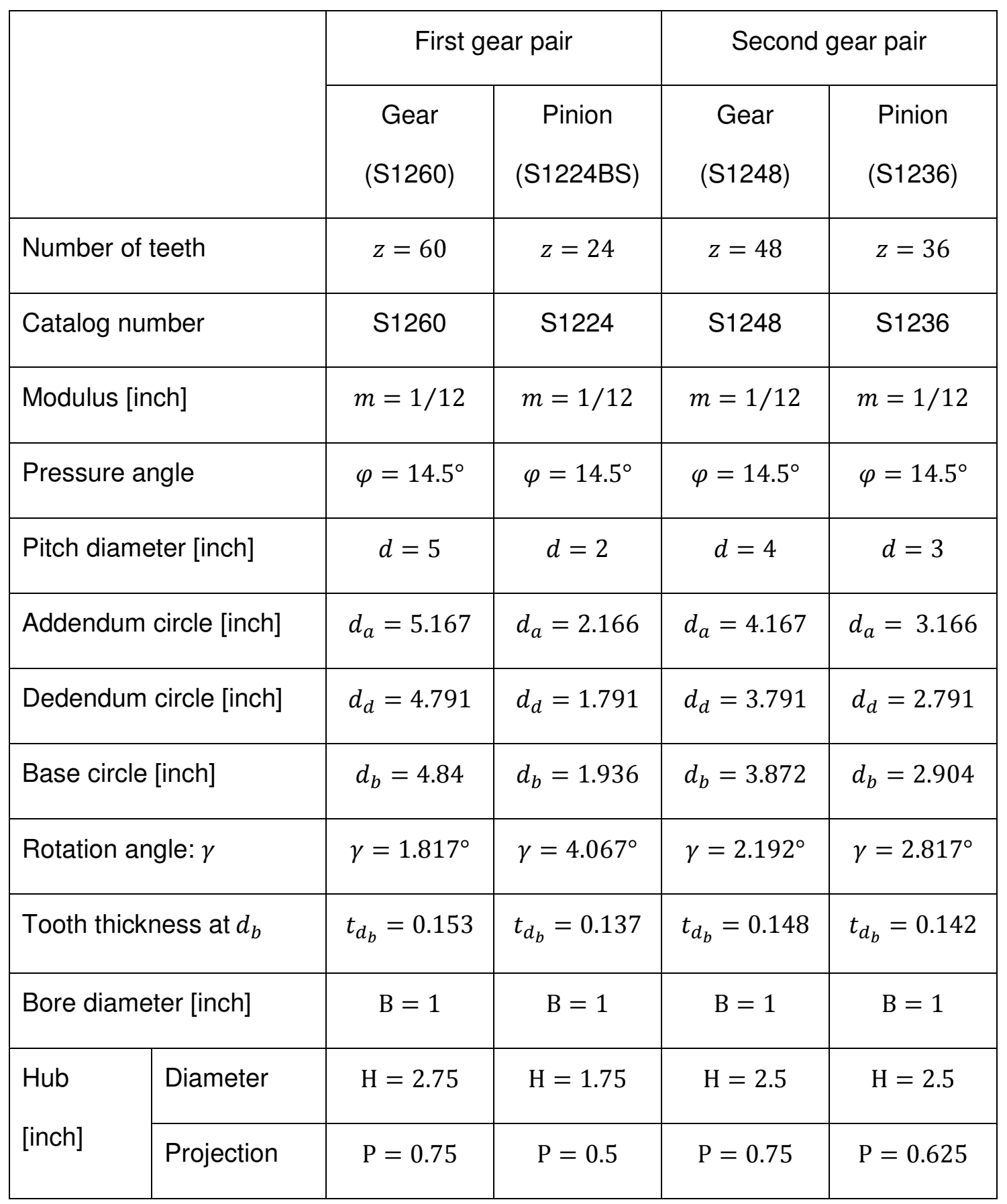




\subsection{Backlash}

In order to reduce noise, friction, and heat, backlash is necessary. Backlash is also called clearance and increases the shaft distance between both gears. The higher the shaft distance, the larger is the backlash. Figure 10 shows backlash $B_{L}$ between PinionS1224 and GearS1260.

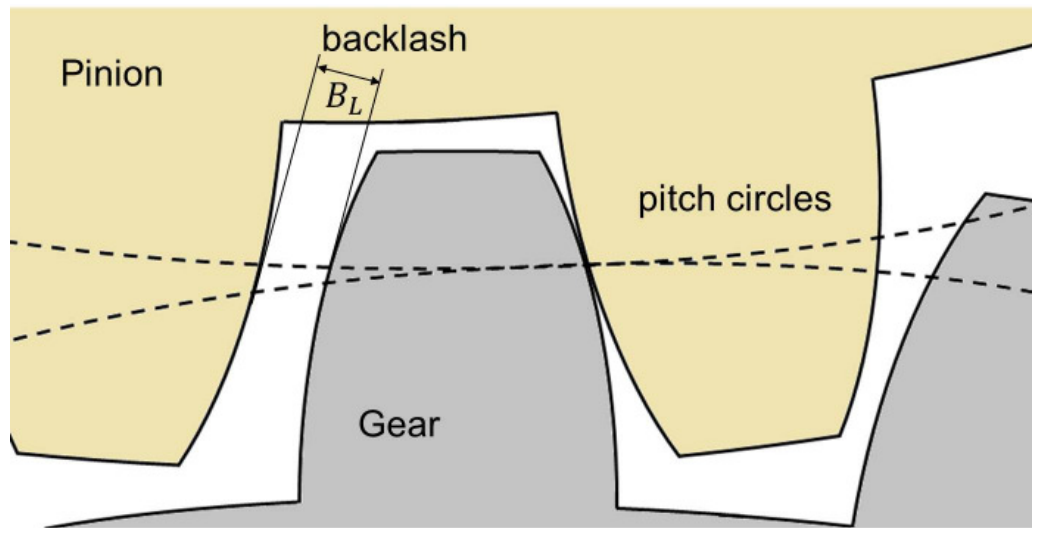

Figure 10. Backlash / clearance on spur gears

Typically, manufacturers suggest a backlash and the corresponding shaft distance where a minimum of noise and vibration occurs. However, some manufacturers suggest only backlash and the operational shaft distance is unknown like the GDS. Therefore, it is necessary to calculate the shaft distance in terms of backlash. Raymond J. Drago suggests in "Fundamentals of Gear Design" [9] a solution to calculate the shaft distance of an involute gear profile for a given backlash. First, tooth thickness at the operating pitch diameter is calculated. Figure 11 shows properties of an involute gear profile. 


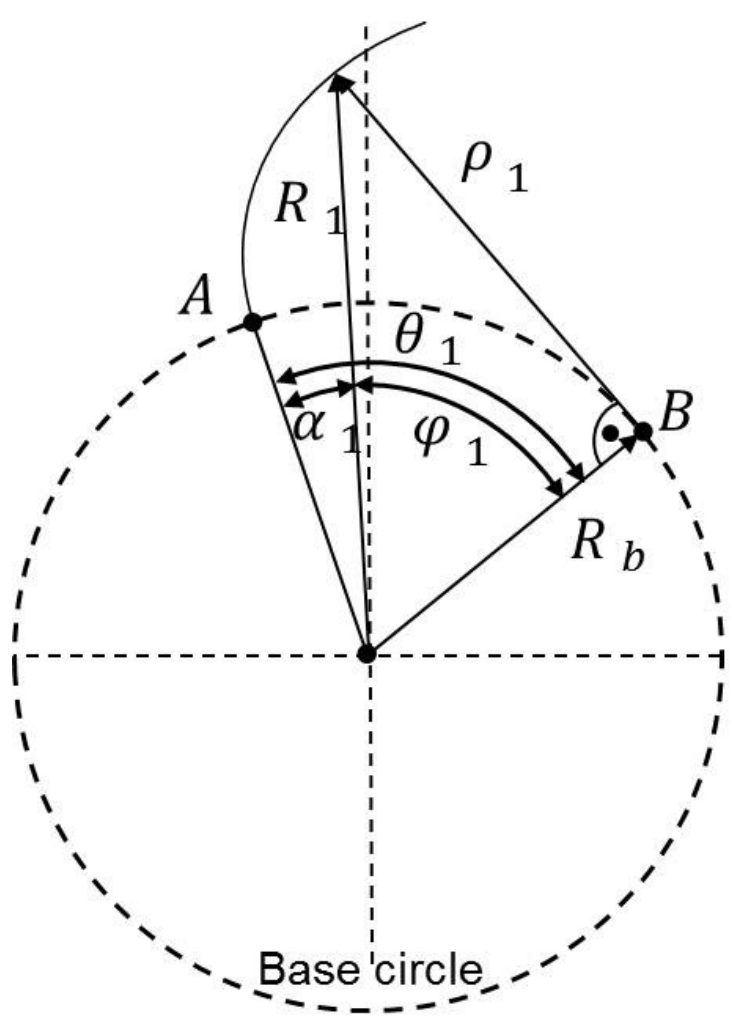

Figure 11. Properties of an involute profile

Roll Angle $\theta_{1}$ can be defined with the arc length between $A$ and $B$ :

$$
\theta_{1}=\frac{\rho_{1}}{R_{b}}
$$

Roll Angle $\theta_{1}$ can be also expressed between the triangle of length $\rho_{1}, R_{b}$ and $R_{1}$ :

$$
\begin{array}{ll}
\tan \left(\varphi_{1}\right)=\frac{\rho_{1}}{R_{b}} \quad[9, \text { eq. 3.20] }
\end{array}
$$

Therefore we can express the angle $\alpha_{1}$ with the angle $\varphi_{1}$ :

$$
\alpha_{1}=\theta_{1}-\varphi_{1}=\tan \left(\varphi_{1}\right)-\varphi_{1}=\operatorname{INV}\left(\varphi_{1}\right) \quad[9, \text { eq. 3.23] }
$$

With these angle relationships the tooth thickness of the operating pitch diameter can be determined. Figure 12 shows a single tooth with two possible tooth thicknesses 
$T_{1}$ and $T_{2}$ along two possible pitch circles. The tooth thickness is a part of circumference of the pitch circle.

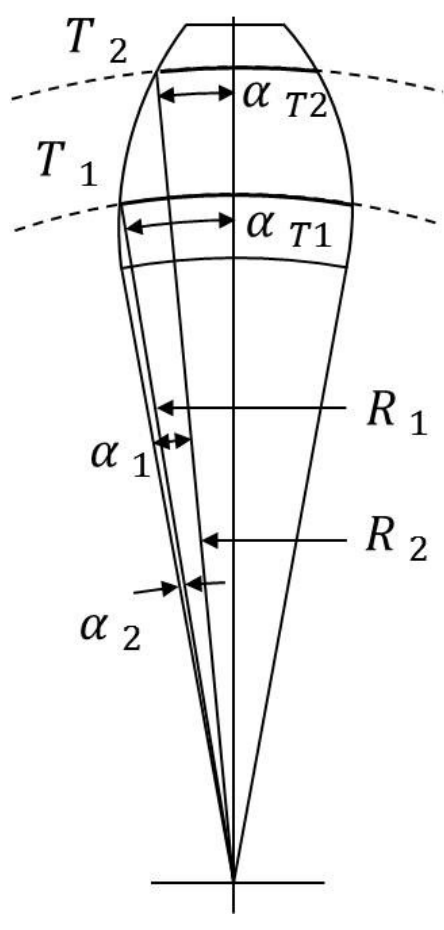

Figure 12. Tooth thickness relations
The angles between the vertical construction line and the outer tooth profile are:

$\alpha_{T 1}=\frac{T_{1}}{2 R_{1}} \quad[9$, eq. 3.128$]$

$\alpha_{T 2}=\frac{T_{2}}{2 R_{2}} \quad[9$, eq. 3.130]

Definition of an angular relation:

$\alpha_{T 2}=\alpha_{T 1}-\left(\alpha_{2}-\alpha_{1}\right)$

Replace the angle with the corresponding relations:

$\frac{T_{2}}{2 R_{2}}=\frac{T_{1}}{2 R_{1}}-\left[\operatorname{INV}\left(\varphi_{1}\right)-\operatorname{INV}\left(\varphi_{2}\right)\right]$

These correlations of tooth thickness can be replaced with the tooth thickness of the operating pitch diameter:

$$
\begin{array}{ll}
T_{o p_{P}}=2 R_{o p_{P}} *\left[\frac{T_{p_{i t c h}}}{2 R_{p i t c h}}+I N V\left(\varphi_{o p_{P}}\right)-I N V\left(\varphi_{\text {pitch }_{P}}\right)\right] & {[9, \text { eq. 3.138] }} \\
T_{o p_{G}}=2 R_{o p_{G}} *\left[\frac{T_{p_{i t c h}}}{2 R_{p i t c h}}+I N V\left(\varphi_{o p_{G}}\right)-I N V\left(\varphi_{\text {pitch }_{G}}\right)\right] & {[9, \text { eq. 3.139] }}
\end{array}
$$




$$
\begin{array}{ll}
T_{o p_{P}} / T_{o p_{G}} & \text { tooth thickness pitch diameter at operating pinion/gear } \\
R_{o p_{P}} / R_{o p_{G}} & \text { radius at the operating pitch diameter of pinion / gear } \\
R_{\text {pitch }} / R_{\text {pitch }_{G}} & \text { radius at the original pitch diameter of pinion / gear } \\
T_{\text {pitch }} / T_{\text {pitch }_{G}} & \text { Pitch diameter pinion / gear }
\end{array}
$$

Recalling Figure 10, the difference between pinion's and gear's tooth thickness can be calculated:

$$
\begin{aligned}
& B_{L}=\mathrm{D}_{P}-\left(\mathrm{T}_{\mathrm{op}_{\mathrm{P}}}+\mathrm{T}_{\mathrm{op}_{\mathrm{G}}}\right) \quad[9, \text { eq. 3.146] } \\
& \text { Where, } \quad \mathrm{B}_{\mathrm{L}}=\quad \text { Backlash (clearance) } \\
& D_{P}=\quad \text { Pitch diameter on operating pitch } \\
& \mathrm{T}_{\mathrm{op}_{\mathrm{P}}}=\quad \text { Pinion tooth thickness on operating pitch diameter } \\
& \mathrm{T}_{\mathrm{op}_{\mathrm{G}}}=\quad \text { Gear tooth thickness on operating pitch diameter }
\end{aligned}
$$

A Matlab® functions solves this equation with certain operational pitch diameter. This is an iterative process, where the radius gets calculated, as long as the backlash difference is less than a certain distance. Figure 13 shows an increase of shaft distance in terms of a certain backlash of the first gear pair of the GDS. 


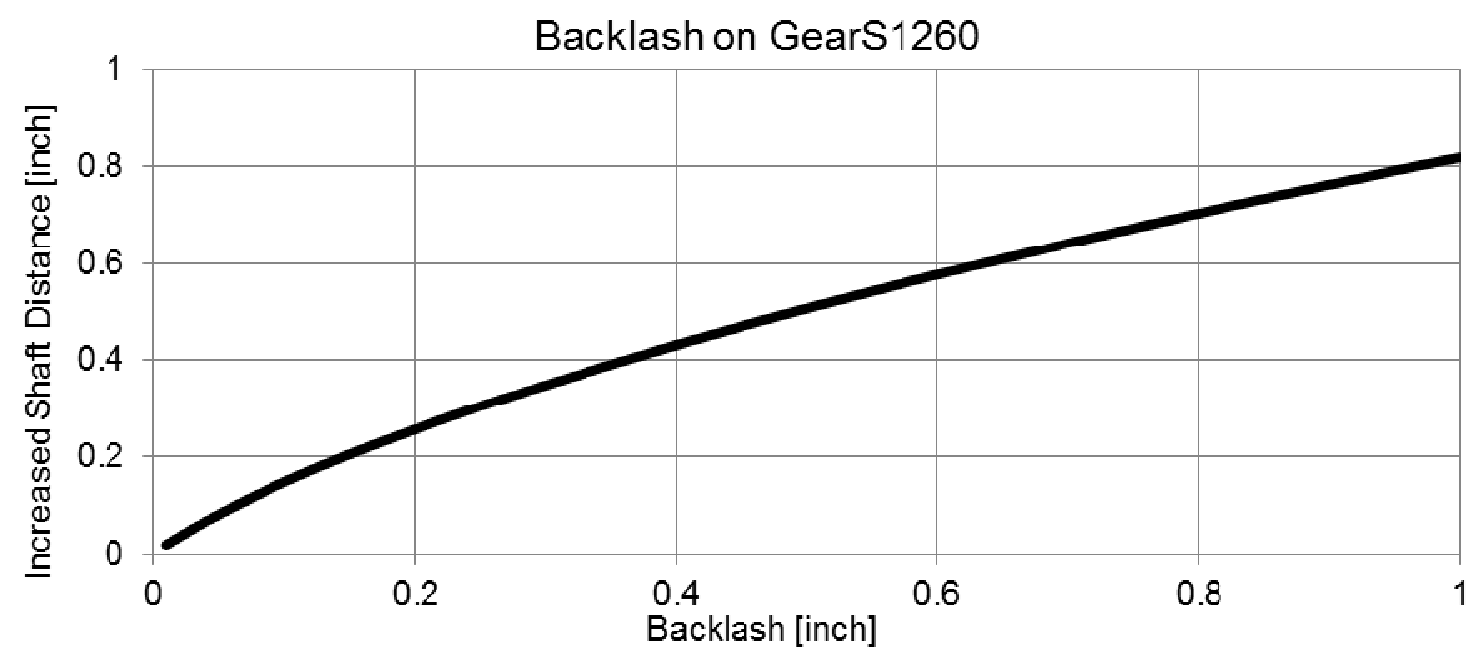

Figure 13. Increased shaft distance vs. backlash of first gear pair

The manufacturer suggests a backlash with a ratio of $B_{L}=\frac{0.157}{P}$. With this equation we can determine the operational shaft distance $D_{\text {Center }}$ shown in Table 2.

Table 2. Backlash values

\begin{tabular}{|c|c|c|}
\hline & First gear pair & Second gear pair \\
\hline Backlash: $B_{L}=\frac{0.157}{P}=\frac{0.157}{12}$ & $B_{L}=0.01308$ & $B_{L}=0.01308$ \\
\hline operational pinion radius & $R_{\text {op }_{\text {Pinion }}}=1.006840$ & $R_{\text {op }_{\text {Pinion }}}=1.510260$ \\
\hline operational gear radius & $R_{o p_{G e a r}}=2.517099$ & $R_{o p_{G e a r}}=2.013679$ \\
\hline operational center distance & $D_{\text {Center }}=3.523939$ & $D_{\text {Center }}=3.523939$ \\
\hline
\end{tabular}




\section{Vibration analysis in Adams $®$}

Based on the developed gear set in SolidWorks ${ }^{\circledR}$, a numerical software product was taken to analyze gear vibration. Adams ${ }^{\circledR}$ uses a rigid-elastic model for multi-body dynamics to examine gear systems. This is a software product from MacNealSchwendler Corporation (MSC). The advantage of Adams ${ }^{\circledR}$ is that dynamics of multi bodies are solved in a short time. A user interface with a model environment helps to define geometry and boundary conditions of the model. A graphical simulation platform allows seeing single contact forces during a load cycle. This is helpful to understand the dynamics of gears and the change in forces along the tooth profile by varying geometry, speed, and load.

This chapter introduces first the model development in Adams ${ }^{\circledR}$. Next, spur gear action with angle of attack and angle of recess are described to judge the system and to describe Tip Relief profiles. The loads along the profile are shown in the last part of this chapter. All parts are shown in Figure 14.

Model development in Adams ${ }^{\circledR}$

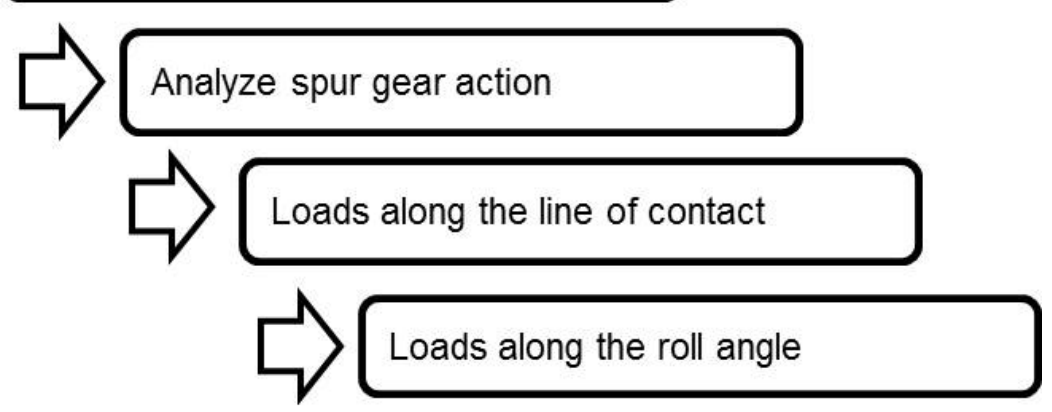

Figure 14. Process flow of vibration analysis in Adams® 


\subsection{Model development in Adams ${ }^{\circledR}$}

MSC Software provides an import interface between SolidWorks ${ }^{\circledR}$ and Adams ${ }^{\circledR}$ which is called "Parasolid". This allows an import of single parts and large assemblies. All designed gear systems described in this thesis are imported from SolidWorks $®$. After importing the model the procedure of the preprocessor is the following:

1. Rename all parts to a meaningful name.

2. Choose steel with their material properties. Material properties are already defined.

3. Place revolute joints on all gears and fix gears on single shafts.

4. Apply impact contact forces, shown below.

5. Apply motion on PinionS1224.

6. Apply torque on all driven gears.

Table 3. Values and names of the generating process of a gear model in Adams ${ }^{\circledR}$

\begin{tabular}{|l|c|c|c|}
\hline & Pinion (S1224) & $\begin{array}{c}\text { Gear (S1260) \& } \\
\text { Pinion (S1236) }\end{array}$ & Gear (S1248) \\
\hline Name of the gear & Input & Medium & Output \\
\hline Density $\left[\mathrm{kg} / \mathrm{mm}^{3}\right]$ & $7.801 * 10^{-6}$ & $7.801 * 10^{-6}$ & $7.801 * 10^{-6}$ \\
\hline Stiffness $\left[\mathrm{N} / \mathrm{mm}^{2}\right]$ & 207,000 & 207,000 & 207,000 \\
\hline Poison's Ratio & 1.5 & 1.5 & 1.5 \\
\hline Name of the joint & Joint_S1224 & Joint_S1260 & Joint_S1248 \\
\hline Torque/Motion name & Motion_Input & Torque_S1260 & Torque_S1248 \\
\hline Torque function $[\mathrm{N} * \mathrm{~mm}]$ & -- & 10,000 & 10,000 \\
\hline Motion function & 3600 deg $*$ time & -- & -- \\
\hline
\end{tabular}


The most important part is to define contact conditions because of their huge influence in gear dynamics. Adams ${ }^{\circledR}$ offers different tools to simulate contact conditions, such as impact, restitution, and user defined contact conditions. All three conditions can be used to calculate resultant contact forces. For gear systems, impact contact condition is recommended. This contact force is nonlinear. An impact of a rigid ball on a plate is shown in Figure 15.
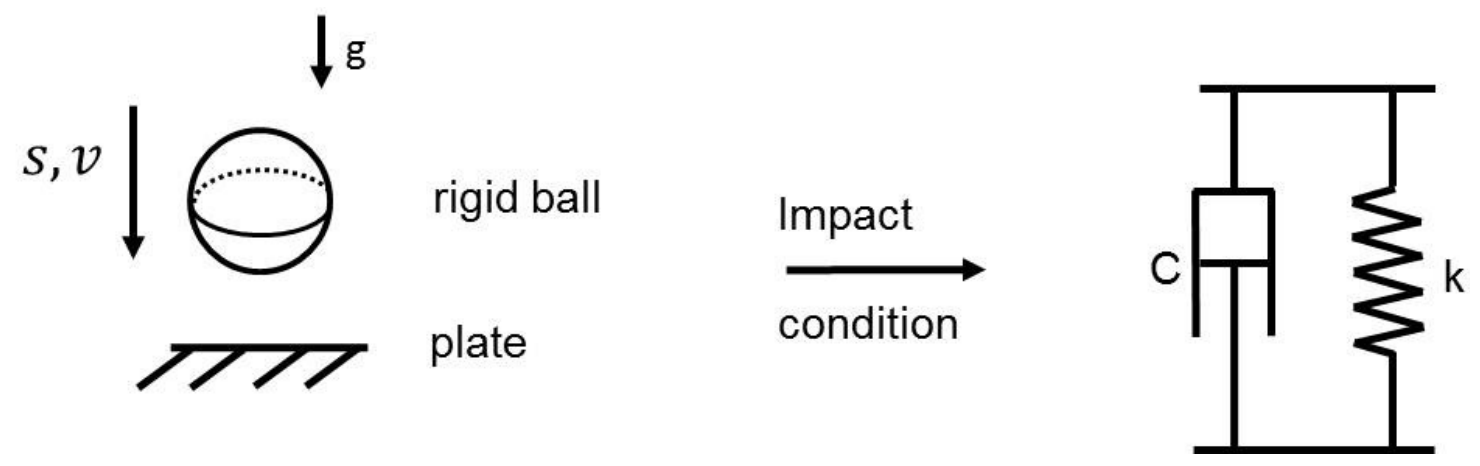

Figure 15. Impact contact condition using a spring-damper-system

Contact forces occur as soon as both bodies are in contact. This resultant contact force is described with the following equation:

$$
F=k * d^{e}-C * v
$$

where, $k=$ stiffness of material

$d=$ depth of both surfaces which are in contact 
Adams ${ }^{\circledR}$ suggests the following impact values for meshing gear:

- Stiffness: $\quad k=100,000 \frac{N}{m^{2}} \quad$ Gear mesh stiffness coefficient

- Force exponent: $\quad e=2.2 \quad$ Nonlinear stiffness exponent

- Damping: $\quad C=1 N \frac{\mathrm{s}}{\mathrm{mm}} \quad$ Gear mesh damping coefficient

- Penetration Depth: $\delta=0.001 \mathrm{~mm} \quad$ Start of calculation

Acting gear system can be subjected to that impact condition. However, this equation doesn't represent real gear dynamics, because the gear mesh stiffness of a tooth is changing, depending on the impact position. In order to get real stiffness of each point along the line of contact, the ratio between input torque and angular displacement has to be determined. An impact contact condition is based on constant stiffness.

Adams simplifies the gear system in a multi-body dynamics environment in two ways:

Real environment

elastic bodies

Contact reaction forces are

changing due to mesh stiffness.
Model environment in Adams

rigid bodies

contact reaction forces are simplified with the impact contact 


\subsection{Analysis of spur gear action}

Gear action takes place between the surface of pinion and gear along the line of contact. The angle of action is also called angle of pressure. It describes where forces act. There are two important states of contact forces gear designers consider:

- "Angle of approach" is the first point contact between two meshing gears.

- "Angle of recess" is the last point of contact between two meshing gears.

Angle of approach is shown in Figure 16.

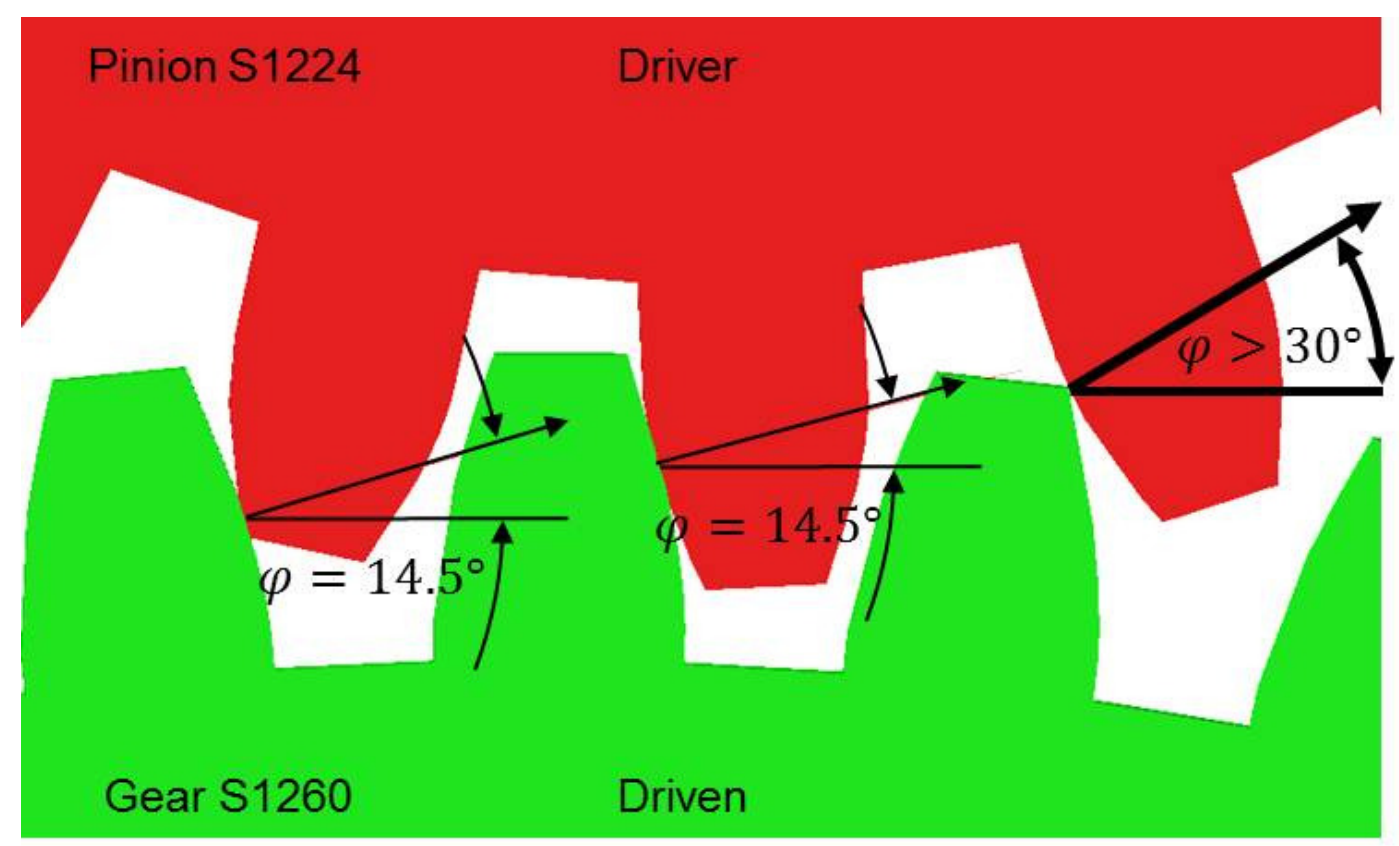

Figure 16. Angle of approach: first gear pair 
The angle of approach occurs at the first point of contact between the pinion and gear. At that specific situation, three teeth pairs are meshing. The last two teeth, on the left side, have the desired pressure angle of $\varphi=14.5^{\circ}$. However, the angle of approach is higher than $\varphi>30^{\circ}$. In theory, acting gears have the same pressure angle throughout the whole transaction. A higher angle of approach worsens gear performance dramatically and must be avoided. Angle of recess is shown in Figure 17.

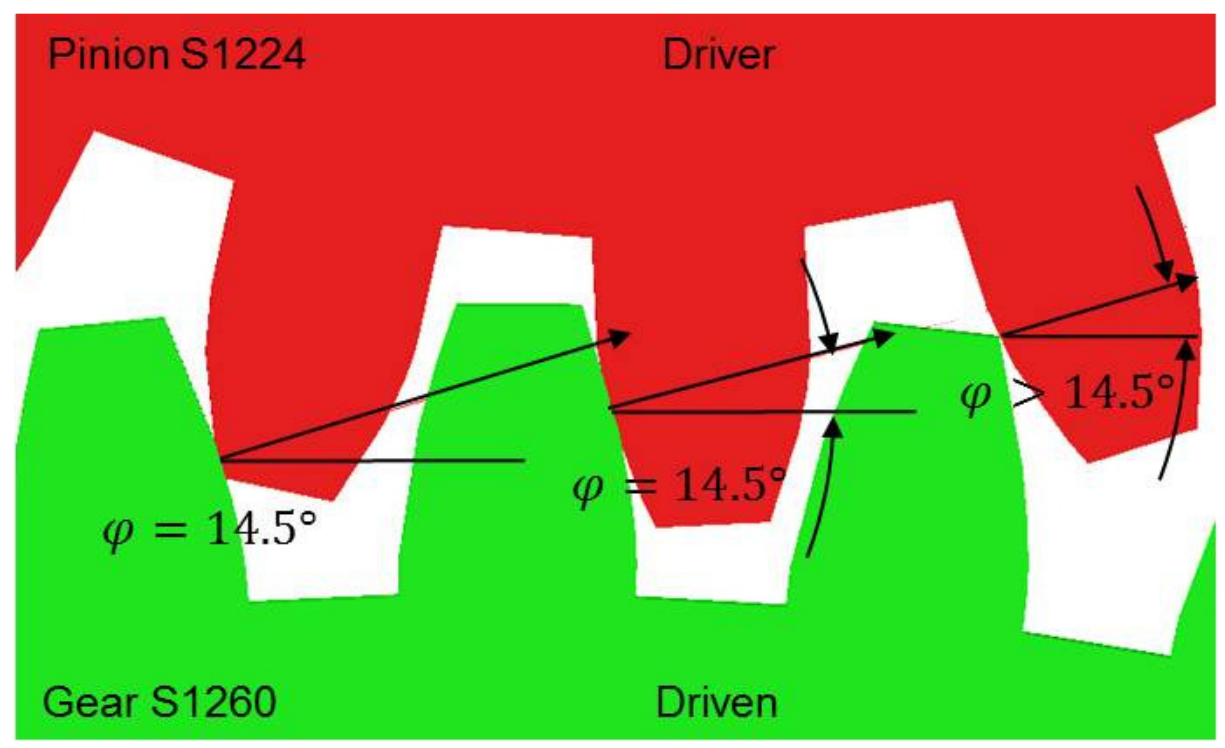

Figure 17. Angle of recess: first gear pair

The angle of recess is the last tooth contact of a single tooth pair. At this point the pinion tooth tip is touching the lowest tooth part of the gear's tooth. This point is called lowest contact (LC) point and is the lowest contact point along the line of contact. At that situation there is also three teeth acting. The angle of recess occurs right after a pinion tooth approached the gear tooth and the first gear angle on the right side has the desired angle of $\varphi=14.5^{\circ}$. 
Possible reasons for a higher angle of approach:

- Tooth spacing on each gear is not constant. Backlash automatically changes the tooth space between pinion and gear a little bit. Angle of attack is therefore increasing.

- Heavy loads change the angular position between driving and driven gear. Tooth deflection allows the driving gear to lead slightly before its correct angular position, and the driven gear to lag slightly behind its correct angular position. Therefore the first point of contact occurs earlier with a change of angle of approach.

- Idealization of tooth profile. The rigid-elastic model in Adams ${ }^{\circledR}$ simplifies the gear system.

In ideal condition all contact forces have the same angle of pressure to get a smooth transition from stage to stage without high impact forces. Tip Relief is a modification of a tooth profile. Metal gets cut away on the tooth tip to compensate for tooth deflection. Several authors studied the correlation between smooth gear action and Tip Relief Profile. 


\subsubsection{Tip Relief in terms of a radius fillet}

P.S. Houghton suggests in Chapter 22 of "GEARS" [3] a tooth profile modification in terms of a fillet radius. A small fillet radius should be neatly blended on the extreme tip of the involute curve, shown in Figure 18. To normalize the radius of the fillet, a "construction line" between base circle and the middle of the tooth tip is used. Another construction line describes all possible center of the Tip Relief circle, which is called the "center of circle line". Both construction lines are shown in Figure 18. A ratio between construction line and center of a radius describes the normalization.

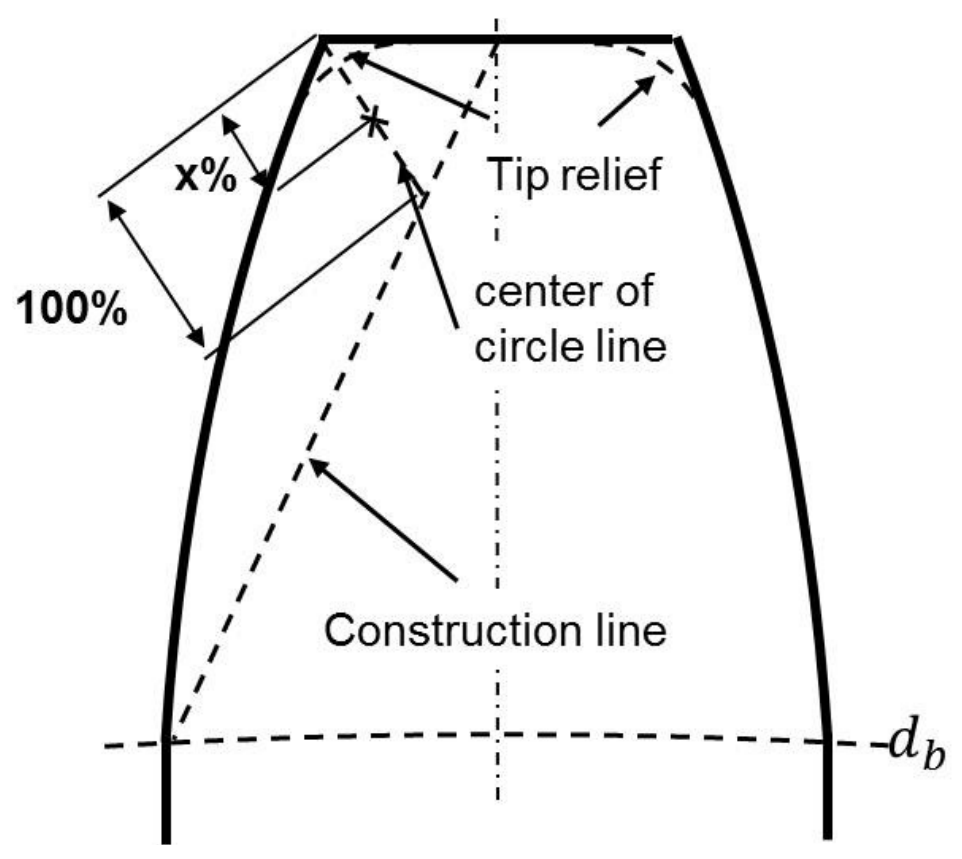

Figure 18. Normalized fillet radii on gear teeth

P.S. Houghton [3] relates the radius to the load of the gear, because the deflections of gears increase by adding more load. For this gear system different radii are used to determine the best relief profile. 
Three different fillet radii are studied to examine the influence of a Tip Relief. Radii are varying between 0 and 100 percent. Figure 19 shows results of different radius angles, such as $10 \%, 20 \%$, and $30 \%$ with an input shaft speed of $10 \mathrm{~Hz}$ of PinionS1224 and a torque on GearS1260 of $10 \mathrm{Nm}$.

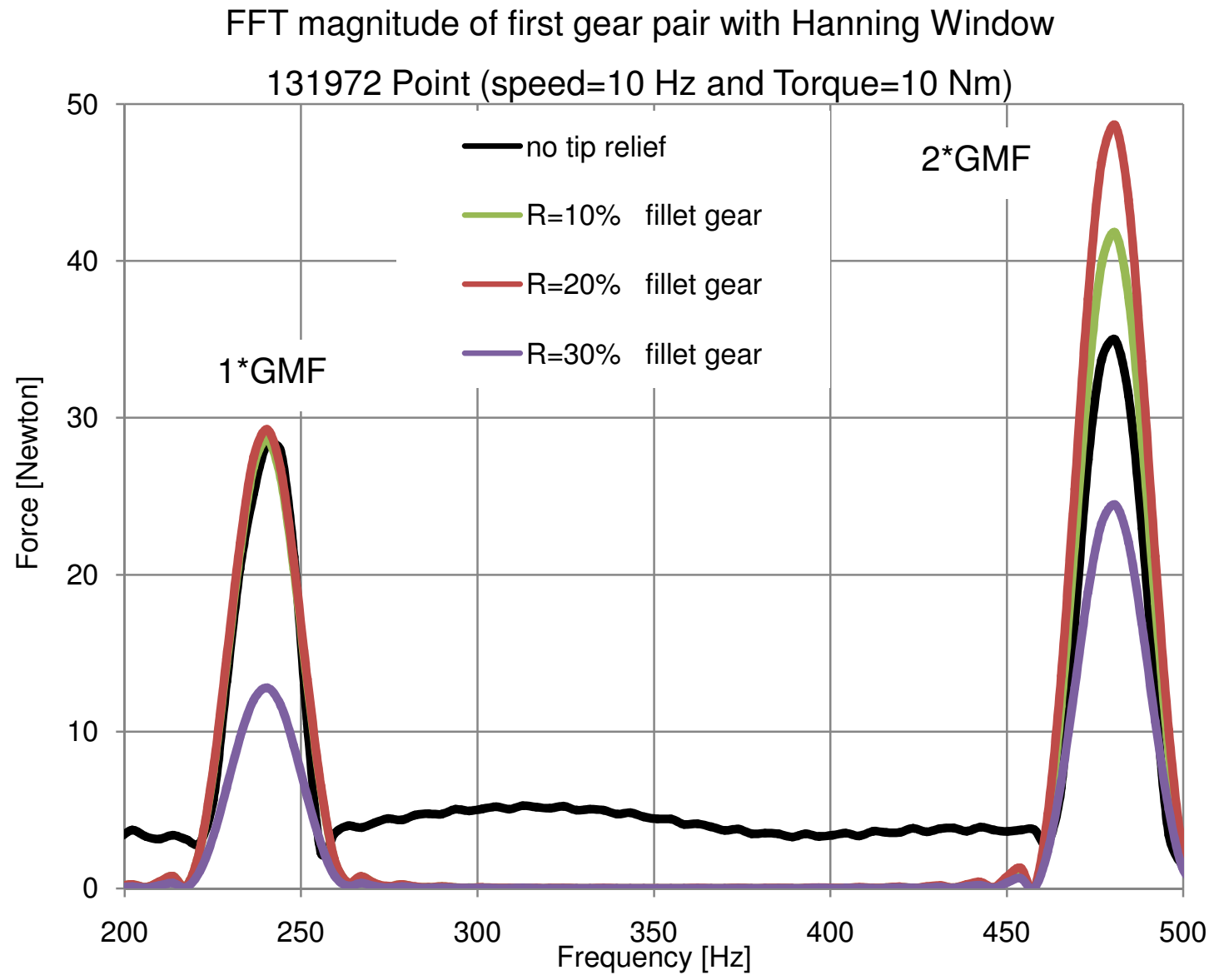

Figure 19. Different tooth tip radius fillet of the first gear pair

A radius fillet of $20 \%$ reduces the force magnitude of the Gear Mesh Frequency of more than $100 \%$ and more than $30 \%$ of the first superharmonic. 


\subsubsection{Tip Relief related to Rothe Erde}

Rothe Erde $\mathrm{GmbH}$, a German gear manufacturer, suggests a more flexible Tip Relief profile with a Tip Relief curve along the addendum area [57]. They assume that the high peak loads acting on the tip edge on the pinion are caused by bending, pitch error, and drive unit. To compensate these effects, they suggest a Tip Relief shown in Figure 20.

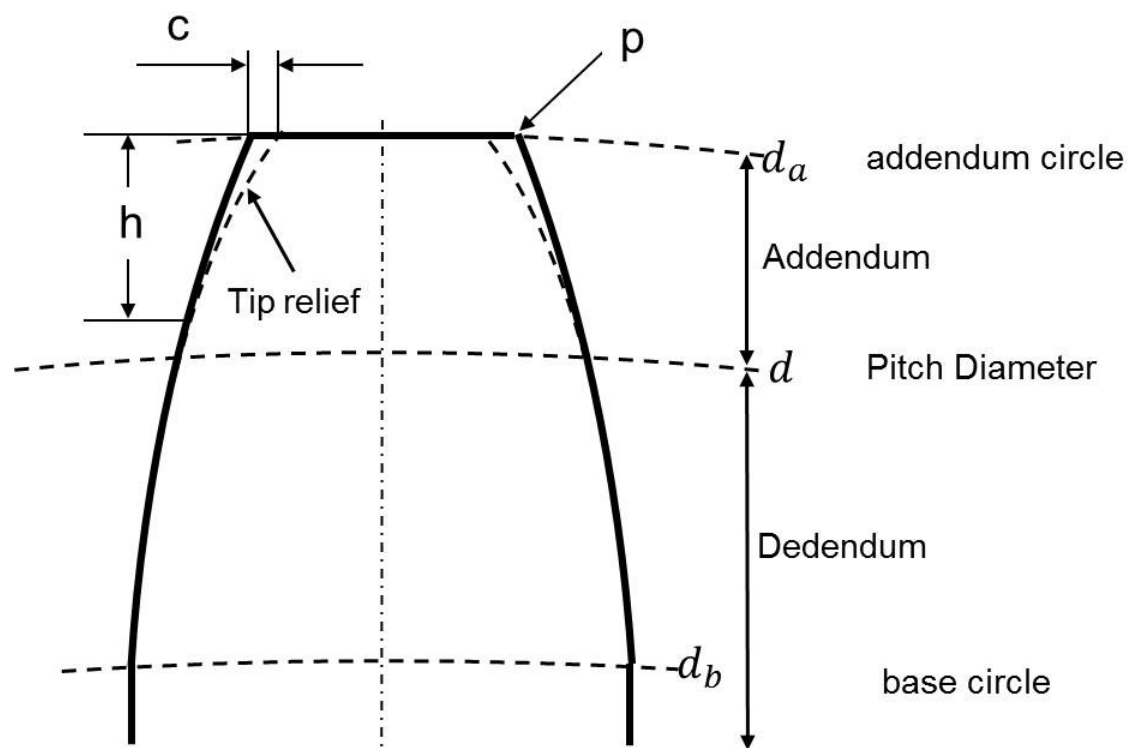

Figure 20. Tip Relief profile according to Rothe Erde GmbH

Rothe Erde $\mathrm{GmbH}$ suggest the following values:

$$
\begin{array}{ll}
c=0.01 * m & (\mathrm{~m}=\text { module }) \\
h=(0.4-0.6) * m & (\mathrm{~m}=\text { module }) \\
c: h=1: 40-1: 60 \quad \text { (based on full tooth width }) & \\
p=(0.1-0.15) * m & \text { (range of } \mathrm{p})
\end{array}
$$


The curve between these points is secret and not published yet. However, "Dipartimento di Ingegneria Meccanica, Nucleare e della Produzione", [58] suggest a Tip Relief profiles in terms of the Roll Angle with the following definition:

"In tooth modification design, Tip Relief is defined as the thickness of the material removed along the tooth flank with reference to the nominal involute profile. Profile modification is usually defined versus the Roll Angle coordinate." [21]

One possible Tip Relief profile is an ellipse, shown in Figure 21. The ellipse is defined with the middle point of the ellipse and the start of the Tip Relief profile at the pitch circle. A varying ellipse angle creates thinner or thicker Tip Relief profiles.

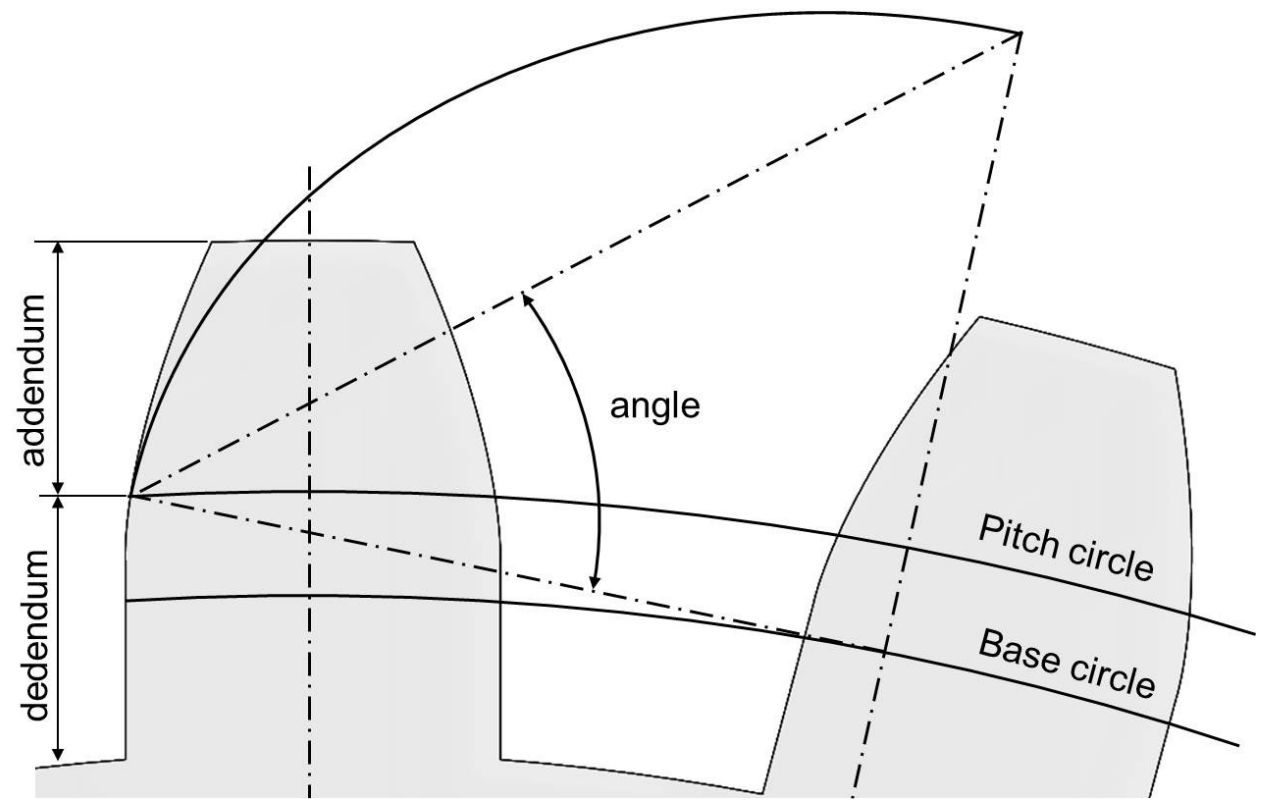

Figure 21. Tip Relief with respect to an ellipse angle

Four different ellipse angles are studied to examine the influence of a Tip Relief. This examines angles of 40 degree, 43 degree, 44 degree and 45 degree. 
FFT magnitude of first gear pair with Hanning Window

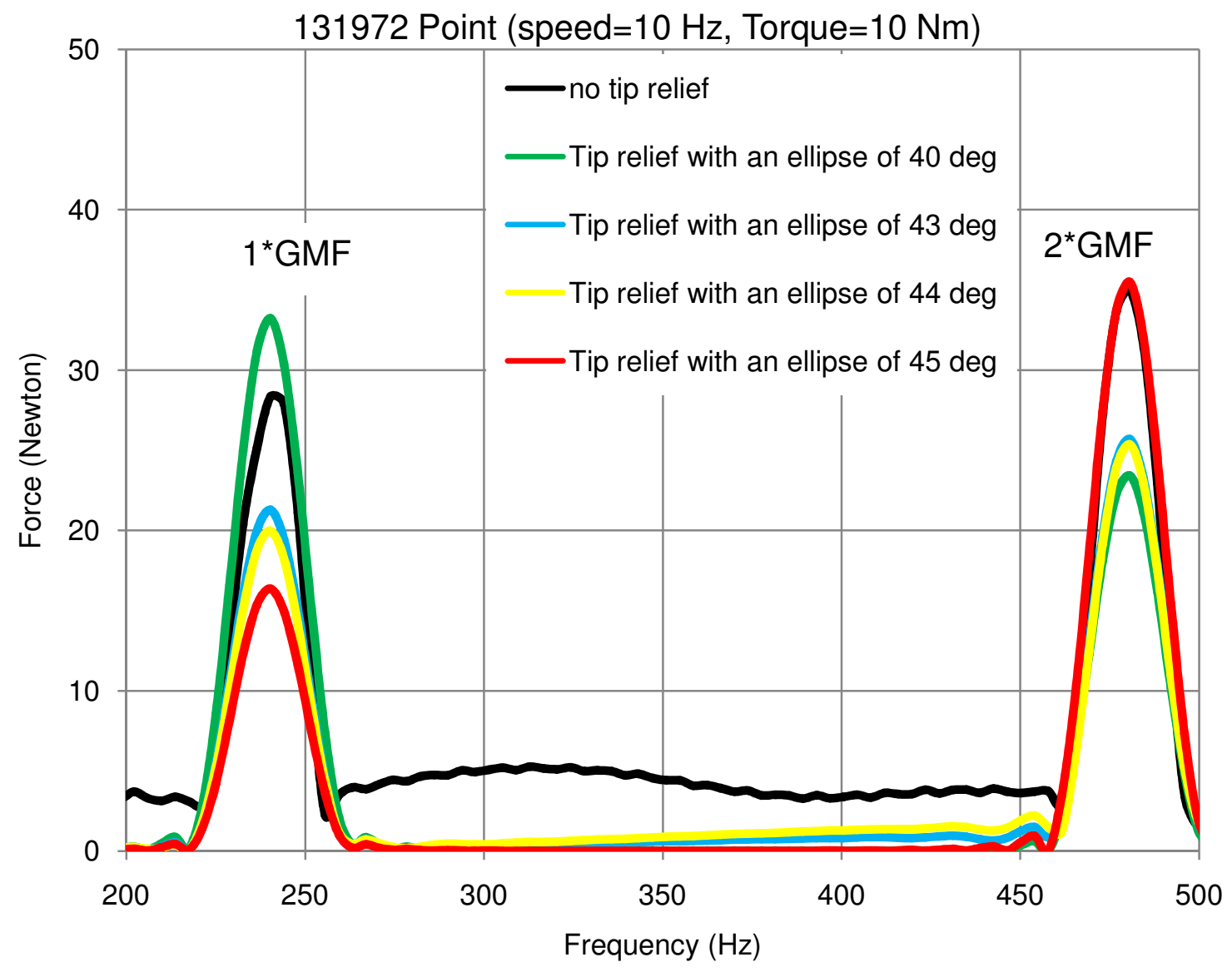

Figure 22. Forces for different ellipse angles

Figure 22 shows a frequency spectrum of an elliptical Tip Relief profile. The gear pair without Tip Relief has some modulations between the gear mesh frequency and the first superharmonic. Noticeable is also the order of force magnitudes between $1^{*} \mathrm{GMF}$ and $2^{*} \mathrm{GMF}$. The bigger the angle of the elliptical curve gets the less force magnitude at $1^{*} \mathrm{GMF}$. However, this order is reversed at $2^{*} \mathrm{GMF}$. The smaller the angle of the elliptical curve, the higher are the force magnitudes. Reasons for that effect are shown in the next chapter when we consider the time response. 


\subsubsection{Comparing Tip Relief profiles}

To determine the right Tip Relief profile is quite difficult. Depending on dynamic boundary conditions, like speed and loads, the Tip Relief profile might change. Both introduced Tip Relief profiles are compared with the time domain which is also a useful method to judge smooth or harsh gear action. A direct comparison, shown in Figure 23, of contact forces of first the gear pair suggests an elliptical Tip Relief profile reduces discontinuities of contact forces in comparison to Tip Relief profile with a fillet radius.

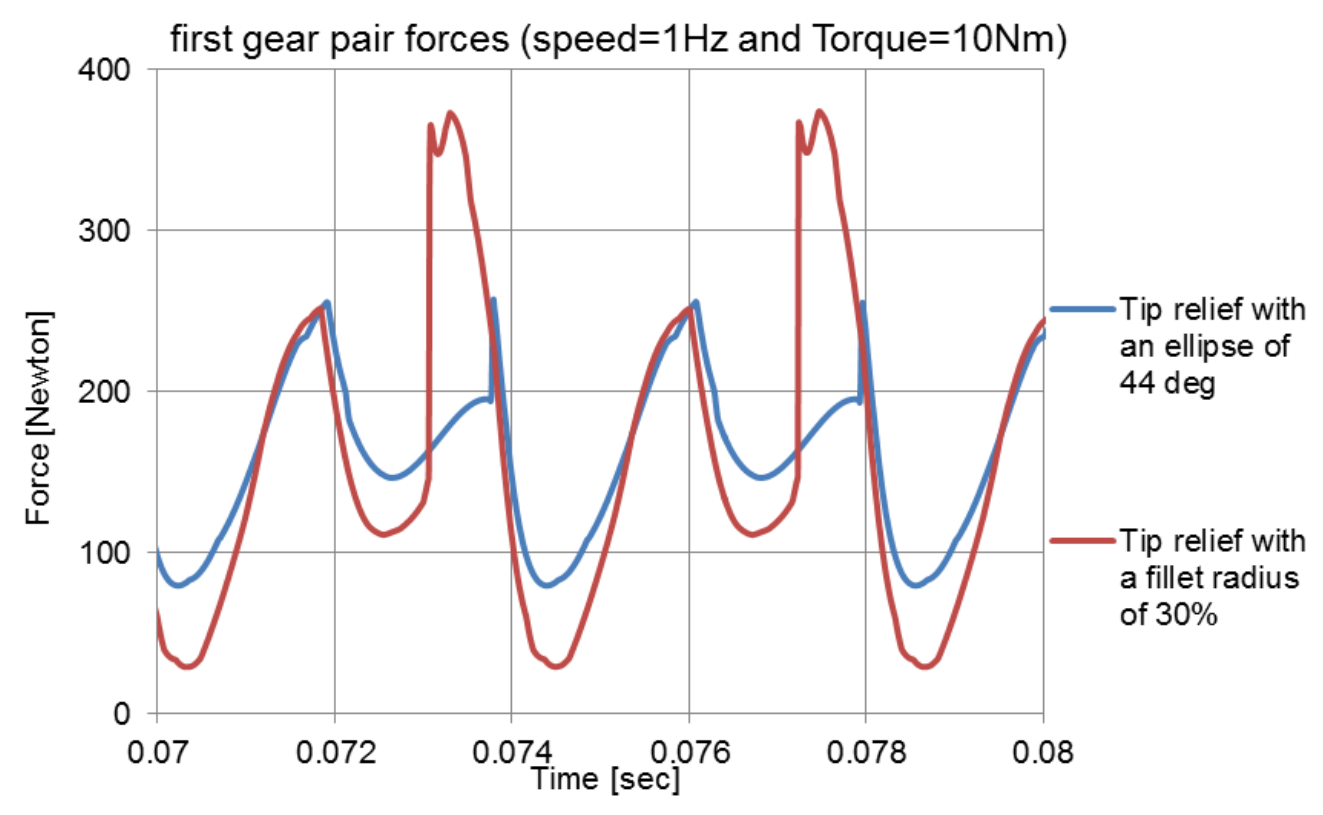

Figure 23. Contact forces of different Tip Relief profile

The aim of profile modification is to find a minimum of vibration according to a Tip Relief profile. Beghini, Presicce and Santus [21] suggest comparing Tip Relief profile in terms of the Roll Angle and filleting depth. The Roll Angle controls the point of tooth and the fillet depth describes the removal of material, shown in Figure 24. Fillet depth and Roll Angle both Tip Relief profiles are shown in Figure 25. 


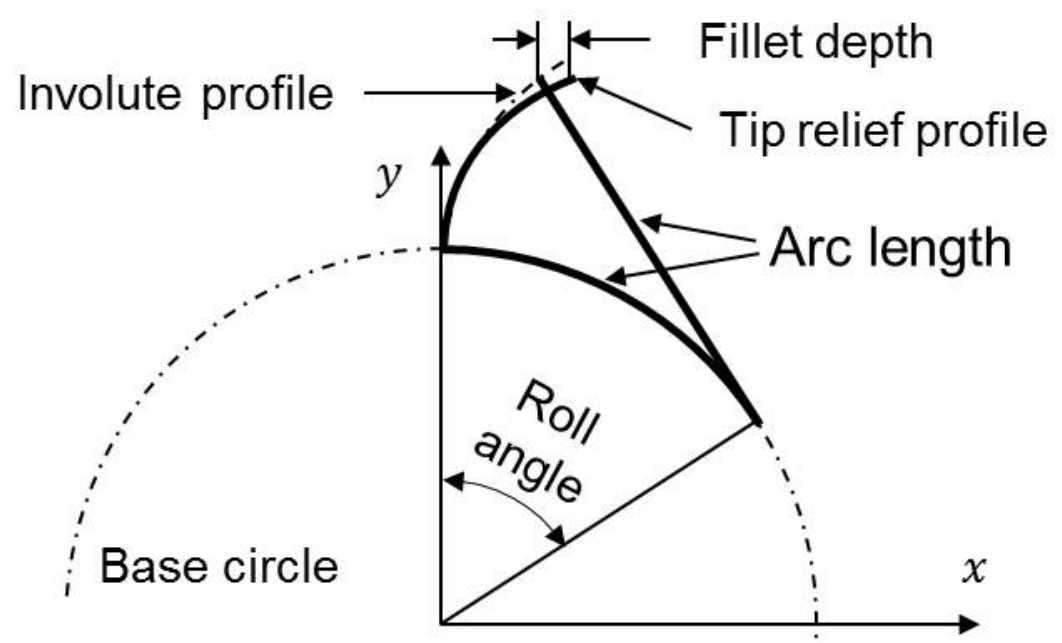

Figure 24. Arc length and Roll Angle

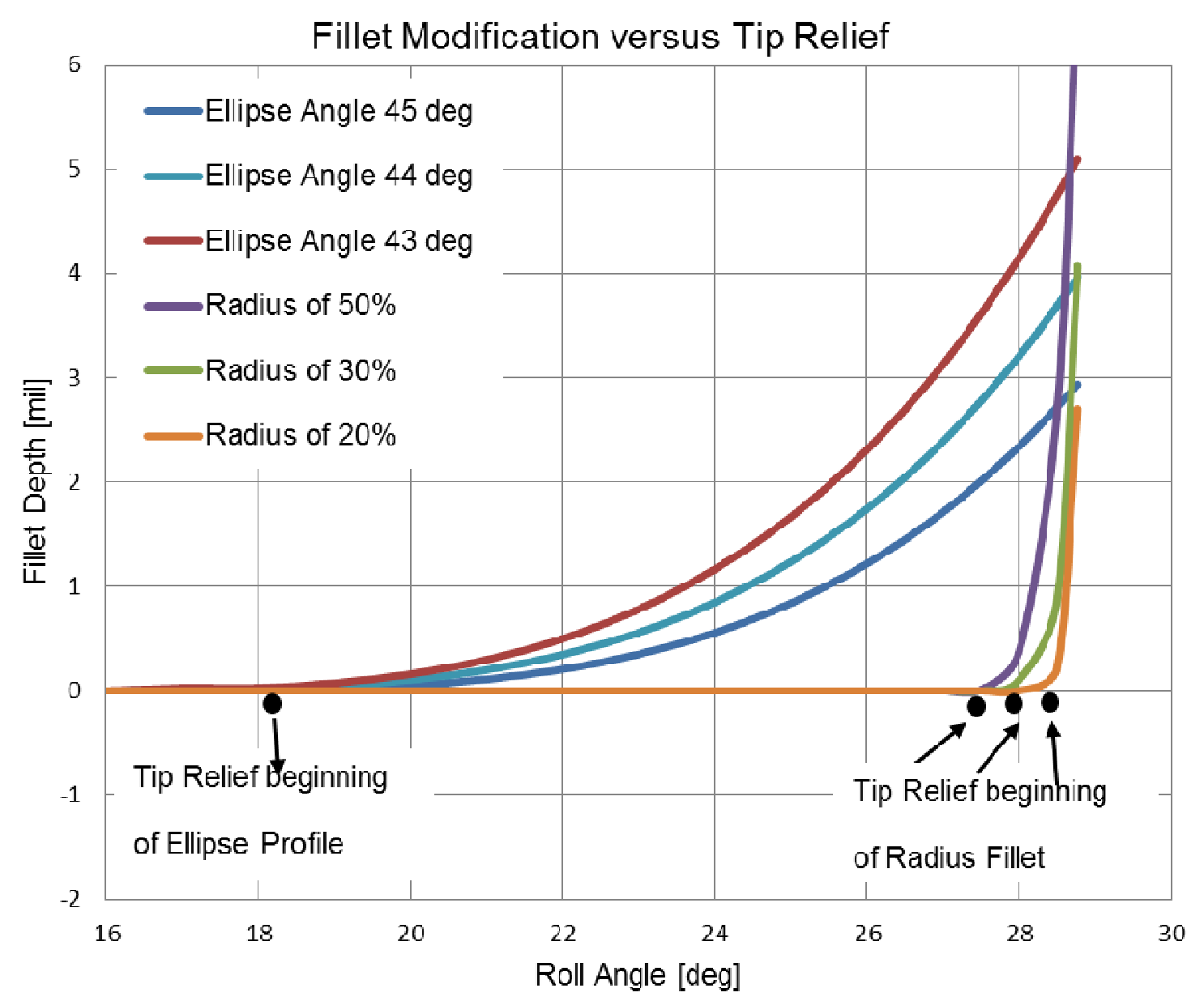

Figure 25. Tip Relief profile in terms of Roll Angle and fillet depth of PinionS1224 


\subsubsection{Spur gear action with Tip Relief profile}

The elliptical Tip Relief profile has the smoothest contact force profile. The following figures show the angle of pressure of an elliptical Tip Relief profile.

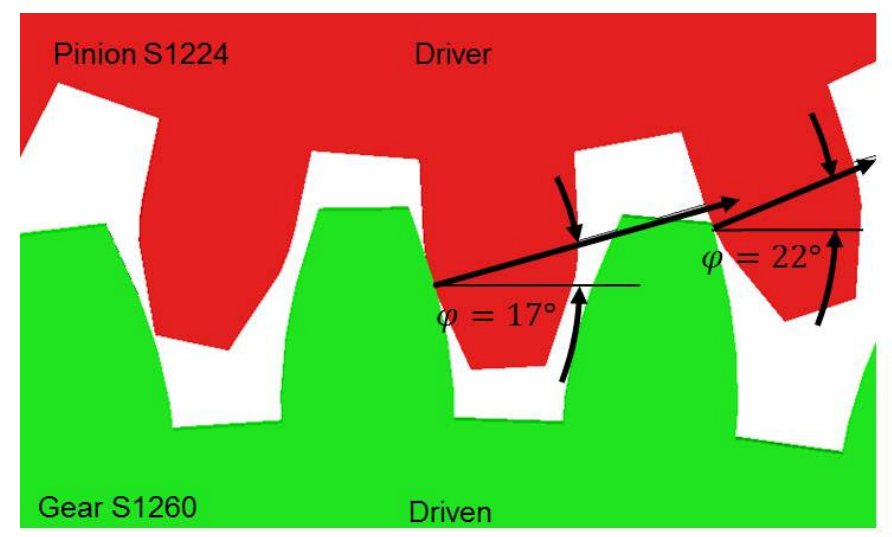

Figure 26. Angle of approach: first gear pair with elliptical Tip Relief

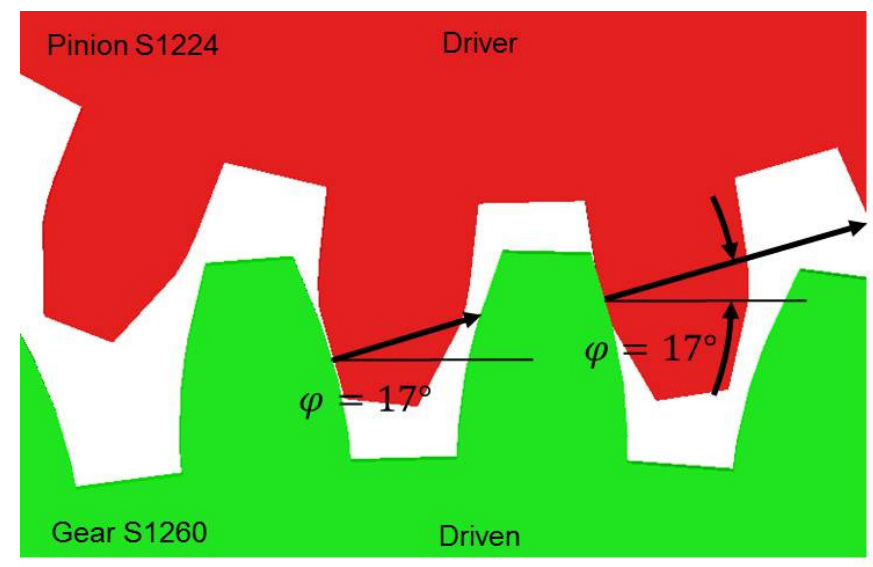

Figure 27. Angle of recess: first gear pair with elliptical Tip Relief

The pressure angle of the angle of approach is reduced from originally $\varphi>30^{\circ}$ to $\varphi=22^{\circ}$. For further consideration an elliptical Tip Relief is considered. 


\subsection{Loads along the line of contact}

Loads along the line of contact are important to judge the quality of gear interaction and especially the Tip Relief profile. Especially the high forces along the line of contact are important to know because this area is exposed to higher pressure and probably higher deterioration or wear. Fast force changes along the line of contact are signs of harsh gear action and are also important to monitor. Analytical solutions and models for contact forces along the line of contact of a dynamic process are rare and normally based on a perfect gear profile. It is easier to determine loads along the line of contact during dynamic process with numerical solutions, like Adams®. The goal is to find a method to describe contact forces along the Roll Angle because loads on the line of contact are usually defined in terms of Roll Angle like Tip Relief.

However, as soon as more than one tooth is meshing at the same time the resultant contact force of gears is the sum of all meshing gears. It is unknown how much contact force each acting tooth has. One possibility to get single tooth forces is to split the resultant contact force into the amount of meshing gears. However, this method is an approximation and necessary information cannot be determined, for instance forces of approaching and recessing teeth, influences of single tooth defects, or influence of a tooth profile in contact areas where more than one tooth is in mesh. Figure 28 shows typical contact forces between two acting gears without splitting contact forces if more than one tooth is in mesh. 


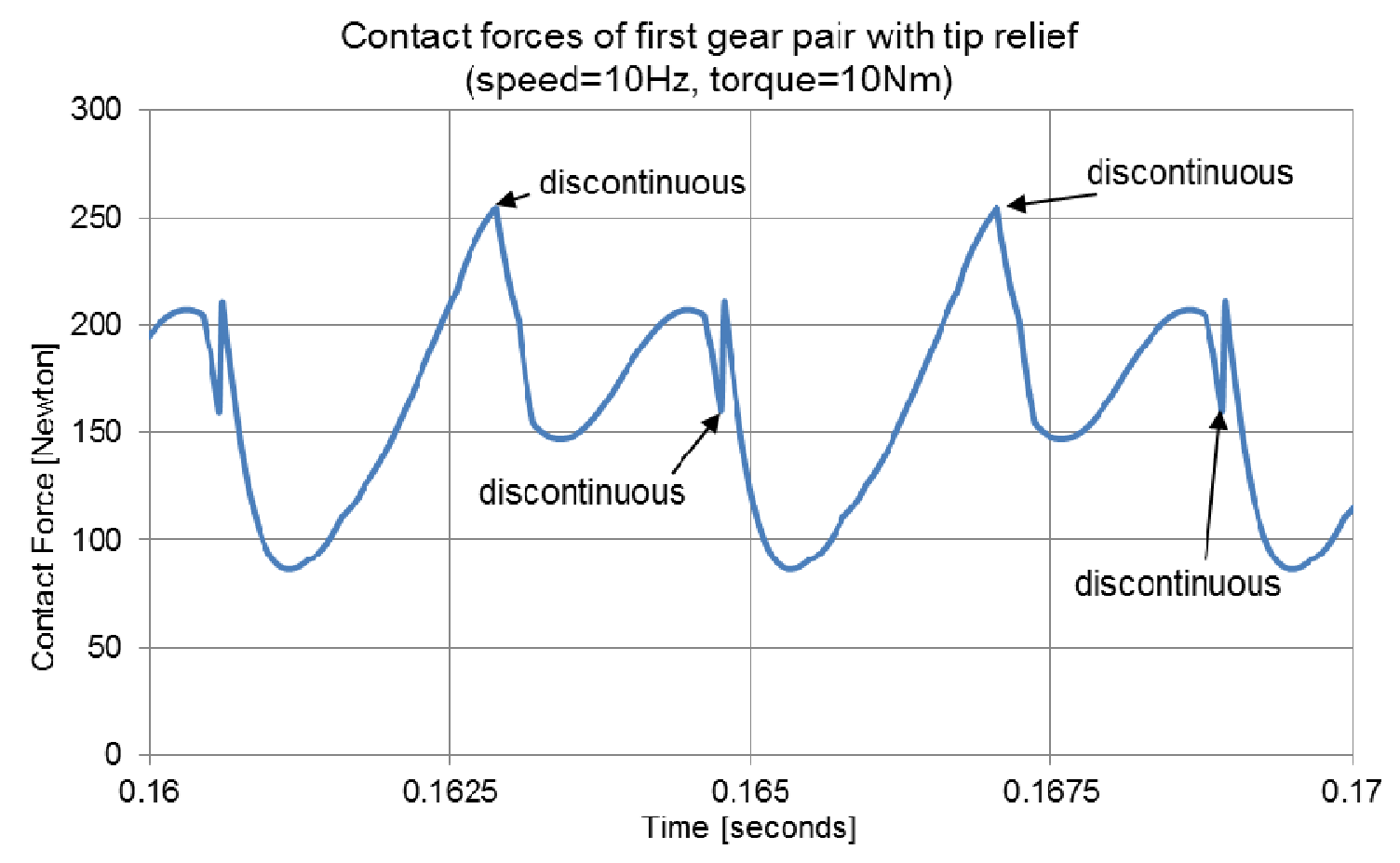

Figure 28. Contact forces of the first gear pair

Discontinuous points of contact force are hints for approaching or recessing teeth. An erratic force change close by 0.165 seconds is probably an approaching tooth and the peak with maximum force magnitude is likely to be a recessing tooth.

To determine single tooth forces along the line of contact, two methods are introduced:

- Split gear pair in two parallel gear pairs

- Divide a gear in two different parts 


\subsubsection{Single contact forces with a split gear pair}

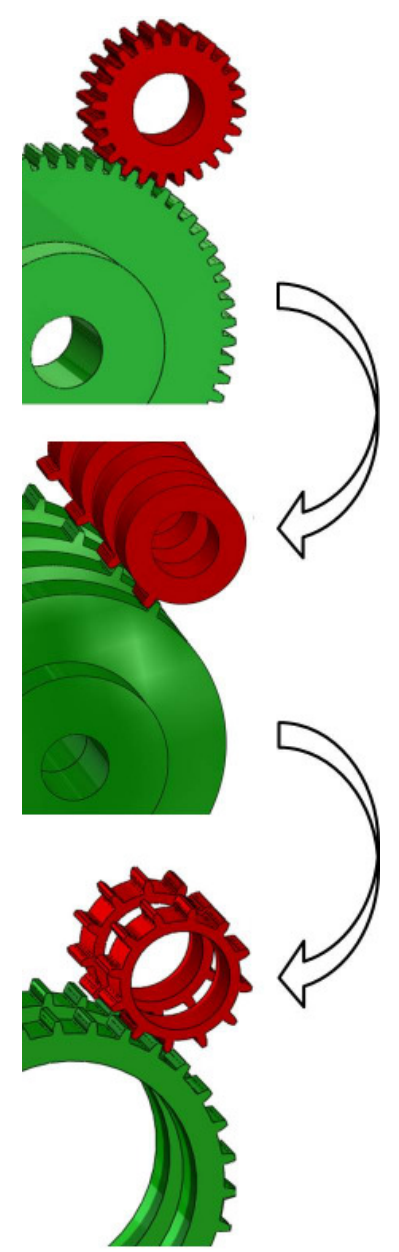

In order to get single tooth forces, a gear can be split up in single gear models. The number of teeth describes the number of single tooth gears. A set of single tooth gears is shown in the first image of Figure 29. Because Adams ${ }^{\circledR}$ is a rigid-elastic model there is no deflection between all gears.

In this unique case the tooth contact ratio is less than two. This means that only one or two teeth pairs are acting and meshing at the same time. To simplify the model only two gears are required. Two twin gear discs are shown on the third image. To get the same moment of inertia as a one tooth model, the bore diameter is adjusted. The calculation of moment of inertia to get the modified bore diameter is shown below.

Figure 29. Model of single tooth contact in Adams

The basic equation for the moment of inertia is: Figure 29

Basic equation: $\quad J=\rho \int r^{2} d V$

where: $\rho=304 \frac{l b}{\text { inch }^{3}} \quad$ density of steel 
In cylindrical coordinates the integral can be replaced with $d V=r d r d \varphi d z$ :

General equation: $\quad J=\rho \int_{z_{0}}^{z_{1}}\left[\int_{\varphi_{0}}^{\varphi_{1}}\left[\int_{r_{0}}^{r(\varphi)} r^{2} r d r\right] d \varphi\right] d z$

$r(\varphi)$ describes the radius to the outer surface of a gear. This is a complicated function, because it is dependent on the Tip Relief profile and changes with each gear. Therefore, the radius is simplified to: $r(\varphi)=r_{b}$.

The gear with the hub can be described with:

$$
J_{\text {gear }_{\text {original }}}=\rho \int_{0}^{.75}\left[\int_{0}^{2 \pi}\left[\int_{1}^{r_{b}} r^{2} r d r\right] d \varphi\right] d z+\rho \int_{0}^{z_{H u b}}\left[\int_{0}^{2 \pi}\left[\int_{1}^{r_{H u b}} r^{2} r d r\right] d \varphi\right] d z
$$

To derive the reduced inner radius $r_{\text {inner }}$ of a split gear system the moment of inertia of the reduced model has to be determined. Matlab® determines $r_{\text {inner }}$ by

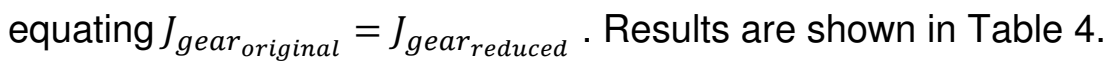

$$
J_{\text {gear }_{\text {reduced }}}=\rho \int_{0}^{.75}\left[\int_{0}^{2 \pi}\left[\int_{r_{\text {inner }}}^{r_{b}} r^{2} r d r\right] d \varphi\right] d z
$$

Table 4. Equivalent moment of inertia for a split gear pair

\begin{tabular}{l|l} 
Gear & Modified bore diameter. \\
\hline Pinion S1224BS 1 & $r_{\text {inner }}=0.7376$ inch \\
Gear S1260 & $r_{\text {inner }}=1.9821$ inch
\end{tabular}




\subsubsection{Single contact forces with a divided gear pair}

Another possibility to derive single tooth forces is to divide a gear into two different parts, shown in Figure 30.

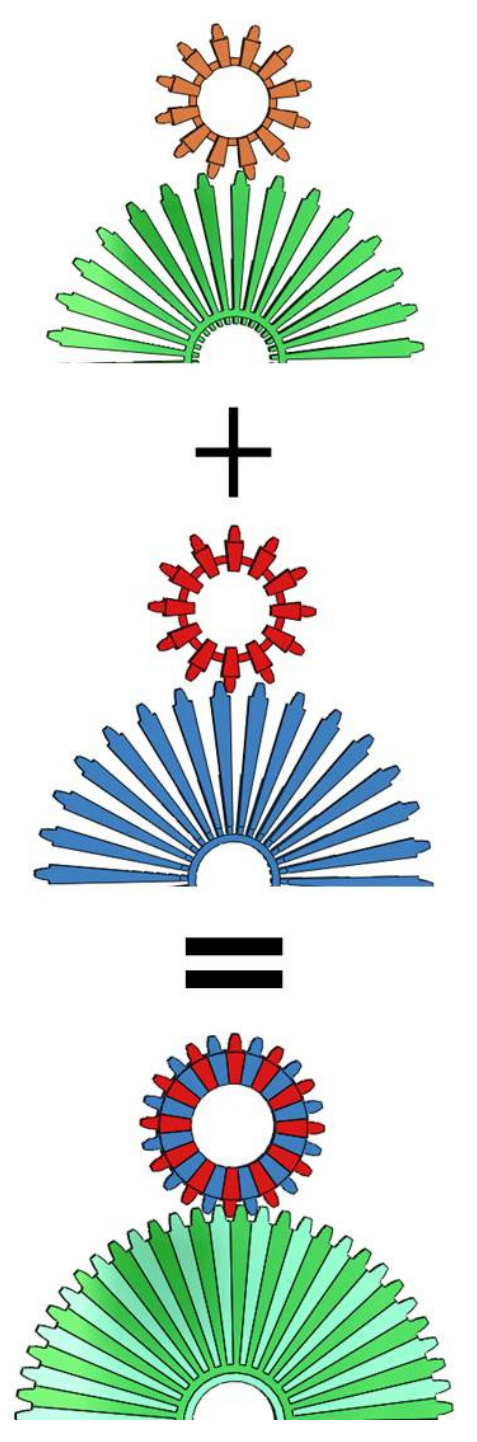

This method cuts every second tooth of a gear. Pinion with originally 24 teeth has therefore only 12 teeth, and Gear with originally 60 teeth has 30 teeth. An assembly of these two parts is shown in the first image of Figure 30.

Another twin pair can be assembled with a certain angular displacement, so that it fits into first assembly. A connection between all single teeth is necessary that Adams ${ }^{\circledR}$ recognizes it as one part.

Two different contact conditions can be applied on one gear pair, because one gear pair consists of two pinions and two gears alternating their contact forces. This is only possible because the contact ratio is less than two. This possibility has the advantage that the moment of inertia is exactly the same like the original gear.

Figure 30. Divided gears 


\subsubsection{Model comparison}

To prove coherency, a comparison of the split gear pair and the divided gear pair with the perfect gear set is necessary. Both contact forces of split gear pair are summed together as well as the divided gear pair, in order to compare contact forces with the perfect gear. Results are shown in Figure 31.

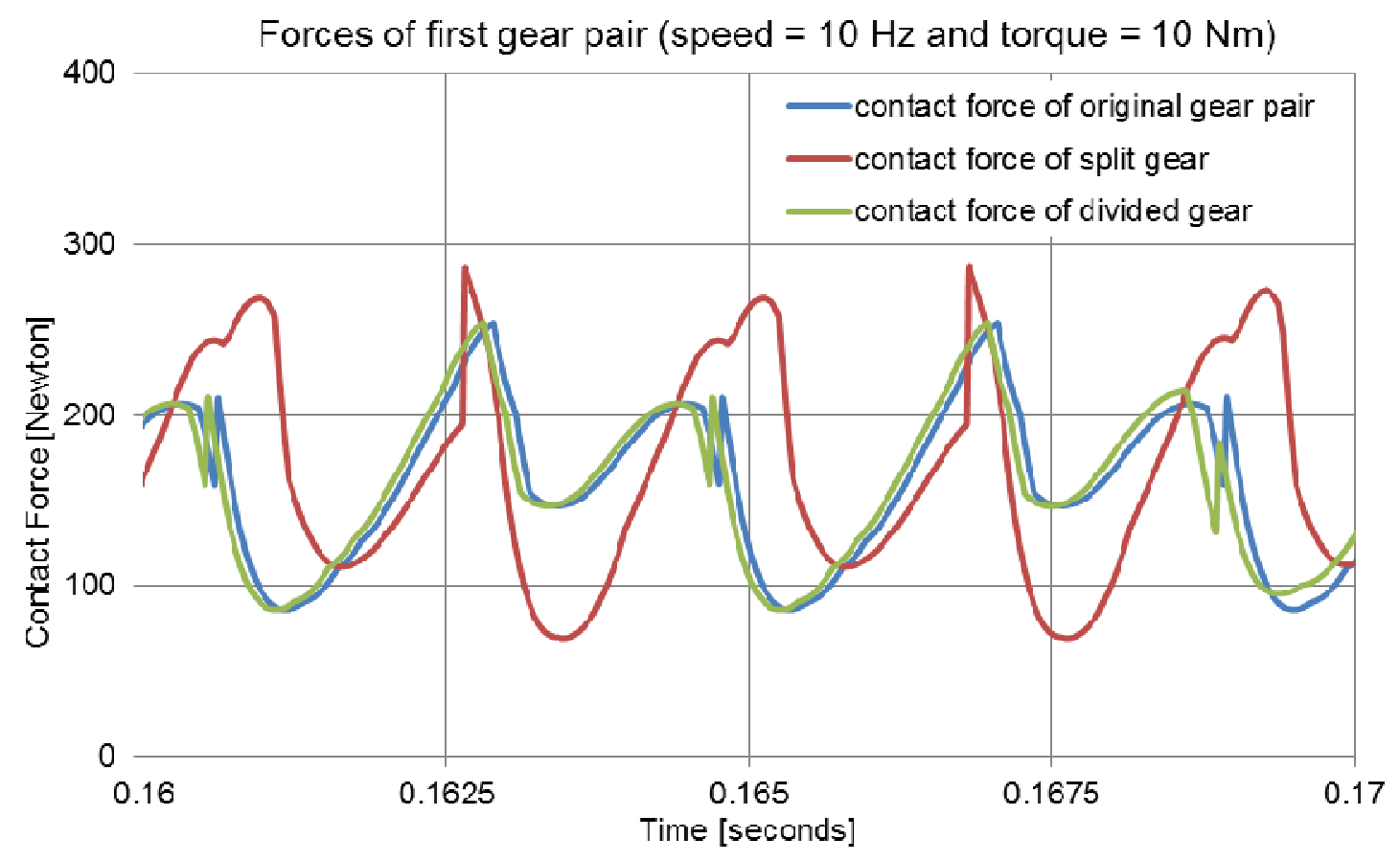

Figure 31. Comparison of split and divided gears to analyze single tooth forces

Unfortunately, the split gear pair has different contact forces than the original gear pair. A possible reason for different forces is the simplified moment of inertia. However, the divided gear equals the original one absolutely. A temporal displacement of the divided gear pair is due to an angular displacement between gear and pinion at the starting position. 
Without summing contact forces, single tooth forces can be shown. Figure 32 shows two separate contact forces in one diagram.

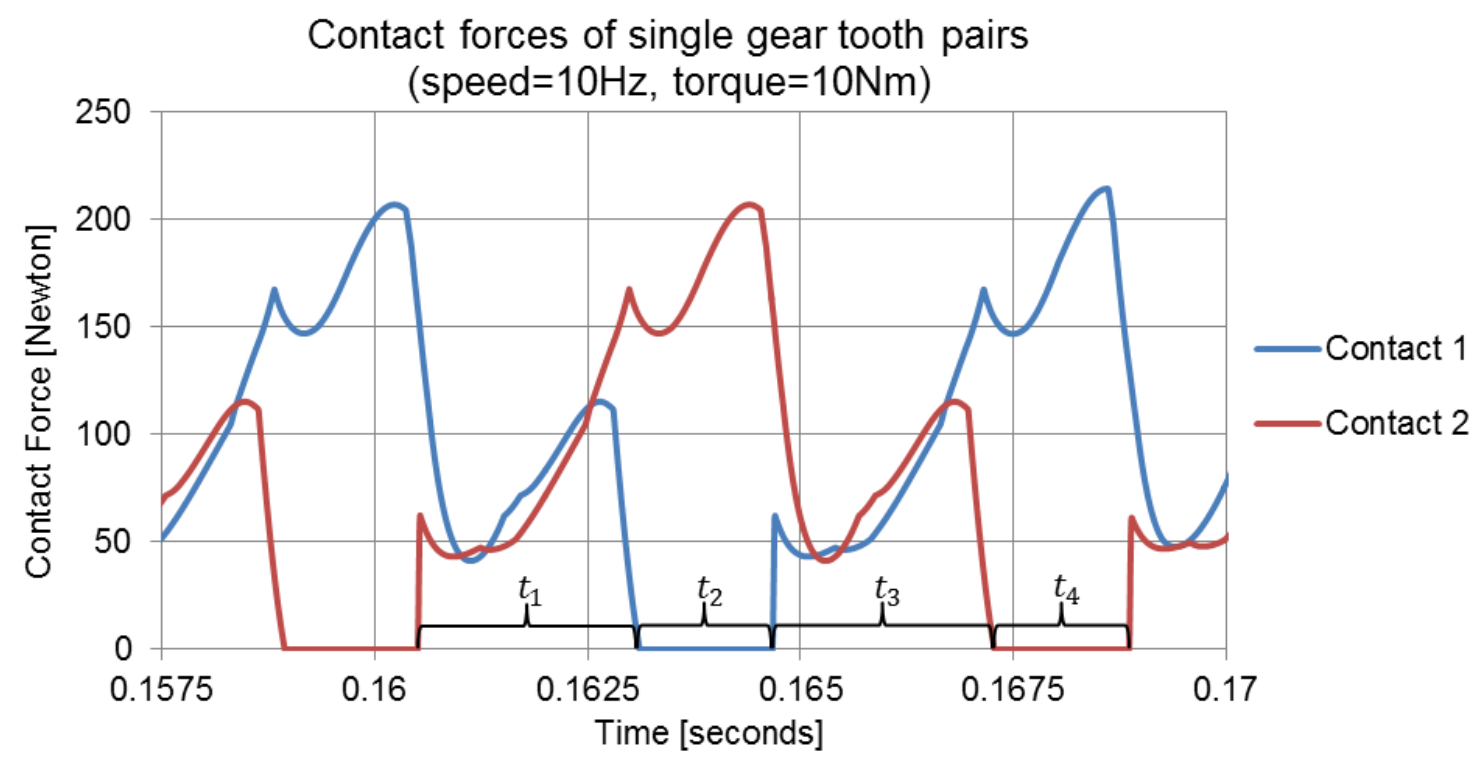

Figure 32. Single tooth contact forces of divided gear set

Compared to the original contact force in Figure 28, the time of approaching and recessing teeth can be identified. Further, the gear contact ratio, which represents the average number of gear tooth pairs in contact, can be determined. The more teeth that are in contact the smoother is the operation. The contact ratio of the gear system can be found According to Figure 32. Two pairs of teeth are in contact during $t_{1}$ and $t_{3}$ and one pair of teeth are in contact during $t_{2}$ and $t_{4}$.

$$
\begin{aligned}
& m_{c}=\frac{2 * t_{1}+1 * t_{2}+2 * t_{3}+1 * t_{4}}{t_{1}+t_{2}+t_{3}+t_{4}} \\
& m_{c}=\frac{2 * 0.00275+1 * 0.00148+2 * 0.00267+1 * 0.00151}{0.00842}=1.644
\end{aligned}
$$




\subsection{Loads along the Roll Angle}

Single teeth pair forces are already shown in Figure 32. However, contact forces are shown in terms of time without any information about where these contact forces act on the line of contact. In order to determine the contact force point, the progression of teeth is used to get a connection between rotational angle and time.

\subsubsection{Progression of teeth}

When rotation is transmitted from pinion to gear, tooth contact takes place along the line of action. Therefore, a relationship between position of rotation and teeth contact point exists. In Figure 33, the line of action is shown in terms of the position of rotation. This figure assumes that not more than two gears are acting at the same time.

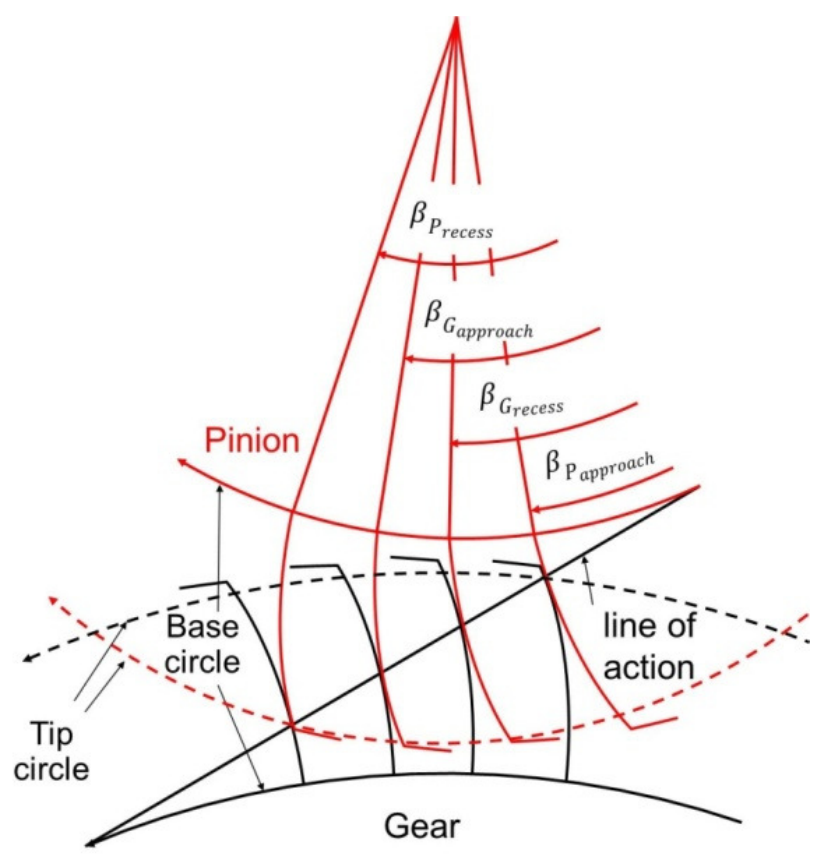

Figure 33. Theoretical progression of teeth of a perfect gear set 
where, $\beta_{P_{\text {approach }}} \quad$ Angle of approach of Pinion,

$$
\begin{array}{ll}
\beta_{P_{\text {recess }}} & \text { Angle of recess of Pinion, } \\
\beta_{G_{\text {approach }}} & \text { Angle of approach of Gear, } \\
\beta_{G_{\text {recess }}} & \text { Angle of recess of Gear, }
\end{array}
$$

J.R Colbourne [12] provides in "Geometry of involute Gears" analytical solution for gear contact ratio in terms of the progression of teeth:

$$
m_{c}=\frac{\Delta \beta_{c}}{\Delta \theta_{p}}
$$

where, $\Delta \beta_{c}=\beta_{P_{\text {recess }}}-\beta_{P_{\text {approach }}} \quad$ Angle of tooth contact between pinion and gear,

$$
\Delta \theta_{p}=360 \mathrm{deg} / N \quad \text { Angular pitch of a gear }
$$

The contact ratio $m_{c}$ describes also how long a single gear tooth pair is in contact. The involute gear profile provides further a linear relationship between angular displacement and progression of teeth, shown in Figure 33. Therefore, the contact ratio $m_{c}$ can further be used to describe the length of the line of contact of one single gear tooth pair. The Roll Angle range, which describes the Roll Angle difference between lowest and highest point of contact, can be determined with the progression of one single tooth times the contact ratio $m_{c}$. This is shown in Table 5 and important to compare results.

Table 5. Contact ratio and Roll Angle for the first gear pair, determined with Adams®

\begin{tabular}{|l|l|l|}
\hline$m_{c}=\frac{\Delta \beta_{c}}{\Delta \theta_{p}}=\frac{\beta_{P_{\text {approach }}}-\beta_{P_{\text {recess }}}}{360 \mathrm{deg} / N_{g}}$ & $m_{c}=\frac{24 \mathrm{deg}}{15 \mathrm{deg}}=1.6$ & $m_{c}=\frac{9.6 \mathrm{deg}}{6 \mathrm{deg}}=1.6$ \\
\hline$\Delta$ roll angle $=m_{c} * \frac{360 \mathrm{deg}}{N_{g}}$ & Sroll angle $=9.6$ & Groll angle $=24$ \\
\hline
\end{tabular}




\subsubsection{Experimental estimation of loads along the Roll Angle}

A relationship between rotational angle and Roll Angle, in terms of a perfect gear set with no backlash and no Tip Relief, is already shown in Figure 33. Since this gear set has backlash and Tip Relief and results are based on a rigid-elastic model, only an approximation of tooth forces along the line of contact is possible. One possibility to connect time with rotational angle is shown in Figure 34. Time refers to a singular specific rotational angle. Each contact force occurs at a certain time and a certain rotational angle.

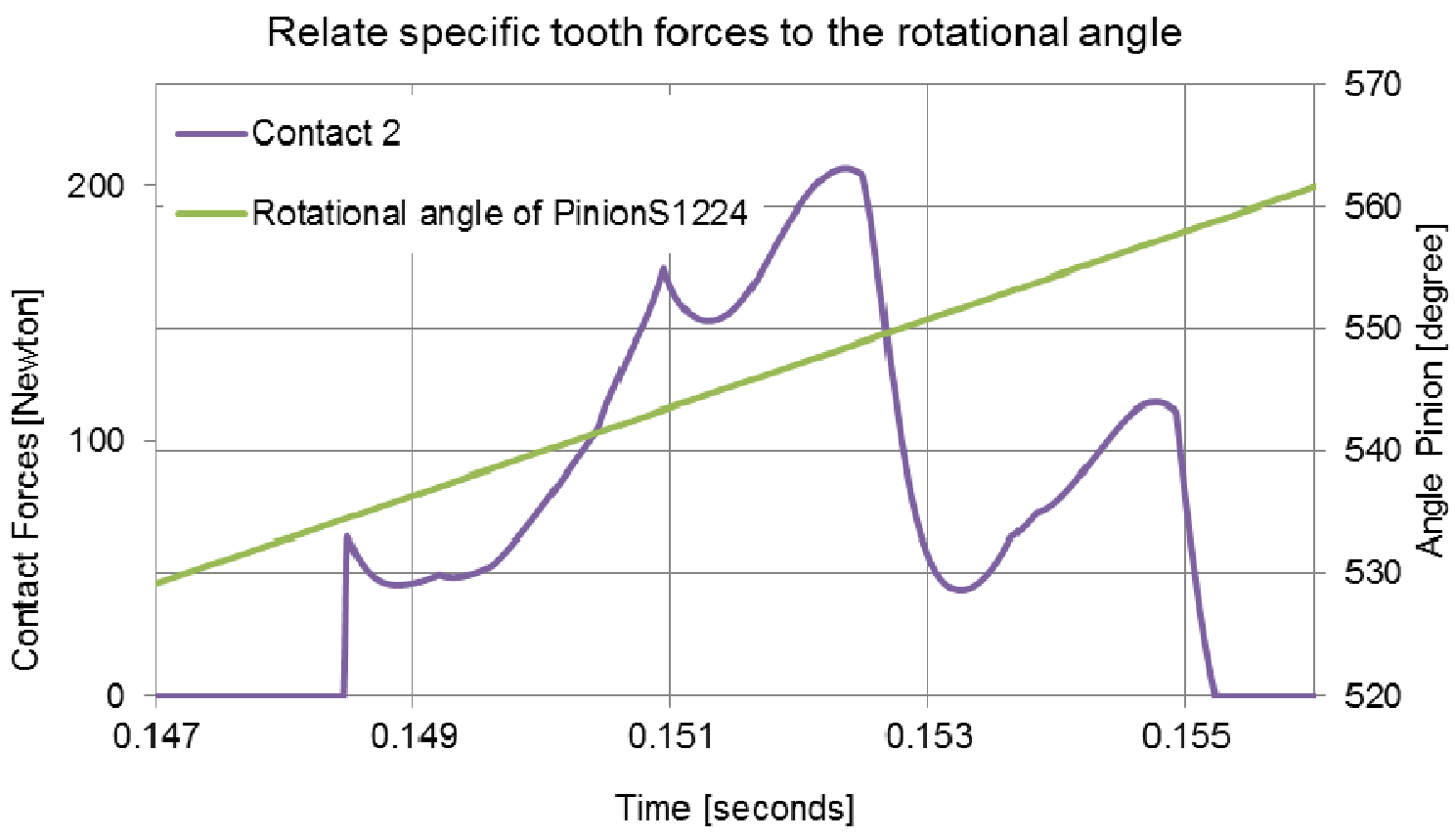

Figure 34. Contact forces and rotational angle of divided gear set

The model in SolidWorks ${ }^{\circledR}$ is used to determine graphically the Roll Angle of lowest and highest points of contact. The rotational angle is a hint to where the tooth pair is in contact. The results are shown in Table 3. 
Table 6. Convert rotational angle with Roll Angle

Rotational angle [degree]

Angle of approach $\quad$ rot angle $=534.4$

Angle of recess $\quad$ rot angle $=198.7$

line of action range $\quad$ rot angle $=24.3$
Roll Angle [degree]

$\rightarrow \quad$ roll angle $=14.1$

$\rightarrow \quad$ roll angle $=22.97$

$\rightarrow \quad$ roll angle $=8.87$

Rotational angle matches the analytical value, in Table 6, quite well. However, Roll Angle is slightly lower compared to the analytical Roll Angle, shown in Table 6 as well. This difference is probably caused by the Tip Relief profile. Using a linear relation between the start and endpoint of the Roll Angle, force can be related to the Roll Angle shown in Figure 35.

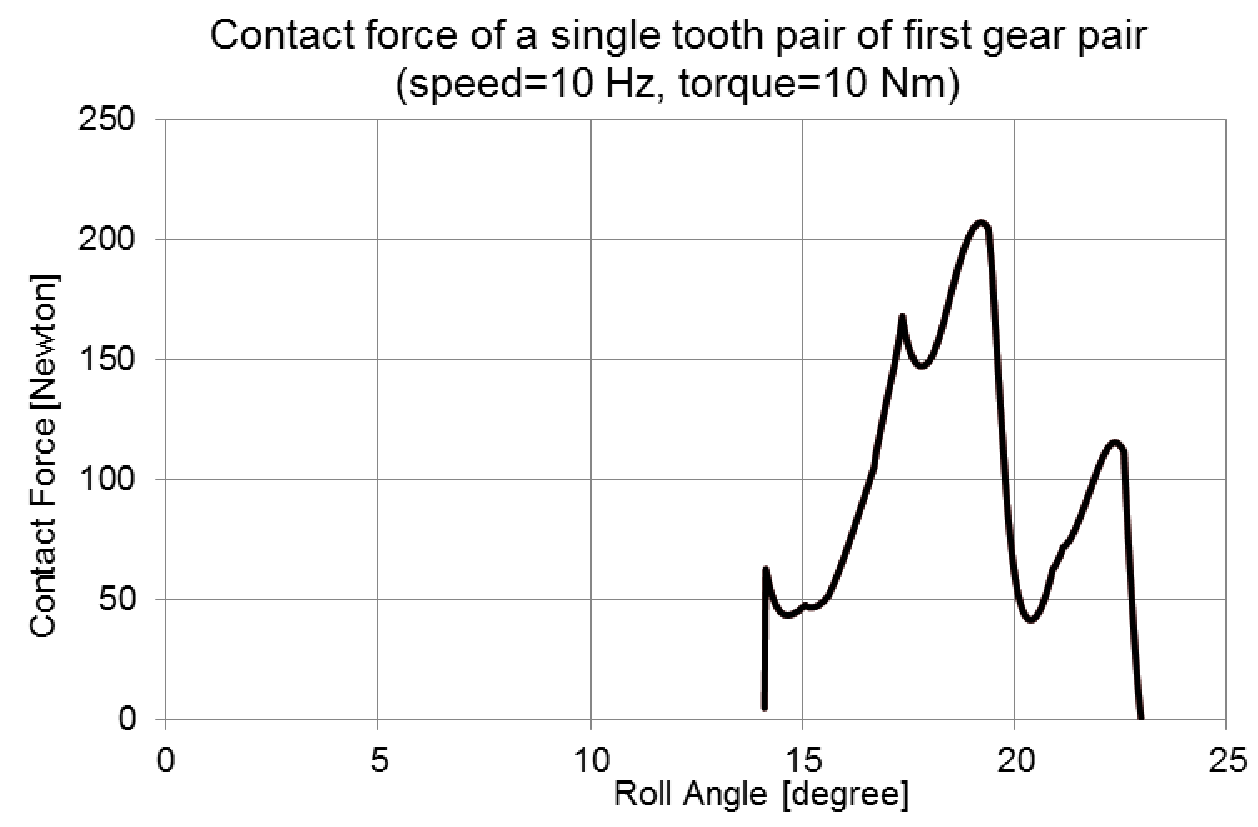

Figure 35. Contact forces along Roll Angle derived by a divided gear set 
The following aspects can be determined from a contact force diagram versus Roll Angle, shown in Figure 35:

- Approaching and recessing teeth loads are indicators for smooth or harsh gear transaction. The smoother that tooth approach the better the gear transaction.

- A general judgment of healthy or unhealthy gear action is possible according to how discontinuous contact force are.

- Maximum stress can be determined according to the gear geometry and highest load along the line of action.

- Contact ratio can be determined in terms of the range of Roll Angle

- Tip Relief profile can be judged. Higher contact forces can be lowered by cutting material at the corresponding Roll Angle.

- Predicting deterioration and wear according to the high loads and stresses along the line of contact.

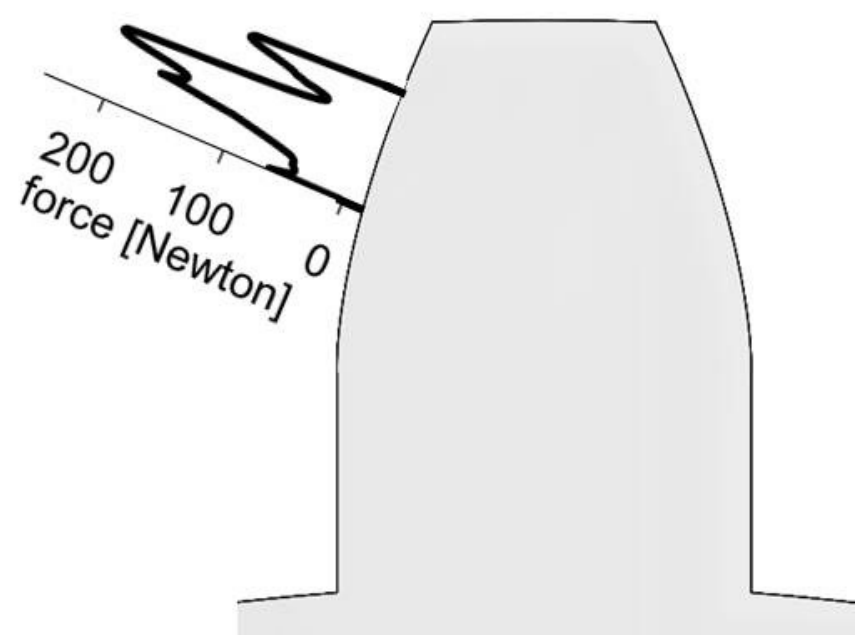

Figure 36. Graphic of tooth force along the tooth profile. 


\section{Vibration analysis in LS-Dyna®}

Acoustics is the science of sound. It describes mechanical waves in gases, liquids, and solids. Pressure changes in gases can be interpreted by a human ear as sound. The frequency range humans detect varies between 20 and $20,000 \mathrm{~Hz}$. Acting gears generate frequencies in that range. This chapter introduces the meshing part of generating numerical solutions to simulate acoustic pressure problems of acting gears.

LS-Dyna®, from Livermore Software Technology Corporation (LSTC), is a program to solve and compute acoustic pressure problems. It is a transient dynamic finite element solver, capable to solve acoustic and vibroacoustic problems with the Boundary Element Method (BEM). It allows converting vibrating surfaces to acoustic signals using the Helmholtz equation. However, the time for simulating acoustic signals is higher compared to vibration results in Adams ${ }^{\circledR}$. Especially for running gear systems where plenty of impacts on tooth surfaces occur. LS-Dyna® is code based software and the whole model development, boundary conditions, and applying motions are written in a text format. Keyword format provides an organized database of cards for the user. These cards are similar to other programming tools and activate specific functions. However, the user can see graphical results after post-processing the code. [24]

Meshing parts is an important aspect of modeling gears, because acoustic pressure changes result from vibrating gears. A good mesh contributes towards a good acoustic solution. TrueGrid® is a mesh generator for FEA programs and generates a high quality mesh using flexible solid brick elements through the whole geometry of a gear tooth. Brick elements are more accurate compared to typical shell elements and are three dimensional space elements with a certain amount of nodes. Therefore, TrueGrid® is a good choice meshing gears especially in terms of gear failure, because defective gears 
have many thickness variations on the tooth surface, like wear or spalling. Solid brick elements can mesh difficult surface geometry successfully. TrueGrid® allows importing IGES files to define the geometry of the outer gear surface. It also generates an output file with all mesh geometries and can be used as an input file for LS-DYNA®. TrueGrid® is also code based software. However, the user has control over the meshing process through a graphical user interfaces.

An efficient, repeatable process to mesh gears with different defects is introduced. 


\subsection{Finite Element mesh with TrueGrid®}

To perform acoustic analysis, brick elements are used through the gears thickness in order to get an accurate thickness on complex surface geometries. The challenge is to adjust these 8 nodes brick elements to a gear. A block mesh in space is used to project the mesh to the outer gear surface. This block mesh is called "dummy" and has no complexities of grooves or notches. It is a smaller and simplified meshed gear to project it to the real outer gear surface. A block mesh of a gear is shown in Figure 37. On the left hand sides a real one tooth model is shown, and on the right hand side a simplified block mesh is shown. A one tooth model includes the tooth and the bottom land of a gear. The first goal is to project a one tooth block mesh model to the outer surface of the gear geometry. The whole gear can be generated by replicating a one tooth model. The geometry of all gear geometries of the "dummy" model is shown in Table 7.

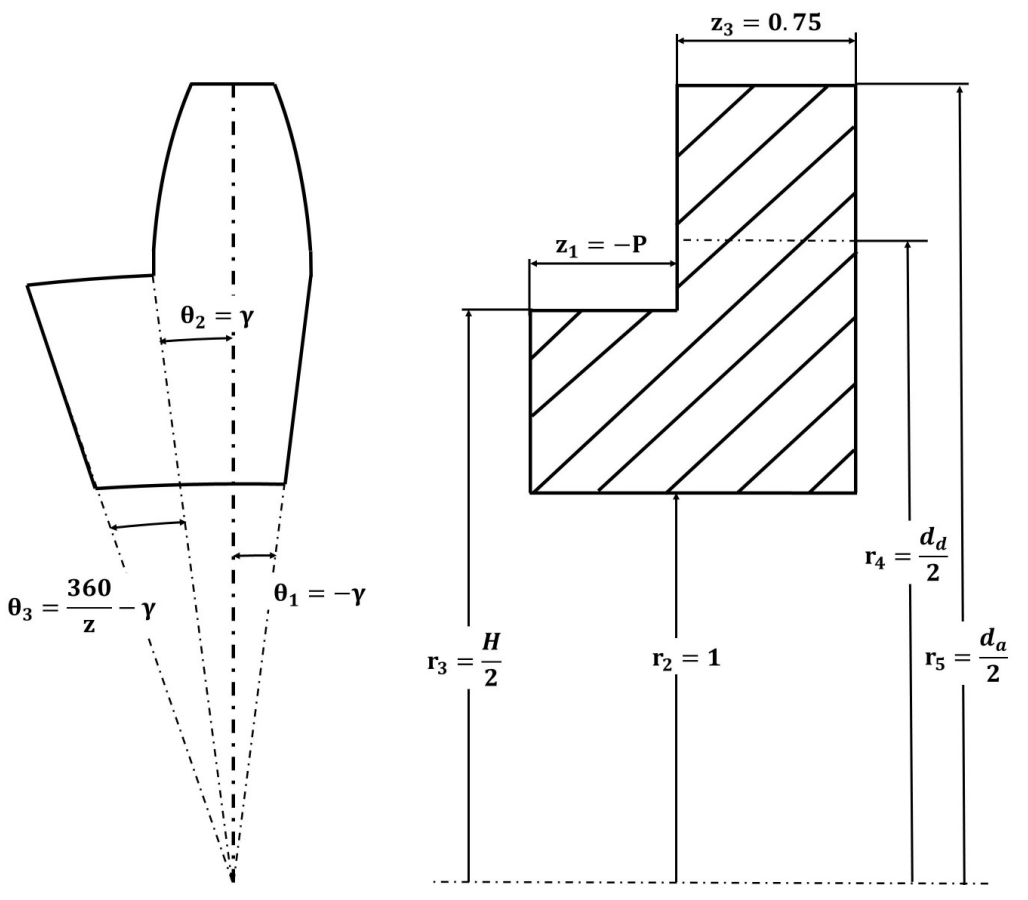

Figure 37. "Dummy” model and block mesh model in TrueGrid® 
Table 7. Geometry of dummy model in TrueGrid

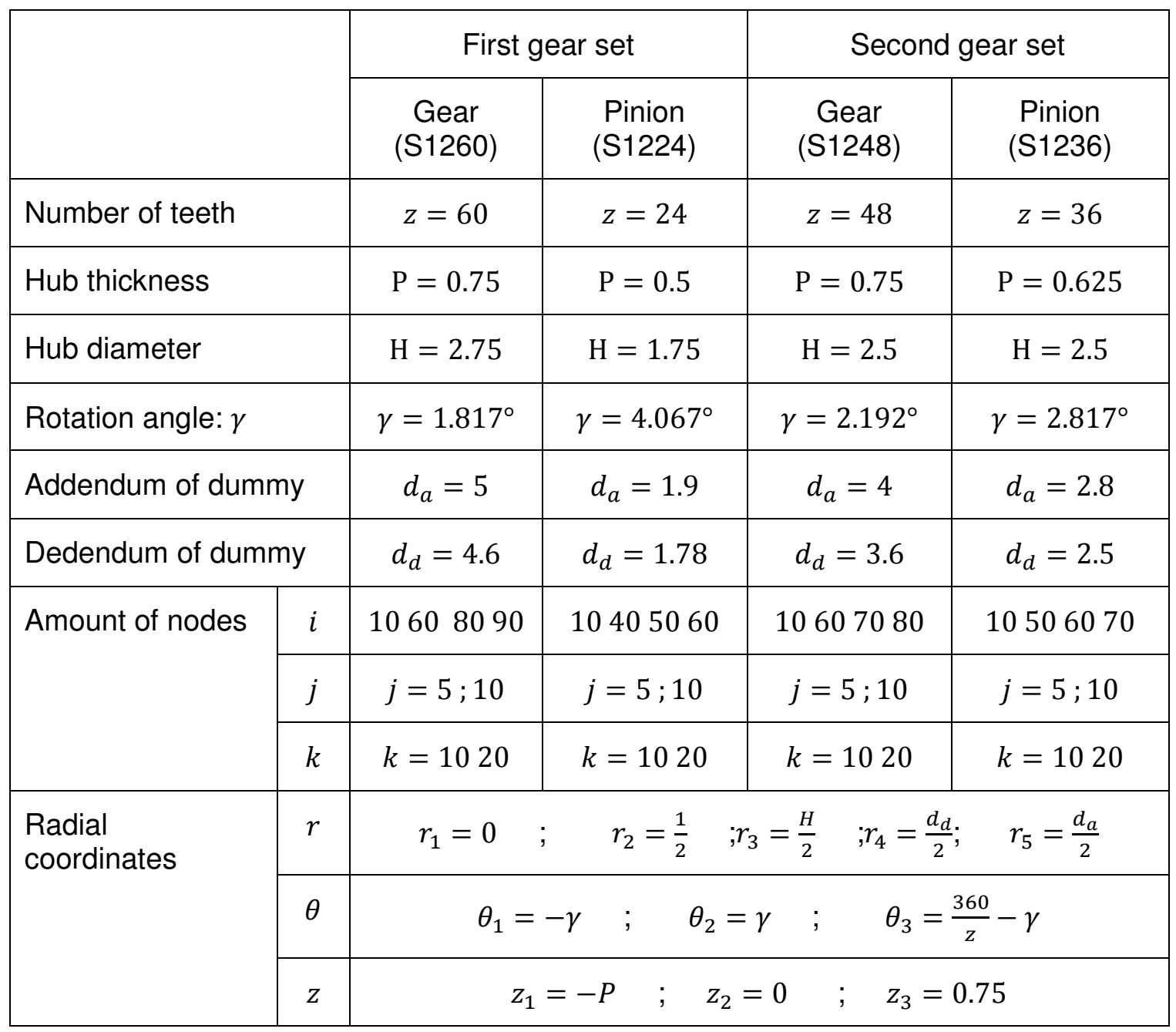

Two graphical user interfaces support the user with all necessary information. The Physical window represents the block mesh element with curves and points. It represents the physical reality in an $x, y, z$-coordinate system with all brick elements. The computational window is independent of the physical display and includes vertices and edges in I, J, K-coordinates. First, the surface of addendum and dedendum cylinder of a gear is created. Cylindrical coordinates are used to create all geometries for the "dummy" model. The axis of the right circular cylinder surface passes through $(0,0,0)$ and is parallel to $(0,1,0)$. A block mesh element in cylindrical coordinates is created 
with the corresponding radial coordinates and amount of nodes shown in Table 7. The computational window and physical window is shown below in Figure 38. Shaft and the last upper corner of the gear system get cut away, shown in Figure 39.
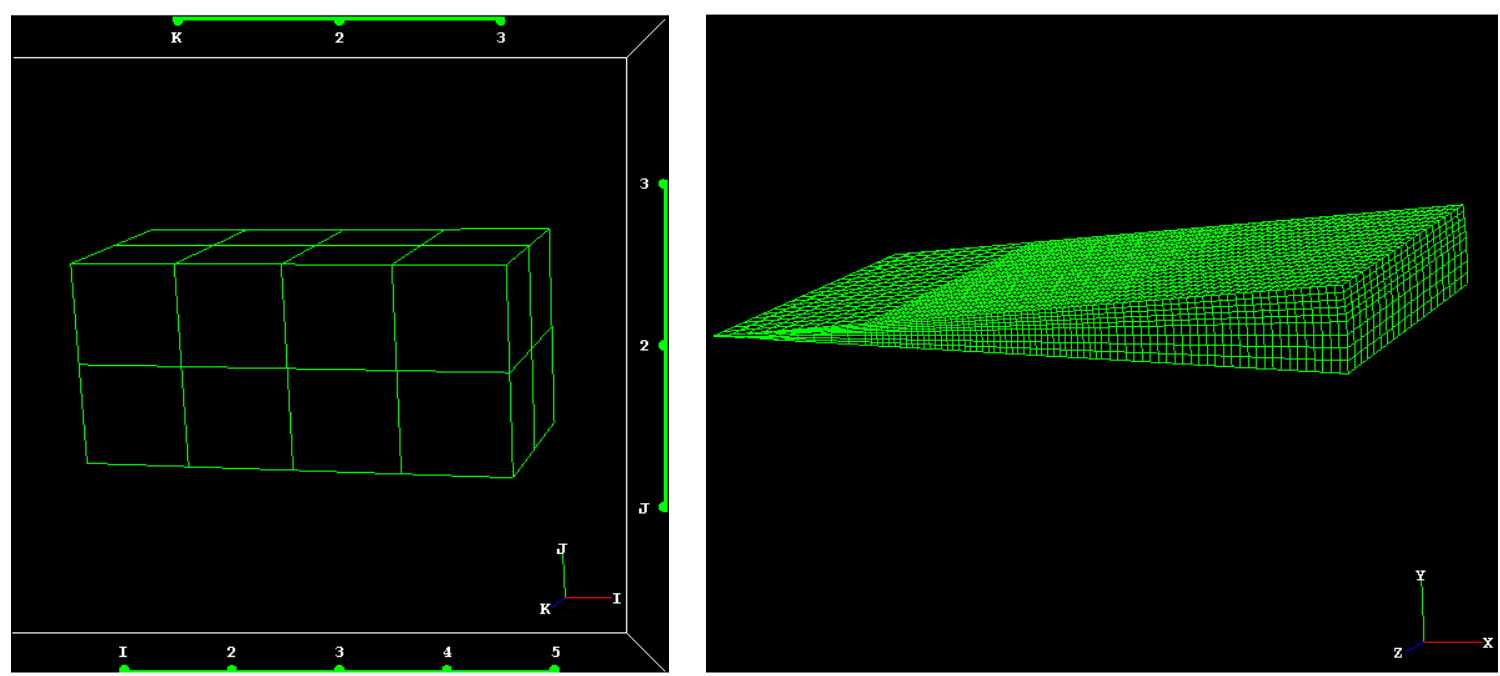

Figure 38. Computational Window and Physical Window of uncut elements
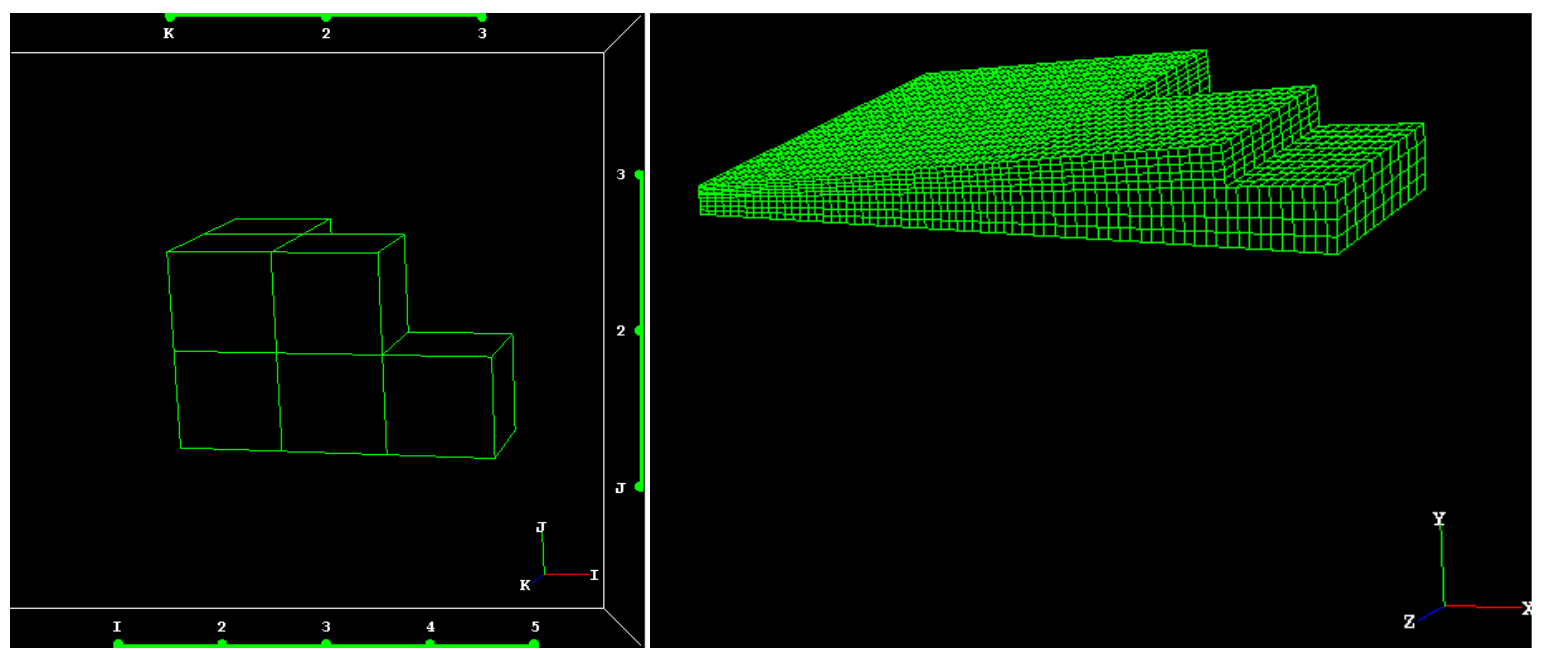

Figure 39. Computational Window and Physical Window of cut elements 
This simplified model can be projected to our real surface geometry of the IGES files. After importing IGES-file edges are converted with the curve definition method. The perfect gear defines eight curves of on a one tooth, shown in Figure 40.
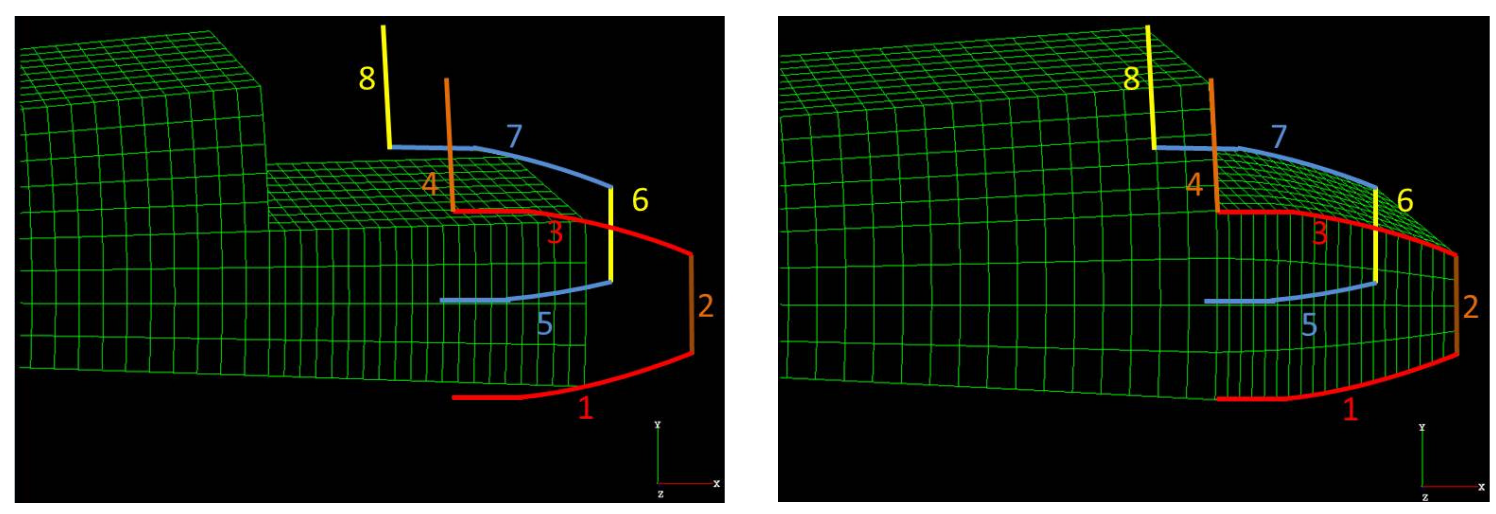

Figure 40. Project lines of a one tooth block mesh model to the outer surface

After all curves are coincident with the curves of the gear model, surfaces on the "dummy" model are further projected to the surface of the original gear model, shown in Figure 41. 


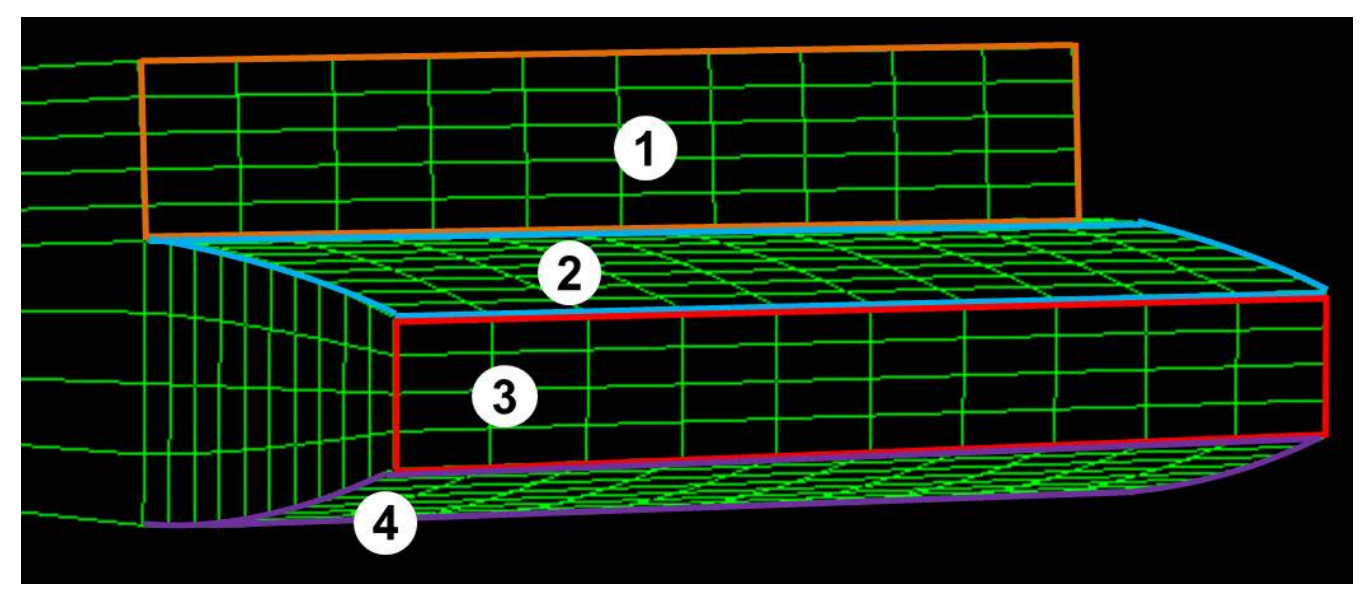

Figure 41. Projection areas

TrueGrid® allows attachment of multiple parts together. The common nodes get merged together with specific tolerances. Therefore, a one-tooth model can be replicated around the origin with the amount of teeth to get a complete gear, shown in Figure 42.

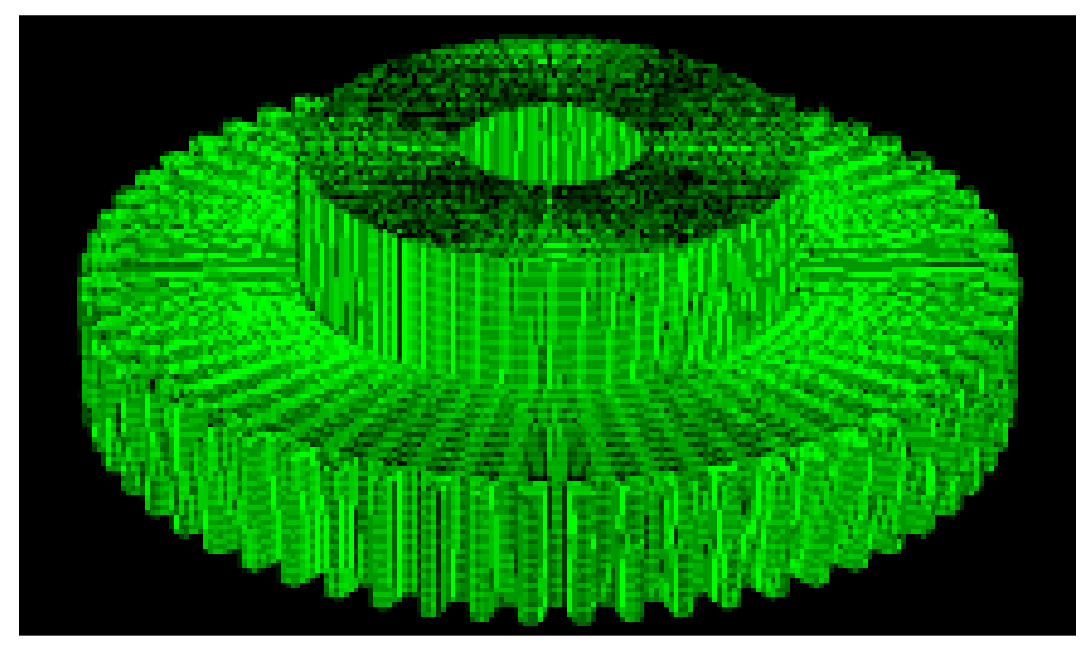

Figure 42. Whole meshed perfect gear 


\section{Gear failure simulated with rigid-elastic model}

This chapter introduces simulations of gear failure with implemented gear failure. Adams $\AA$, using a rigid-elastic model, is used to simulate it. These simulations allow characterizing and identifying certain types of gear failure. Preliminary stages of gear failure can be applied to recognize first stages of gear failure. These data can be compared with vibration measurements and the implemented gear failure can be further adjusted to get closer to the real physical results.

The most common gear failure mechanism is wear and covers a huge range of deterioration mechanism. It appears after a certain run time and it is almost impossible to avoid. The first simulated gear failure mechanism describes wear and deterioration. Another typical gear failure mechanism is spalling. It occurs to just one single tooth in a gear pair and is the second simulation. As soon as one tooth has a defect, it's harder to re-establish an oil film on a meshing tooth pair. Therefore, all teeth meshing with the damaged tooth gets damaged too and is shown in the third examination. Another typical failure mechanism is eccentricity and introduced in the fourth simulation. However, the most important gear failure in this Chapter is tooth breakage. Tooth breakage is also simulated with the Gearbox Dynamic Simulator and can be compared to numerical solutions of Adams®. 


\subsection{Wear on a gear pair}

Wear covers a huge range of different types of deterioration. Most published papers, patents, and scientific articles are written about gear failure and introduced in Gear failure, Chapter 2. To simulate wear, holes on a gear tooth are implanted on PinionS1224 on all teeth. A drawing of one tooth is shown in Figure 43. Table 8 shows all the values for two different wear cases. "Pattern x" and "Pattern y" signify number of hole repetitions in the $\mathrm{x}$ and $\mathrm{y}$ direction.
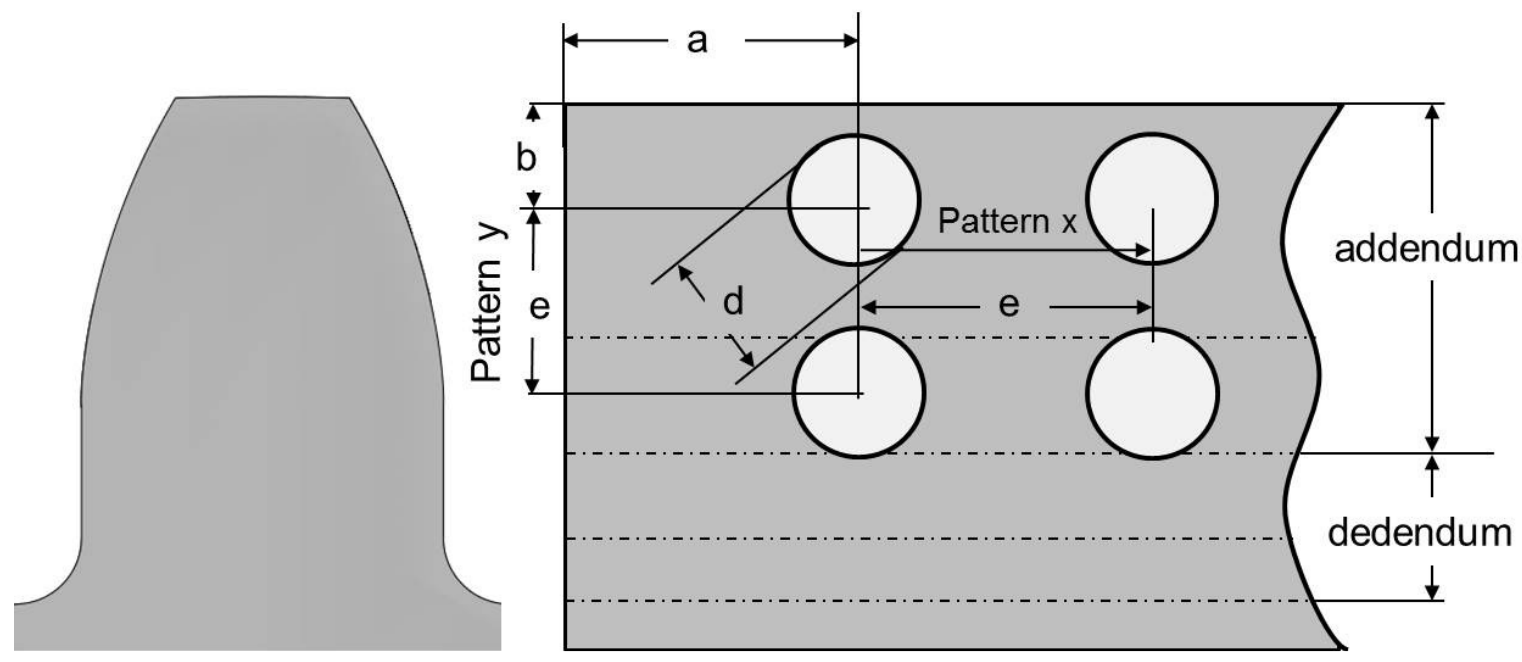

Figure 43. Model of wear on all teeth of PinionS1224

Table 8. Wear modification values of Figure 43

\begin{tabular}{|l|l|l|l|l|l|l|}
\hline & $a$ [inch] & $b$ [inch] & $d$ [inch] & e [inch] & Pattern x & Pattern y \\
\hline Wear Case 1 & 0.05 & 0.03 & 0.05 & 0.7 & 10 & 2 \\
\hline Wear Case 2 & 0.05 & 0.03 & 0.01 & 0.35 & 10 & 2 \\
\hline
\end{tabular}




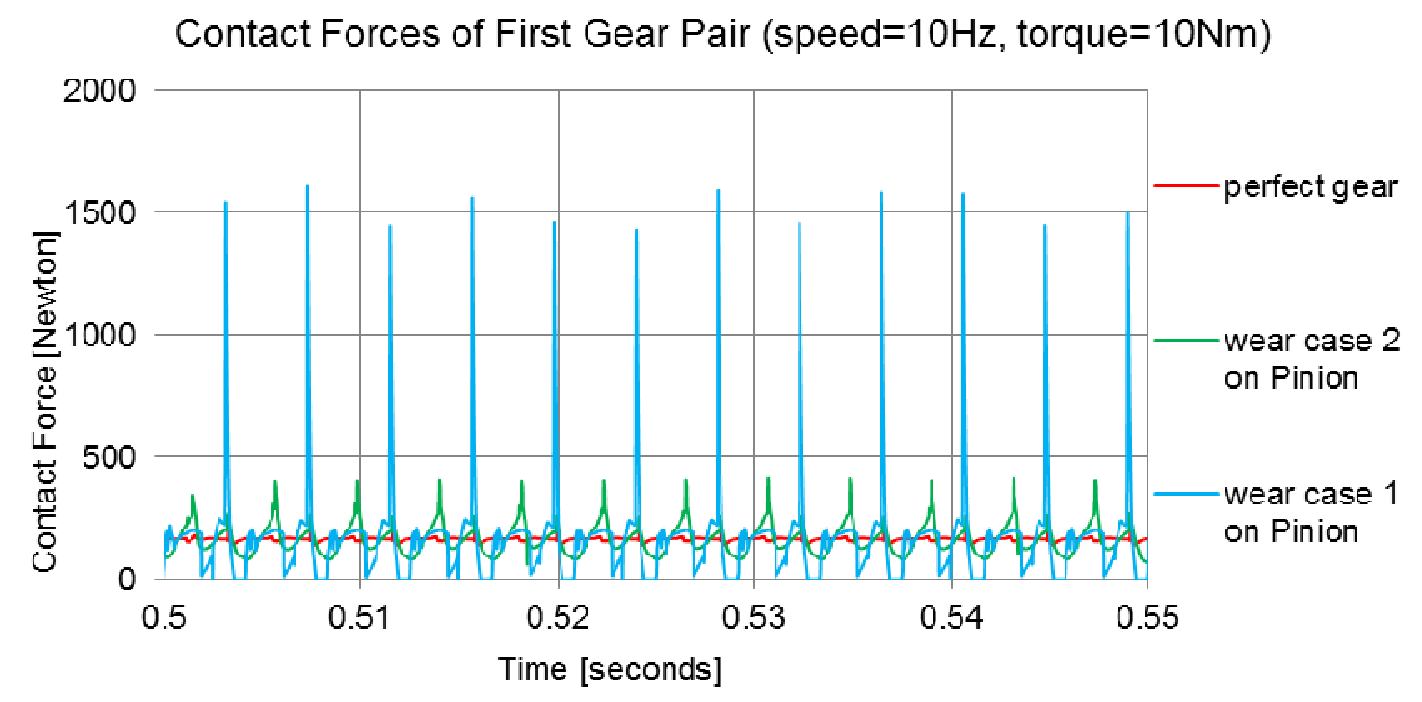

Figure 44. Time response plots of different wear cases

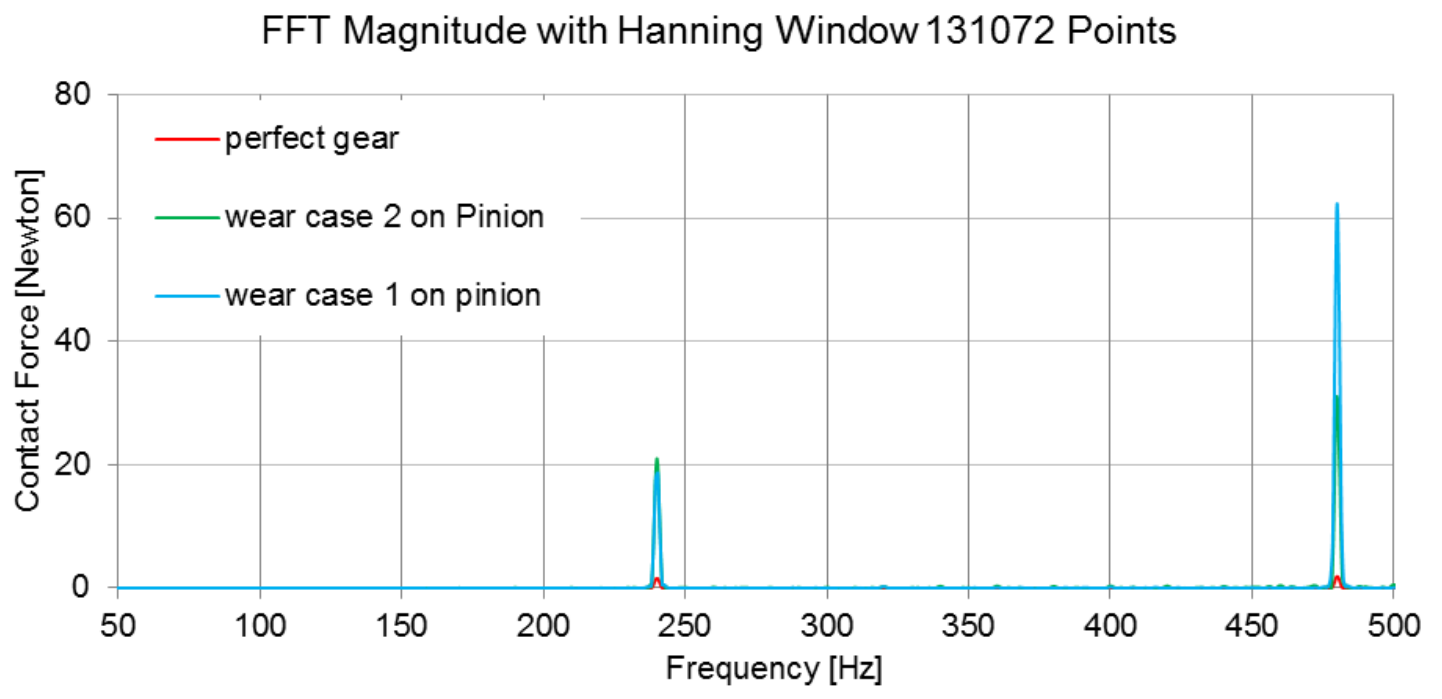

Figure 45. Frequency response plots of different wear cases

Gear Mesh Frequency of $244 \mathrm{~Hz}$ is clearly evident. Time plot responses have dramatically higher contact forces on wear case 1 , which is also shown in the first and second superharmonic of the frequency response plot. Magnitudes on wear case 2 are lower in time and frequency response. 


\subsection{Spalling of a single tooth}

Spalling is a result of continuation of macro pitting and is part of fatigue. A model of spalling is similar to other gear failure like wear. Spalling occurs typically to just one tooth of a gear. The model of spalling is simplified to single holes along the addendum circle with different sizes. This happens if a part of the tooth's surface pop off. Contact area between meshing tooth decreases. This gear defect is implanted in the first acting tooth of the PinionS1224.

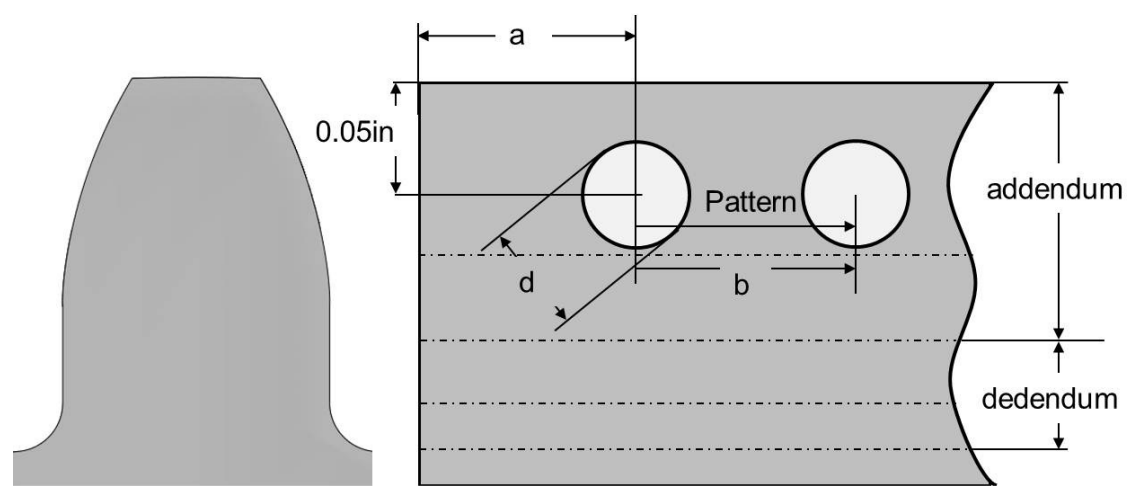

Figure 46. Model of spalling on one tooth of PinionS1224

Table 9. Spalling modification values of Figure 46

\begin{tabular}{|l|l|l|l|l|}
\hline & a [inch] & b [inch] & Pattern & d [inch] \\
\hline spalling case 1 & 0.1 & 0.05 & 7 & 0.05 \\
\hline spalling case 2 & 0.02 & 0.05 & 38 & 0.01 \\
\hline spalling case 3 & 0.02 & 0.05 & 15 & 0.02 \\
\hline
\end{tabular}




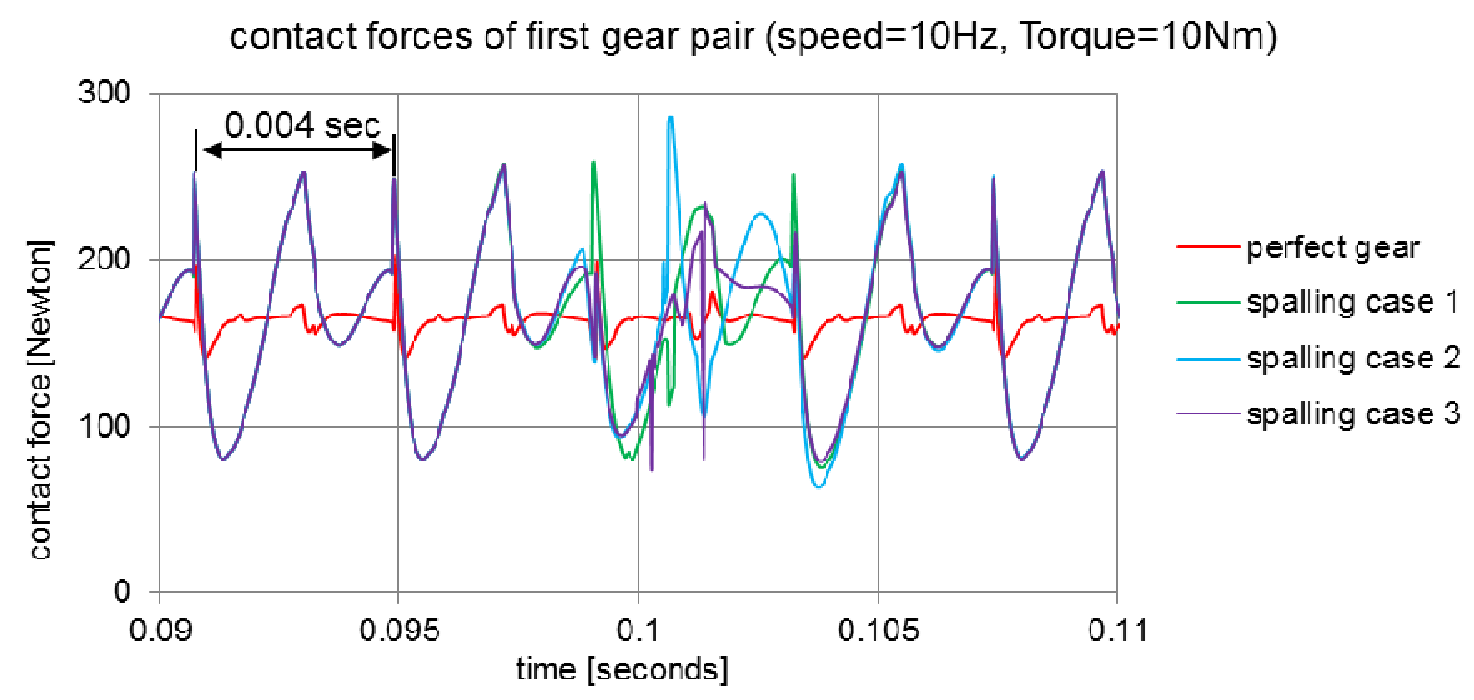

Figure 47. Time response plots of different spalling cases

FFT Magnitude with Hanning Window 131072 Points

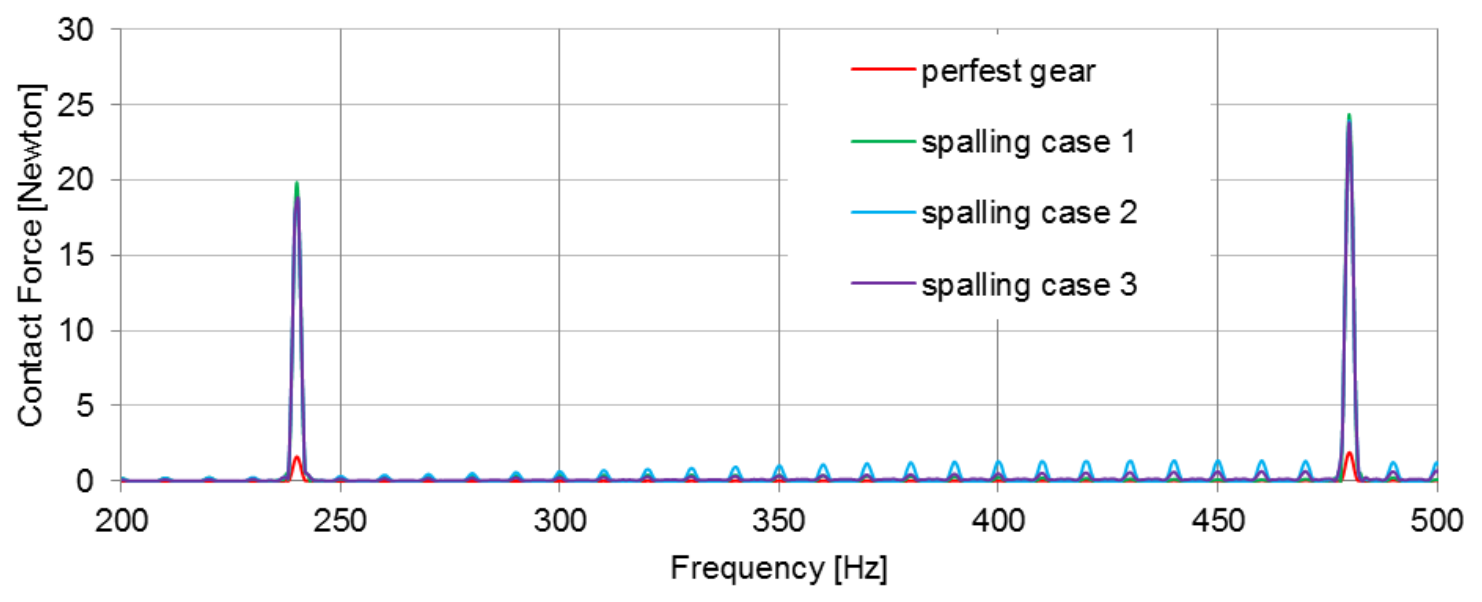

Figure 48. Frequency response plots of different spalling cases

Gear Mesh Frequency of $244 \mathrm{~Hz}$ is clearly evident. Time response plots in Figure 47 shows discontinuous contact forces at 0.1 seconds. At that time, the defect tooth is in contact and induces an erratic contact force change. Two teeth cycles later regular contact forces show up. 

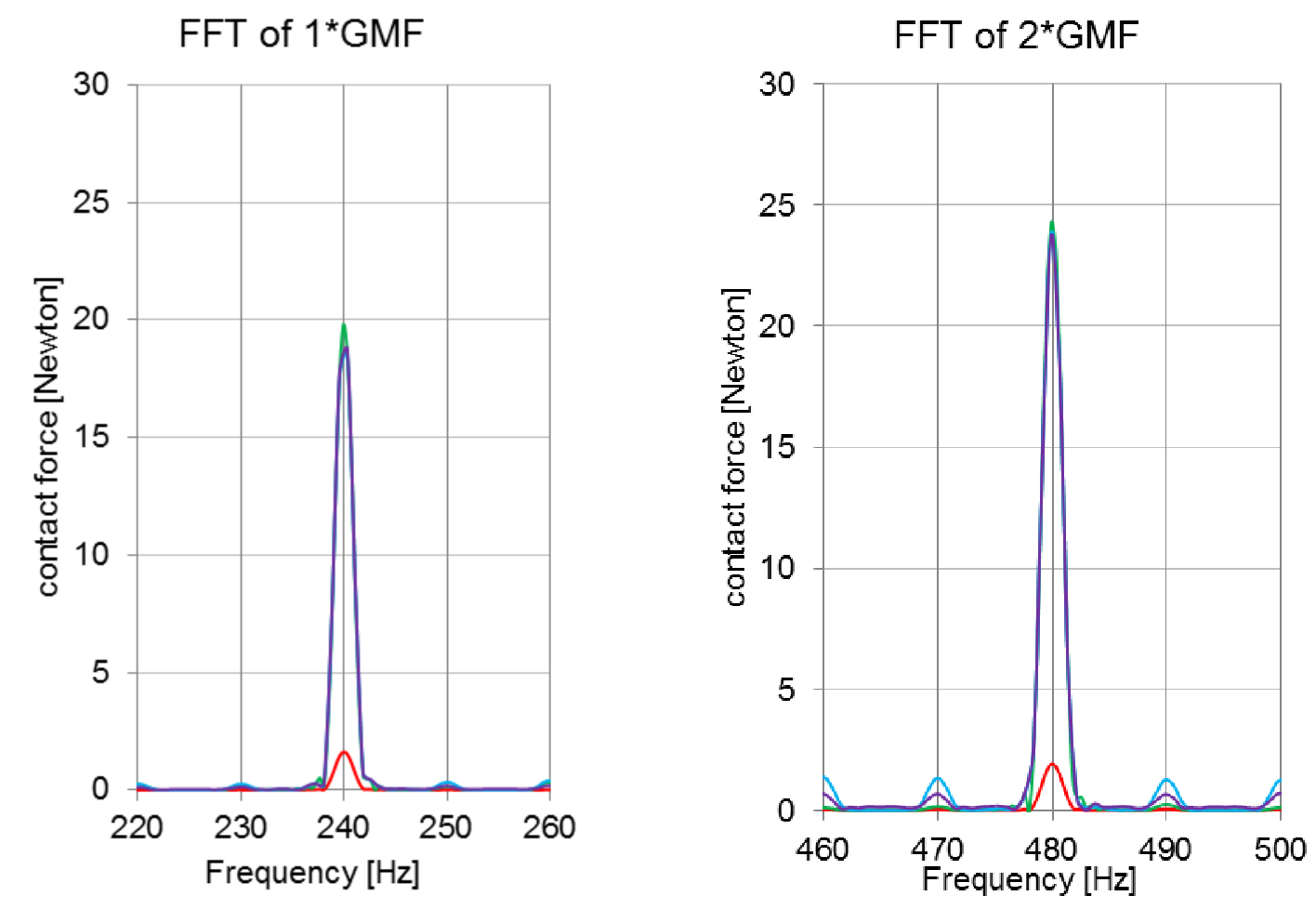

Figure 49. 1*GMF and 2*GMF of spalling. Legend follows Figure 48.

The amplitudes of $1^{*} \mathrm{GMF}$ and $2^{*} \mathrm{GMF}$ of all three spalling cases are extremely high compared to the perfect gear. Spalling probably excites the $1^{*}$ GMF and $2^{\star}$ GMF. All spalling cases have similar magnitudes. Therefore, the change in amount and size of holes has minor influence in frequency response plots. $1^{*}$ GMF and $2{ }^{*} \mathrm{GMF}$ have frequency modulation of $10 \mathrm{~Hz}$ around them. This correlates with the Pinioin shaft speed. 


\subsection{Fracture on a single tooth}

In reality, one damaged tooth has a major influence in an acting gear system. As soon as one tooth has a defect, it is harder to re-establish an oil film between gears. After a certain time all gears which are meshing with the defective gear get imprinted and damaged. A fractured tooth is one example. The common factor (CF) identifies the number of teeth from one bad tooth to the next bad tooth as soon as a fracture occurs on one single tooth. This gear defect is implanted in all influenced teeth of PinionS1224 and GearS1260. Figure 50 shows on the left hand side the model of fracture and on the right side, all imprinted defective gears marked with an arrow.
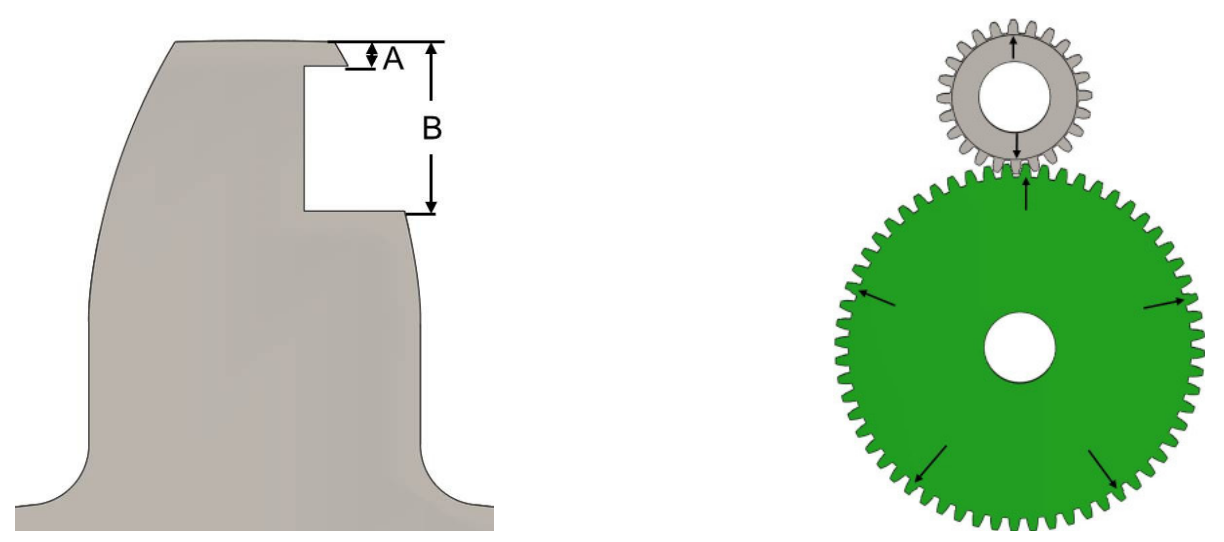

Figure 50. Model of fracture of all influenced teeth of PinionS1224 and GearS1260

Table 10. Fracture modifications values of Figure 50.

\begin{tabular}{|l|l|l|}
\hline & A [inch] & B [inch] \\
\hline Fracture at pitch circle & 0.01 & 0.07 \\
\hline Fracture on tooth tip & 0 & 0.05 \\
\hline
\end{tabular}




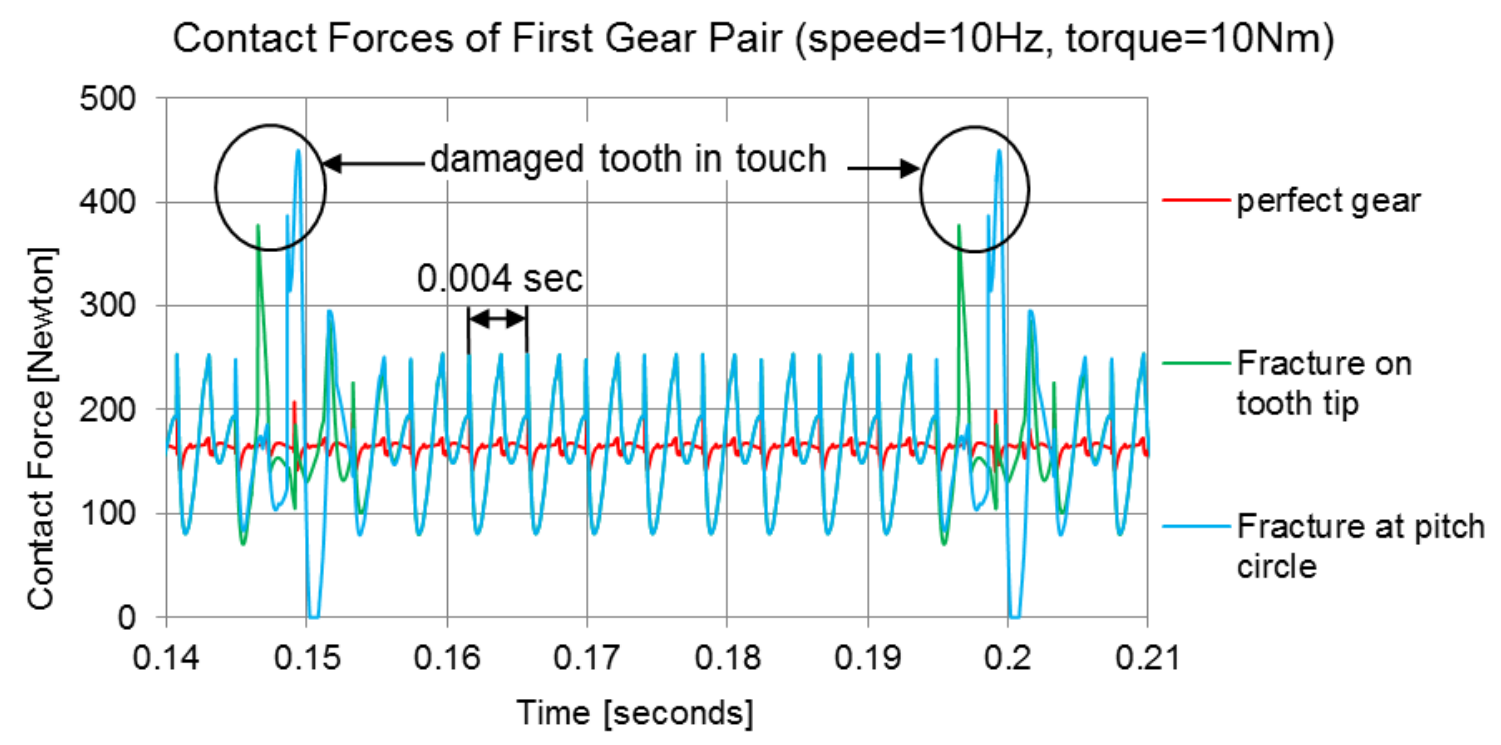

Figure 51. Time response plots of different fractures

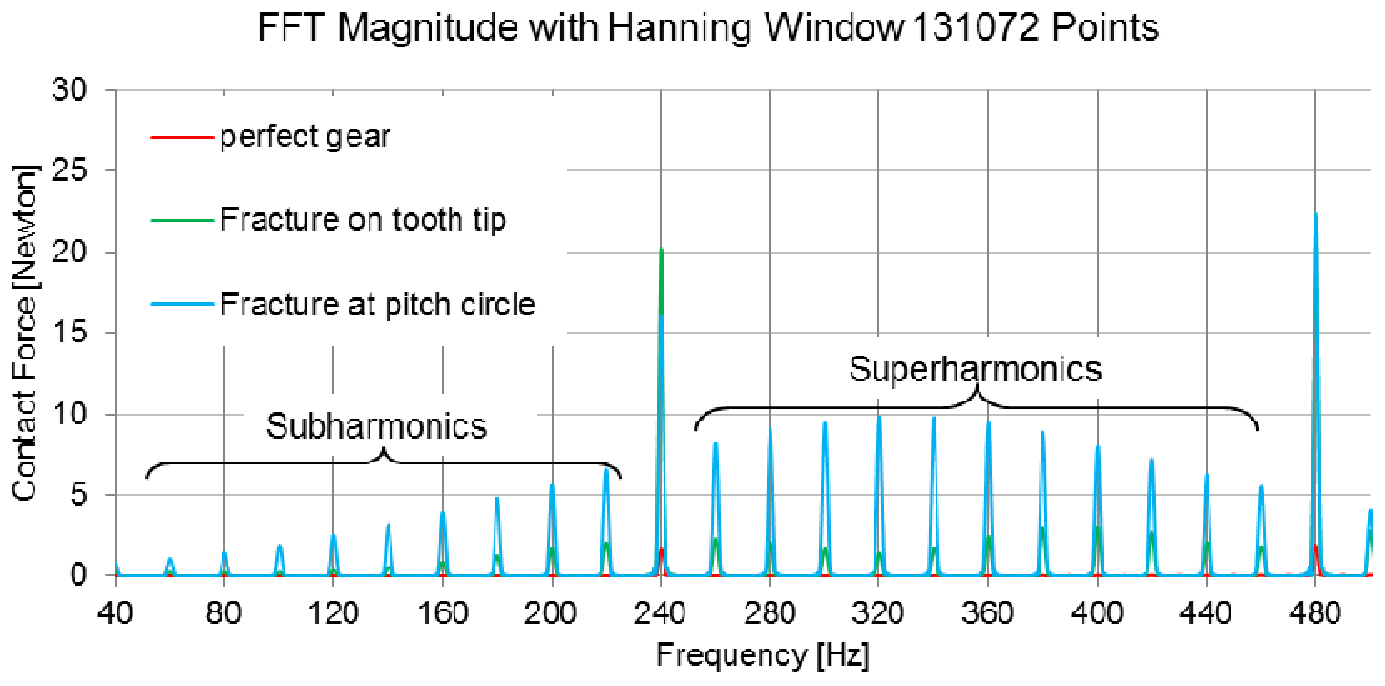

Figure 52. Frequency response plots of different fractures

Gear Mesh Frequencies of time and frequency plots are clearly evident. Sidebands show up between $1{ }^{*}$ GMF and $2{ }^{*}$ GMF, marked in Figure 52 . These sidebands can be determined with the common factor. The calculation is shown in the next Chapter under "Gear Frequency". 


\subsection{Eccentricity of a gear pair}

Eccentric gears rotate about a point other than its geometrical center and run out of the pitch line. One method is an offset of the center of PinionS1224, shown in Figure 53. The distance of eccentricity varies and is shown in Table 11. The influence of this eccentricity is considered in this part of simulation.

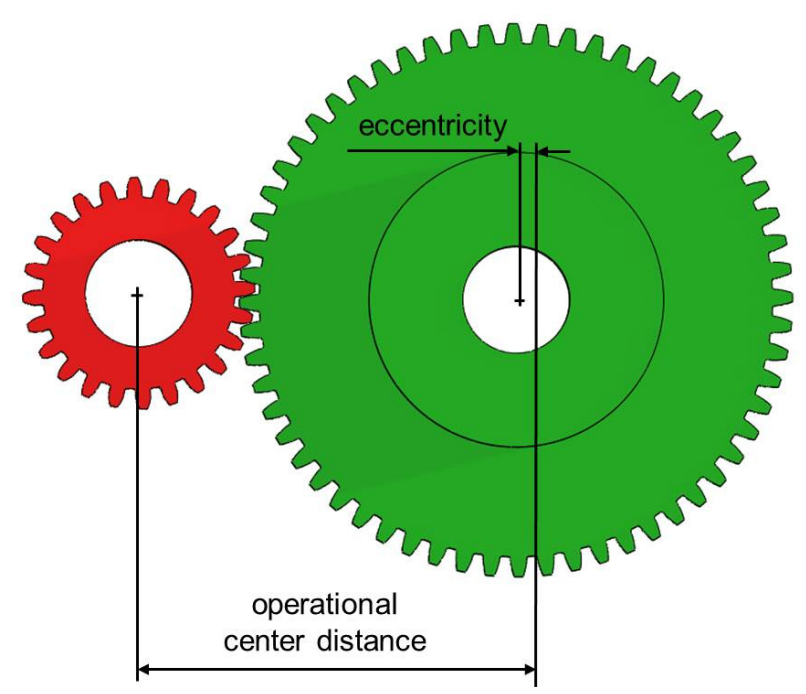

Figure 53. Model of eccentricity

Table 11. Eccentricity modification of Figure 53

\begin{tabular}{|l|l|}
\hline Name of simulation & Distance of eccentricity \\
\hline eccentricity of $0.1 \mathrm{~mm}$ & eccentricity $=0.1 \mathrm{~mm}$ \\
\hline eccentricity of $0.2 \mathrm{~mm}$ & eccentricity $=0.2 \mathrm{~mm}$ \\
\hline eccentricity of $0.4 \mathrm{~mm}$ & eccentricity $=0.4 \mathrm{~mm}$ \\
\hline
\end{tabular}




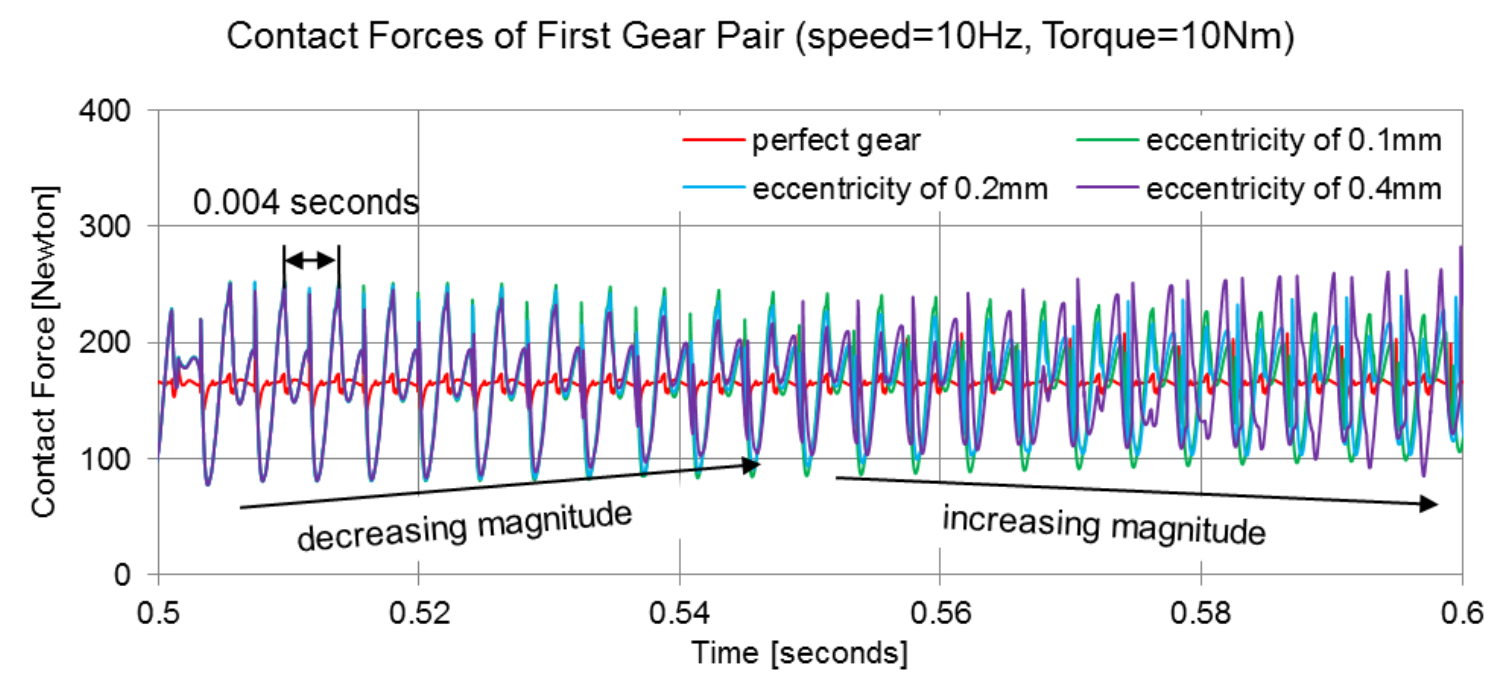

Figure 54. Time response plots of different eccentricity cases

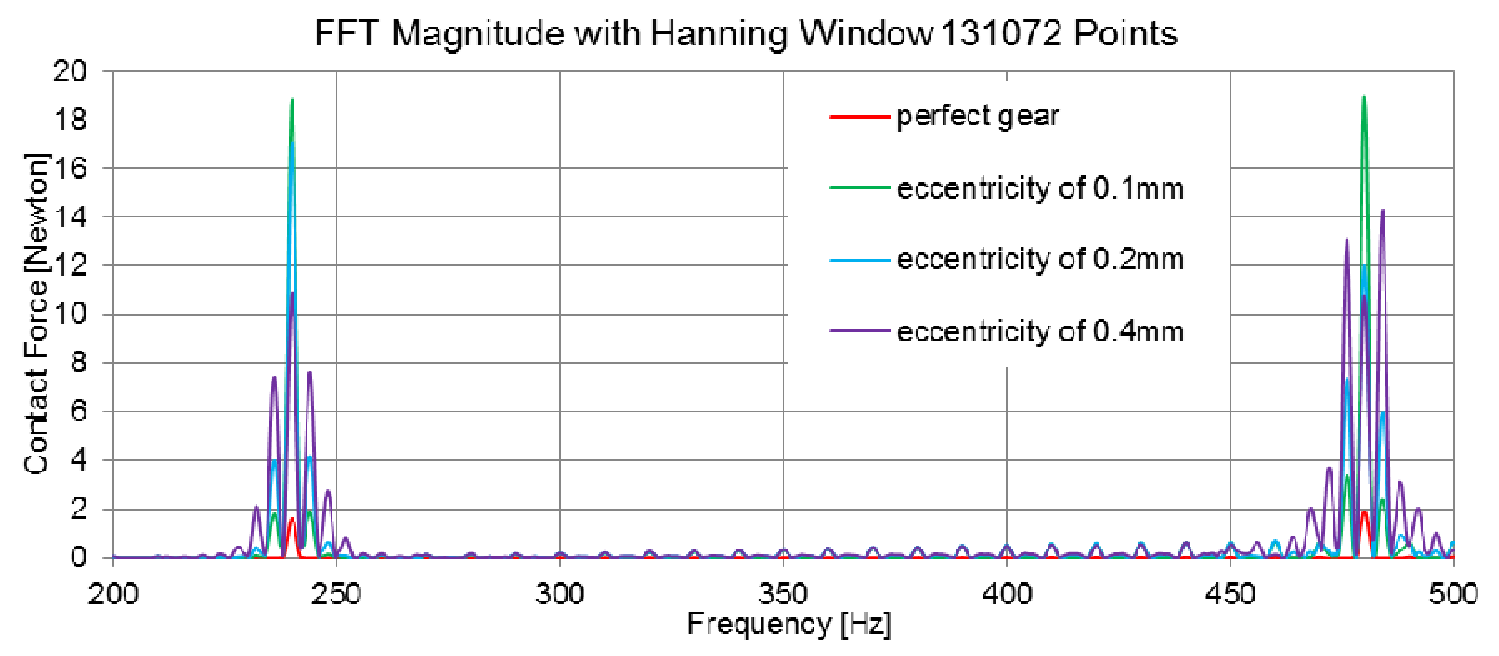

Figure 55. Frequency response plots of different eccentricity cases

Gear Mesh Frequencies of time and frequency plots are clearly evident. The time response plots show increasing and decreasing contact force magnitude. Modulation on $1{ }^{*}$ GMF and $2{ }^{*}$ GMF show up as sidebands in Figure 55. 

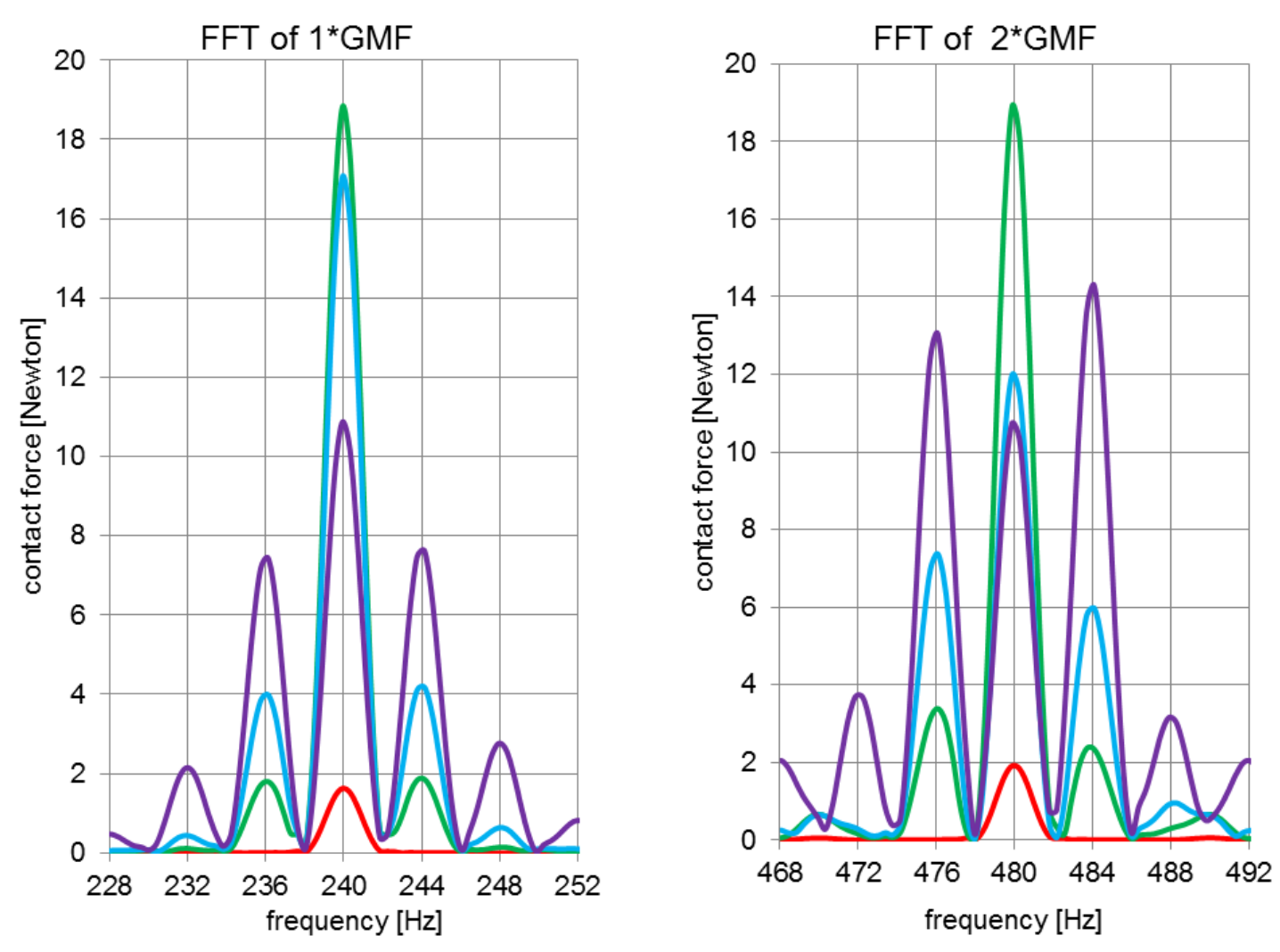

Figure 56. 1*GMF and 2*GMF of eccentricity. Legend follows Figure 55.

Sidebands around $1^{*} \mathrm{GMF}$ and $2^{*} \mathrm{GMF}$ are modulated with $4 \mathrm{~Hz}$. This modulation correlates to the corresponding shaft speed of the eccentric gear. The higher the eccentricity is, the higher are magnitudes of the sidebands next to $1^{*} \mathrm{GMF}$ and $2{ }^{*} \mathrm{GMF}$. The further away sidebands are, the lower are sideband's magnitudes. Netexpress USA, Incorporated [25], reports some of these characteristics like sidebands around superharmonics modulated with $1^{*}$ rpm of the eccentric gear. However, no information about the unexpected twisted order of magnitude on $1{ }^{*} \mathrm{GMF}$ and $2^{*} \mathrm{GMF}$ are included. Wear patterns and backlash have similar symptoms and has to be inspected as soon as these characteristics show up. 


\subsection{Tooth breakage}

Tooth breakage is a fracture of a substantial part of a tooth or whole tooth. Tooth breakage is caused by an overload of a single tooth beyond its endurance limit. The model of tooth breakage is simply a missing tooth on PinionS1224, shown in Figure 60. This gear failure is matched by experimental results in Chapter 7.

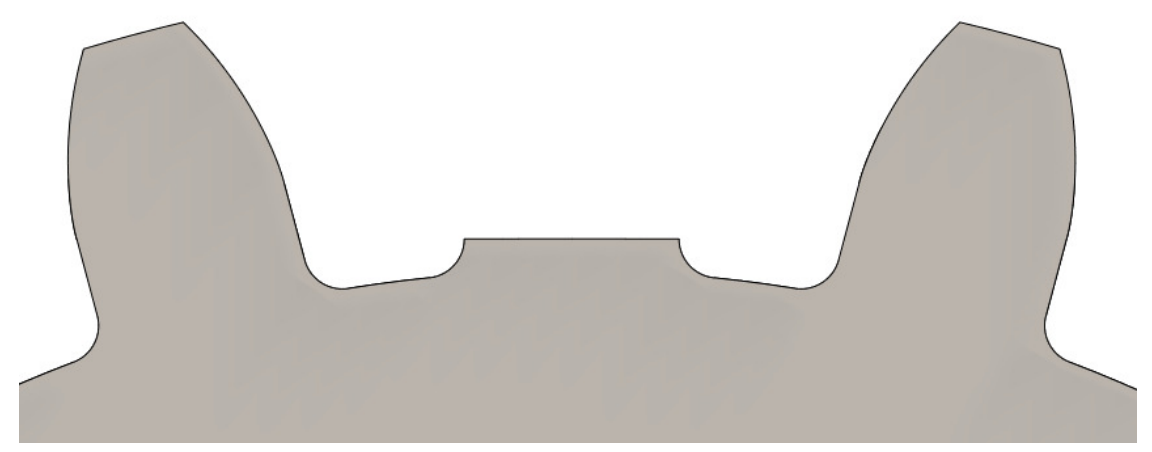

Figure 57. Broken tooth on PinionS1224

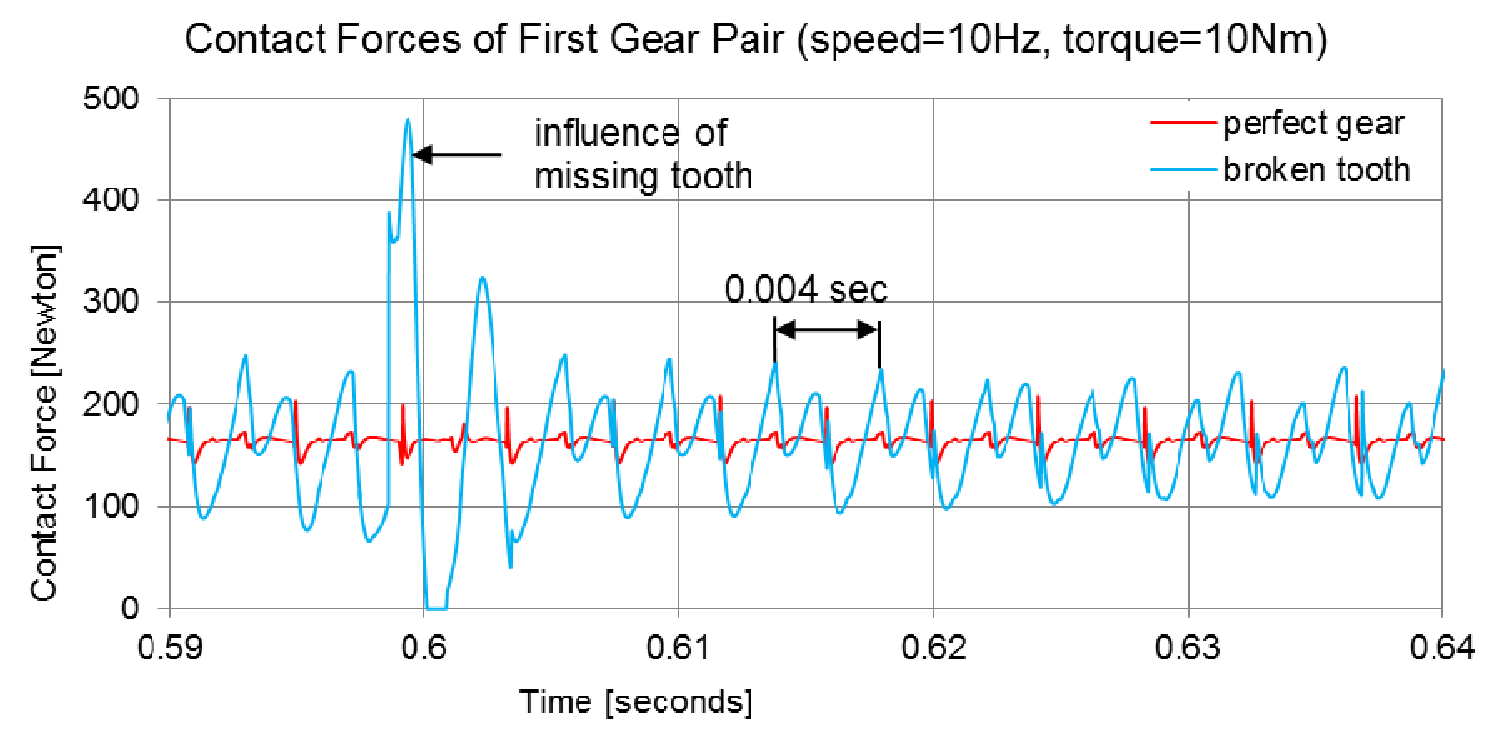

Figure 58. Time response plot of a broken tooth 
FFT Magnitude with Hanning Window 131072 Points

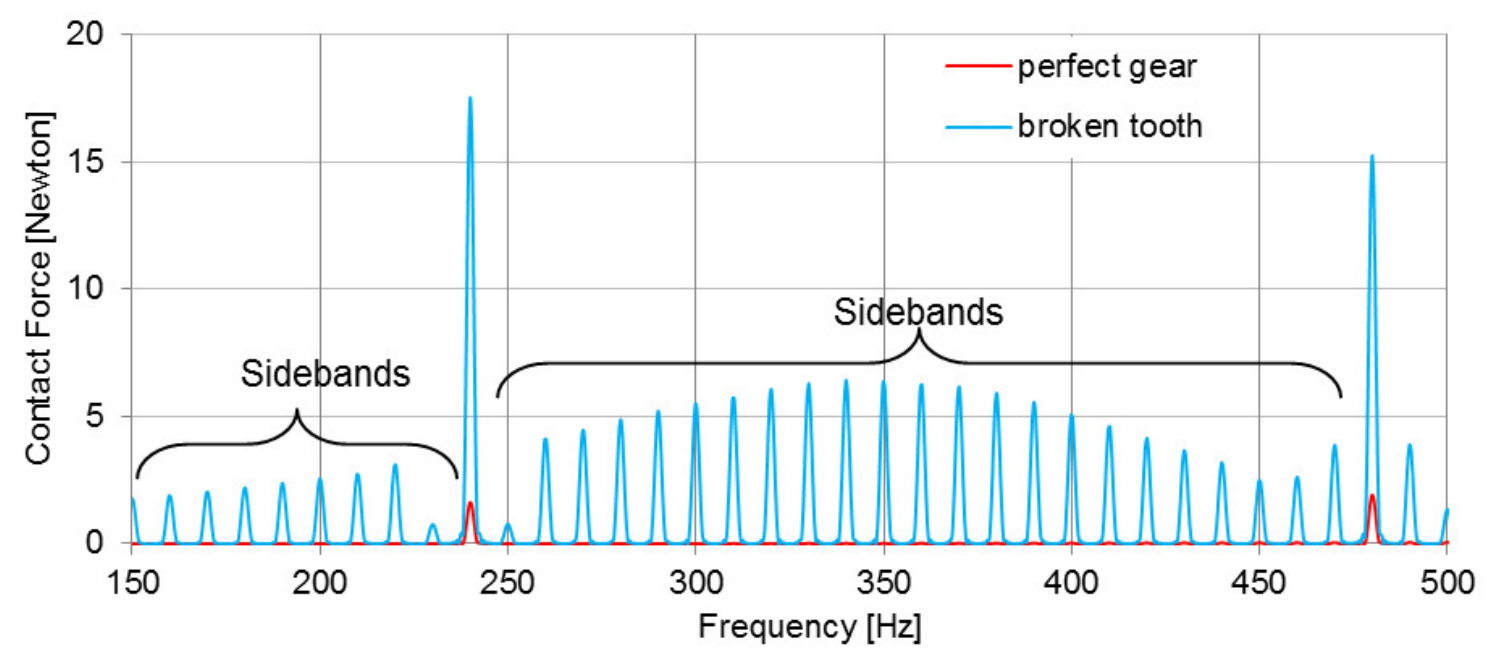

Figure 59. Frequency response plot of broken tooth

Gear Mesh Frequencies of $240 \mathrm{~Hz}$ is clearly evident. Sidebands around Gear Mesh Frequencies and their superharmonic are shown in Figure 59. The frequency response plot is quite similar to frequency response plots of Fracture on a single tooth. Sidebands next to the $1{ }^{*} \mathrm{GMF}$ have smaller magnitude compared to others and show up at $10 \mathrm{~Hz}$ which correlates with the shaft speed of PinionS1224. Magnitudes of $1^{*} \mathrm{GMF}$ and $2^{*} \mathrm{GMF}$ are clearly higher than the perfect gear. 


\section{Experimental results}

This chapter uses a gearbox to verify the rigid-elastic model and identify possible gear failure mechanisms. Methods used to monitor a gear system are vibrating and acoustic monitoring techniques. Both methods use a power spectrum, derived with a fast Fourier transformation (FFT), to interpret the health of gear systems.

Monitoring gear failure is difficult because the considered Gearbox Dynamic Simulator (GDS) has many Gear Mesh Frequencies (GMF) and bearing frequencies. Random noise reflected from housing complicates acoustic identification of gear frequencies and gear failure.

After identifying bearing and gear frequencies the Gearbox Dynamic Simulator (GDS) is introduced with all its features. Vibration and Acoustic Setup is introduced with their settings and sensor positions. A data acquisition system is used to analyze experimental acoustic and vibrating results. A gear failure is used to simulate and identify a gear failure mechanism. These results are compared with numerical solution derived with the rigid-elastic model in Adams ${ }^{\circledR}$. All parts of this chapter are shown below:

- Gearbox Dynamic Simulator (GDS)

- Analytical calculation of frequencies

- Experimental Setup

- Data Acquisition of physical experimental results 


\subsection{Gearbox Dynamic Simulator (GDS)}

For experimental examination, a "Gearbox Dynamics Simulator (GDS)", manufactured from Spectra Quest, is used. It has three parallel shafts with a motor and a braking system. The whole system consists of motor, motor control interface, speed sensor, gearbox, and brake system, shown in Figure 60 and described below.

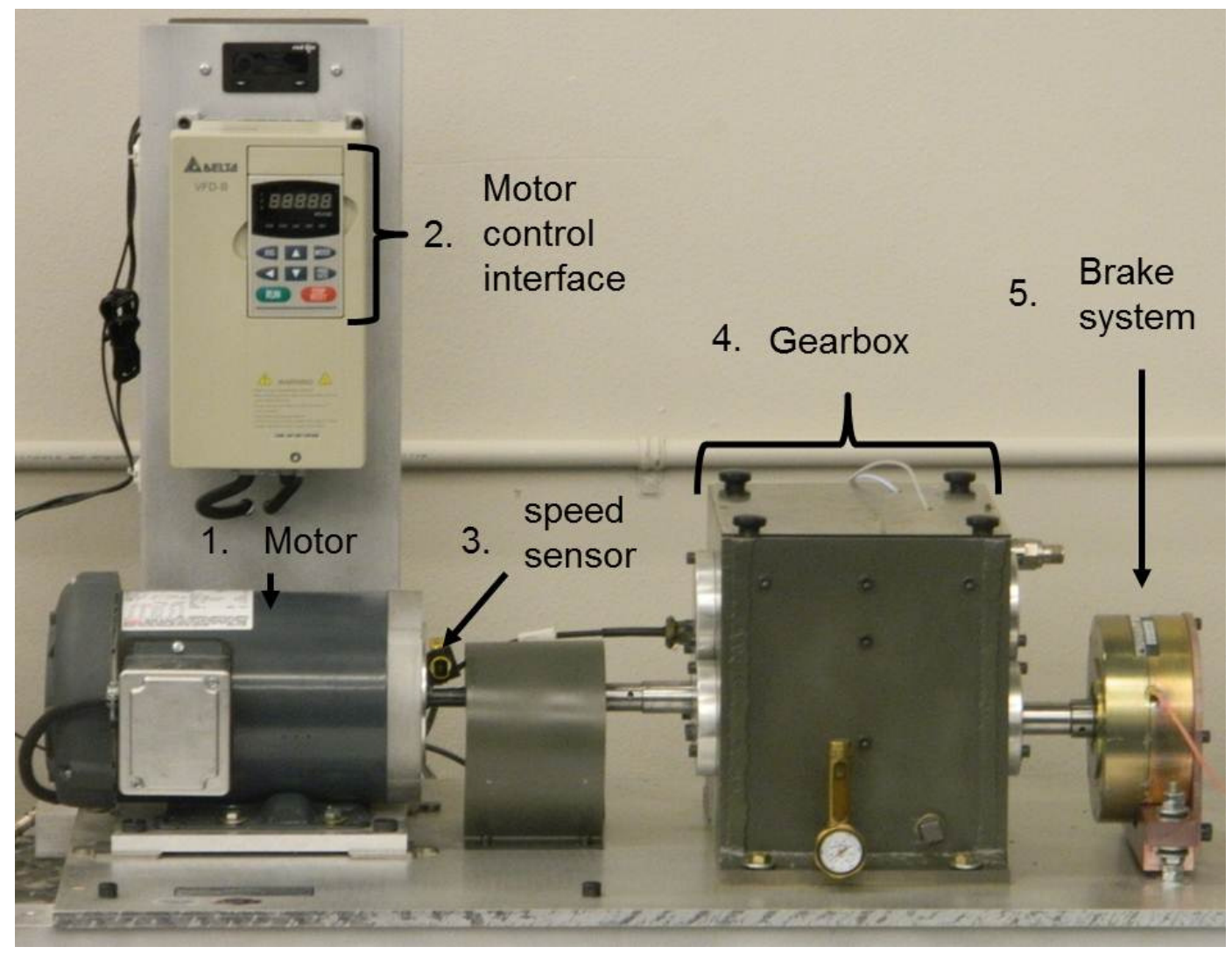

Figure 60. Gearbox Dynamic Simulator: Setup

\section{Motor: Marathon Electric (EVC 56T34F5306J P):}

This is a 3 horsepower, 2-pole, and 3-phase motor. The speed range is between 0 and $3,600 \mathrm{rpm}$. This motor is fixed on a plate for gearbox alignment. To compensate other alignment errors a clutch connects the output shaft of the motor with the input shaft of the gearbox. 


\section{Motor control interface: Delta Electronics Inc}

A user can control the speed of the motor. Changes are possible even during operation. The control system is designed to control a 3-phase motor.

\section{Speed sensor: Banner engineering Corp.}

A non-polarized retro-reflective sensor is used to indicate the shaft speed. This sensor sends a constant light and measure the time frame between light impulses it receives. To reflect light, a reflective tape sticks on the motors shaft so that the sensor gets a light impulse each revolution.

\section{Gearbox Dynamic Simulator(GDS)}

The selected gearbox is manufactured by Spectra Quest and it is called the Gearbox Dynamics Simulator (GDS). It is built and assembled with high tolerances so that no undesired vibration affects the measurements. Three parallel shafts with a two stage spur gear system are used to measure experimental results and to study performance. Gears can be easily exchanged to study all kinds of gear failure. The gearbox is filled with SAE 80W-90 lubricant.

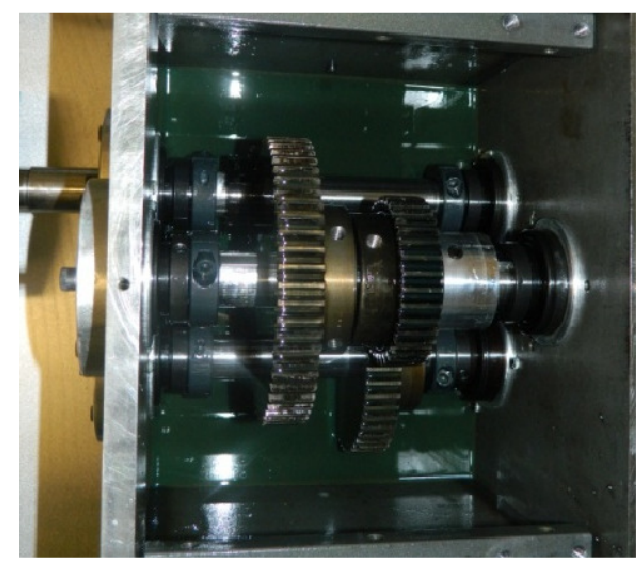

Figure 61. Two stage spur gears system on three parallel shafts 


\section{Brake system: magnetic particle BRAKE B220-24-14 SERIAL \# 07-60}

A brake system from PLACID INDUSTRIES, INC provides torque on the output shaft of the gearbox to force greater vibration amplitude. Numerical simulation tools, like Adams $\AA^{\circledR}$, apply also torque at the output shaft. Therefore, torque is important to compare results between experimental and numerical data in Adams $\AA$. The amount of torque can vary with the amount of current of the brake system. Torque can be determined with the performance characteristics, shown in Figure 62:

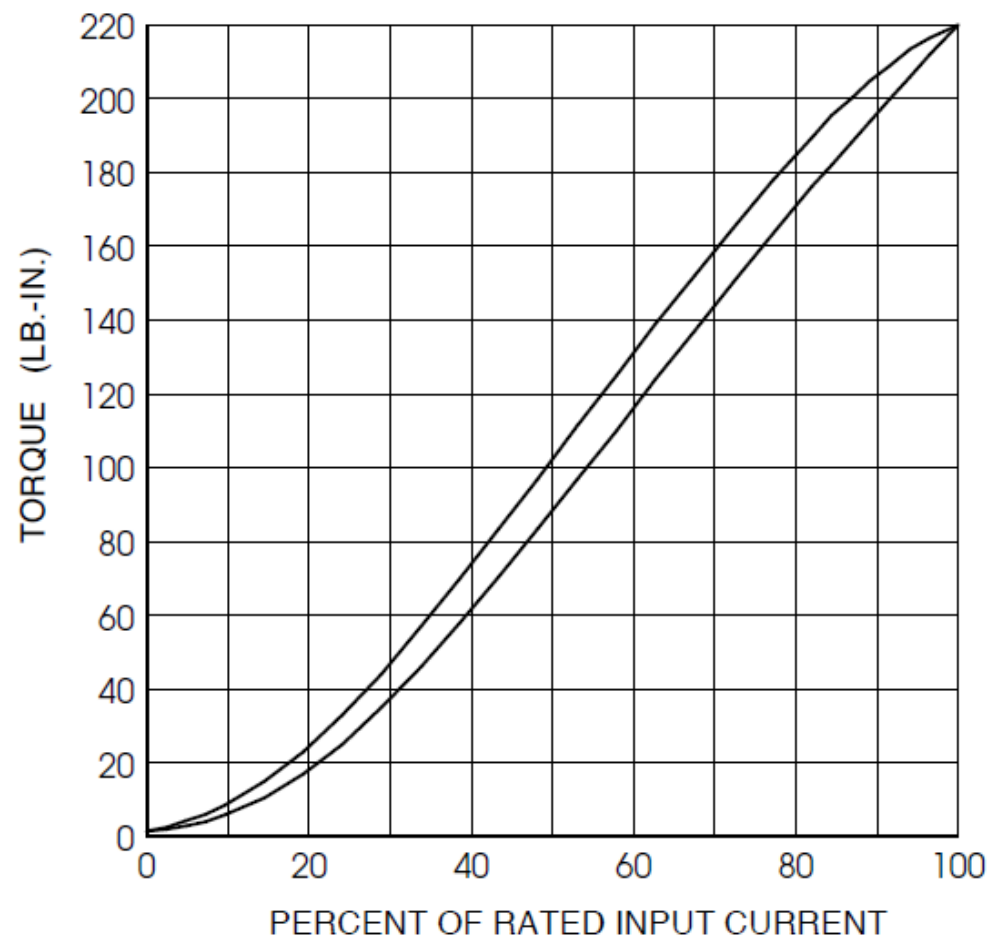

Figure 62. Magnetic particle BRAKE B220: brake performance characteristics

Table 12. Current range for different voltages

\begin{tabular}{|l|l|l|l|}
\hline & $12 \mathrm{~V}$ & $24 \mathrm{~V}$ & $90 \mathrm{~V}$ \\
\hline Coil resistance (ohms) & 7.9 & 31 & 375 \\
\hline $100 \%$ input current & 1.45 & 0.72 & 0.2 \\
\hline
\end{tabular}




\subsection{Analytical calculation of frequencies}

To validate experimental results, analytical calculations of gears and bearings are necessary. Analytical calculations of frequencies consider all frequencies which might appear according to gears and bearings geometry and don't consider natural frequencies of the gearbox, shaft, bearings, and gears. Furthermore, the equation of motion is introduced to determine influencing parameters during gear dynamics.

\subsubsection{Equation of motion}

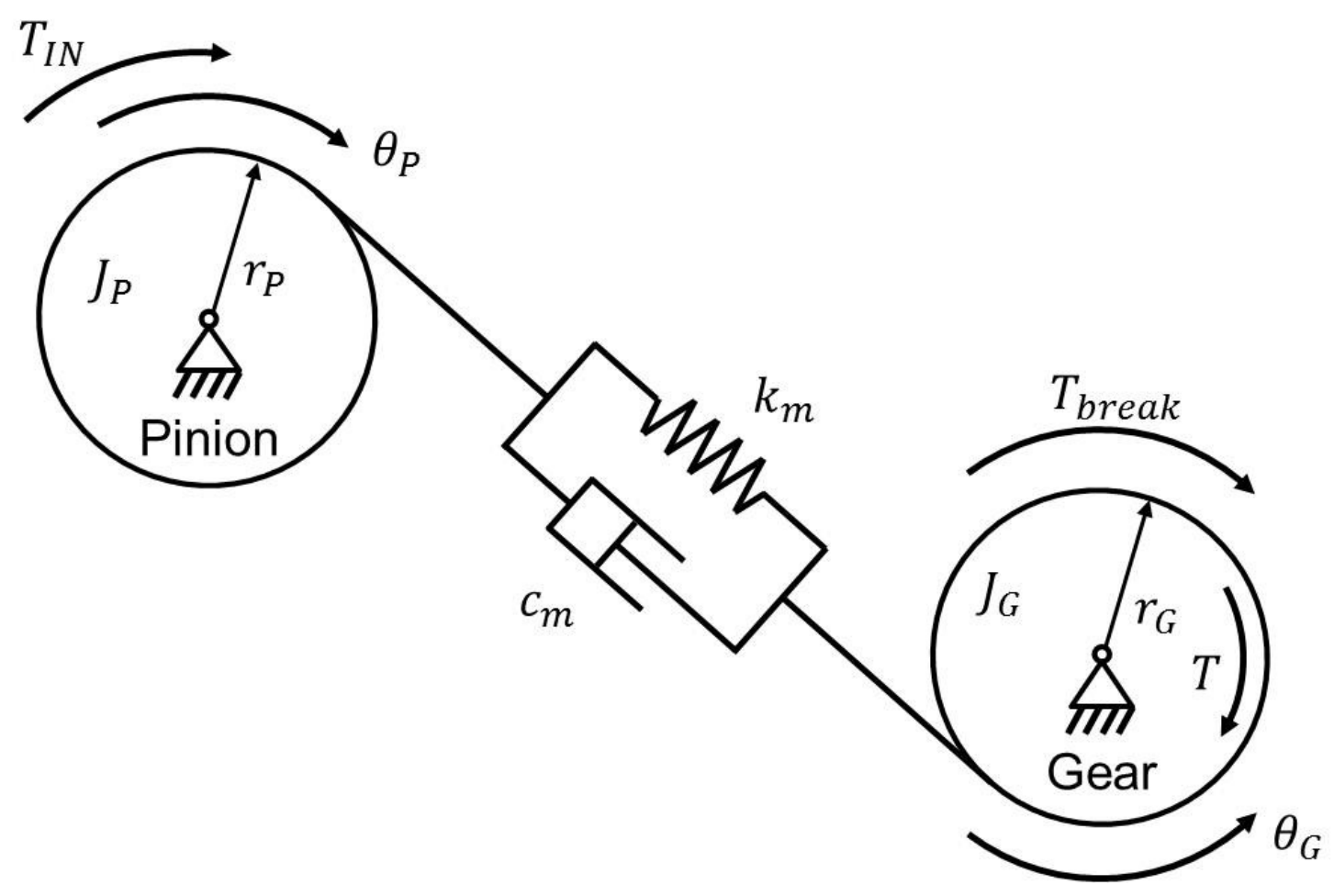

Figure 63. Free body diagram of an acting gear pair 
where,

$T_{\text {break }}=$ Break torque

$T_{I N}=$ Input torque,

$r_{P}, r_{G}=$ Pinion and Gear Radius: with respect to the point of action,

$J_{P}, J_{G}=$ Moment of inertia: Pinion and Gear,

$c_{m}=$ Linear tooth mesh damping,

$k_{m}=$ Linear tooth mesh stiffness,

$\theta_{G}, \dot{\theta}_{G}, \ddot{\theta}_{G}=$ Angular displacement / velocity / acceleration of Gear,

$\theta_{P}, \dot{\theta}_{P}, \ddot{\theta}_{P}=$ Angular displacement / velocity / acceleration of Pinion.

\section{Equation of motion:}

Moment forces of Pinion: $\quad J_{P} \ddot{\theta}_{P}+c_{m} r_{P}\left(r_{P} \dot{\theta}_{P}-r_{G} \dot{\theta}_{G}\right)+k_{m} r_{P}\left(r_{P} \theta_{P}-r_{G} \theta_{G}\right)=T_{I N}$

Moment forces of Gear: $\quad J_{G} \ddot{\theta}_{G}+c_{m} r_{P}\left(r_{P} \dot{\theta}_{P}-r_{G} \dot{\theta}_{G}\right)+k_{m} r_{P}\left(r_{P} \theta_{P}-r_{G} \theta_{G}\right)=-T_{\text {break }}$

The differential equation of motion in matrix form:

$$
\left[\begin{array}{cc}
J_{P} & 0 \\
0 & J_{G}
\end{array}\right]\left(\begin{array}{c}
\ddot{\theta}_{P} \\
\ddot{\theta}_{G}
\end{array}\right)+c_{m}\left[\begin{array}{cc}
r_{P}{ }^{2} & r_{P} r_{G} \\
r_{P} r_{G} & r_{G}{ }^{2}
\end{array}\right]\left(\begin{array}{c}
\dot{\theta}_{P} \\
\dot{\theta}_{G}
\end{array}\right)+k_{m}\left[\begin{array}{cc}
r_{P}{ }^{2} & r_{P} r_{G} \\
r_{P} r_{2} & r_{G}{ }^{2}
\end{array}\right]\left(\begin{array}{c}
\theta_{P} \\
\theta_{G}
\end{array}\right)=\left[\begin{array}{c}
T_{I N} \\
T_{\text {break }}
\end{array}\right]
$$


The equation of motion has all variables influencing the dynamics of a gear system. It is important to know what influences vibration and acoustics results. Changing one of these variables has influence in gears dynamic and the whole gear action changes. The most significant variables with their influences are listed below in Table 13 .

Table 13. Analytical Model Parameters

\begin{tabular}{|l|l|}
\hline Parameter & Their influence \\
\hline$r_{P}, r_{G}$ & $\begin{array}{l}\text { Radius changes along line of contact. Depending on where load } \\
\text { is transmitted the deflection changes in a nonlinear way. }\end{array}$ \\
\hline$k_{m}, c_{m}$ & $\begin{array}{l}\text { According to the gear geometry and the radius of contact, the } \\
\text { deflection versus load changes. Therefore the stiffness and } \\
\text { damping ratio coefficient is nonlinear and difficult to determine. }\end{array}$ \\
\hline$J_{P}, J_{G}$ & Moment of inertia doesn't change during motion. \\
\hline
\end{tabular}




\subsubsection{Gear Frequency Identification}

Gear ratio:

Where, $N_{p}$ and $N_{g}$ are teeth of pinion and gear

$$
g_{n}=\frac{N_{p}}{N_{g}}
$$

Gear Mesh Frequency:

$$
G M F=N_{p} * \Omega_{p}=N_{g} * \Omega_{g}
$$

Where, $\Omega_{p}$ and $\Omega_{g}$ are the rotational speeds

Fractional Gear Mesh Frequency:

$$
F G M F=\frac{n}{C F} * G M F
$$

Where $n=1,2 \ldots$ and $C F=$ common factor

Hunting Tooth Frequency:

Where, $U F_{p}$ and $U F_{g}$ are the uncommon factors

$$
H T F=\frac{\Omega_{g}}{U F_{p}}=\frac{\Omega_{p}}{U F_{g}}
$$

Common factor (CF):

$$
\begin{array}{ll}
\text { Gear (S1260): } & N_{\mathrm{S} 1260}=60=1 * 2 * 2 * 3 * 5=12 * 5 \\
\text { Pinion (S1224): } & N_{\mathrm{S} 1224}=24=1 * 2 * 2 * 2 * 3=12 * 2 \\
\text { Pinion (S1236): } & N_{\mathrm{S} 1236}=36=1 * 2 * 2 * 3 * 3=12 * 3 \\
\text { Gear (S1248): } & N_{\mathrm{S} 1248}=48=1 * 2 * 2 * 2 * 2 * 3=12 * 4
\end{array}
$$

Both gear sets have a common factor (CF) of 12 , which identifies the number of teeth from one bad tooth to the other bad tooth. The uncommon factor identifies the number of bad teeth on each gear. It also identifies the amount of revolutions of the other gear, before the same teeth are in mesh again 


\subsubsection{Bearing Frequency Identification}

Number of rollers: $N_{d}=16$

Pitch diameter: $\quad P_{d}=1.5237$ inch

Ball diameter: $\quad B_{d}=0.225 \mathrm{inch}$

Contact angle: $\quad \varnothing=10^{\circ}$

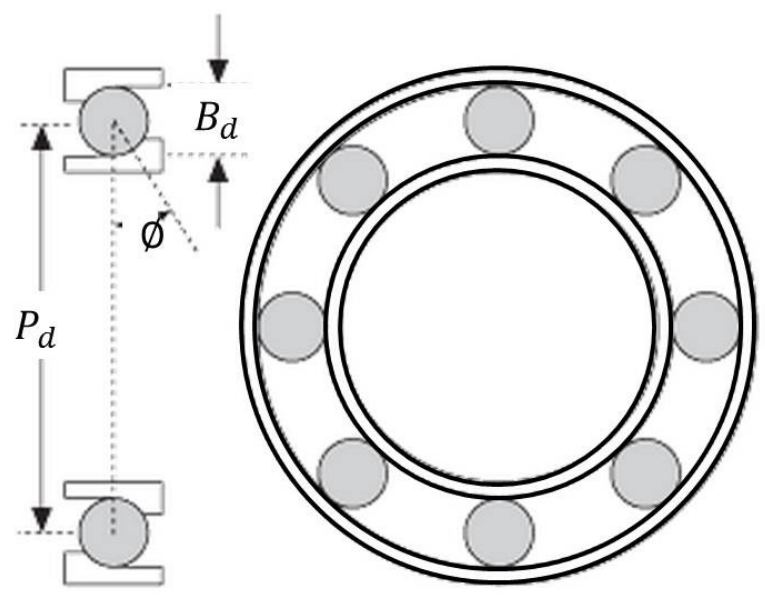

Figure 64. Rolling element of a bearing

Fundamental Train Frequency:

$F T F=S *\left(\frac{1}{2}\right) *\left[1-\frac{B_{d} * \cos (\varnothing)}{P_{d}}\right]$

Ball Pass Frequency Outer race:

$B P F O=S *\left(\frac{N_{d}}{2}\right) *\left[1-\frac{B_{d} * \cos (\varnothing)}{P_{d}}\right]$

Ball Pass Frequency Inner race:

$B P F I=S *\left(\frac{N_{d}}{2}\right) *\left[1+\frac{B_{d} * \cos (\varnothing)}{P_{d}}\right]$

Ball Spin Frequency:

$B S F=S *\left(\frac{P_{d}}{2 * B_{d}}\right) *\left[1-\left(\frac{B_{d} * \cos (\varnothing)}{P_{d}}\right)^{2}\right]$

where, $\mathrm{S}=$ shaft speed 


\subsection{Experimental Setup}

The right setup is important to get reproducible and correct results. The microphone is placed above the gear box. The position of the microphone is $0.1 \mathrm{~m}$ above the cover of the gear system. The golden rule is to get as close to the source as possible without getting unwanted effects like distortion. Better gear acoustics can be measured by putting the microphone inside of the gear box. The whole setup of acoustic measurement with the position of the microphone is shown in Figure 65.

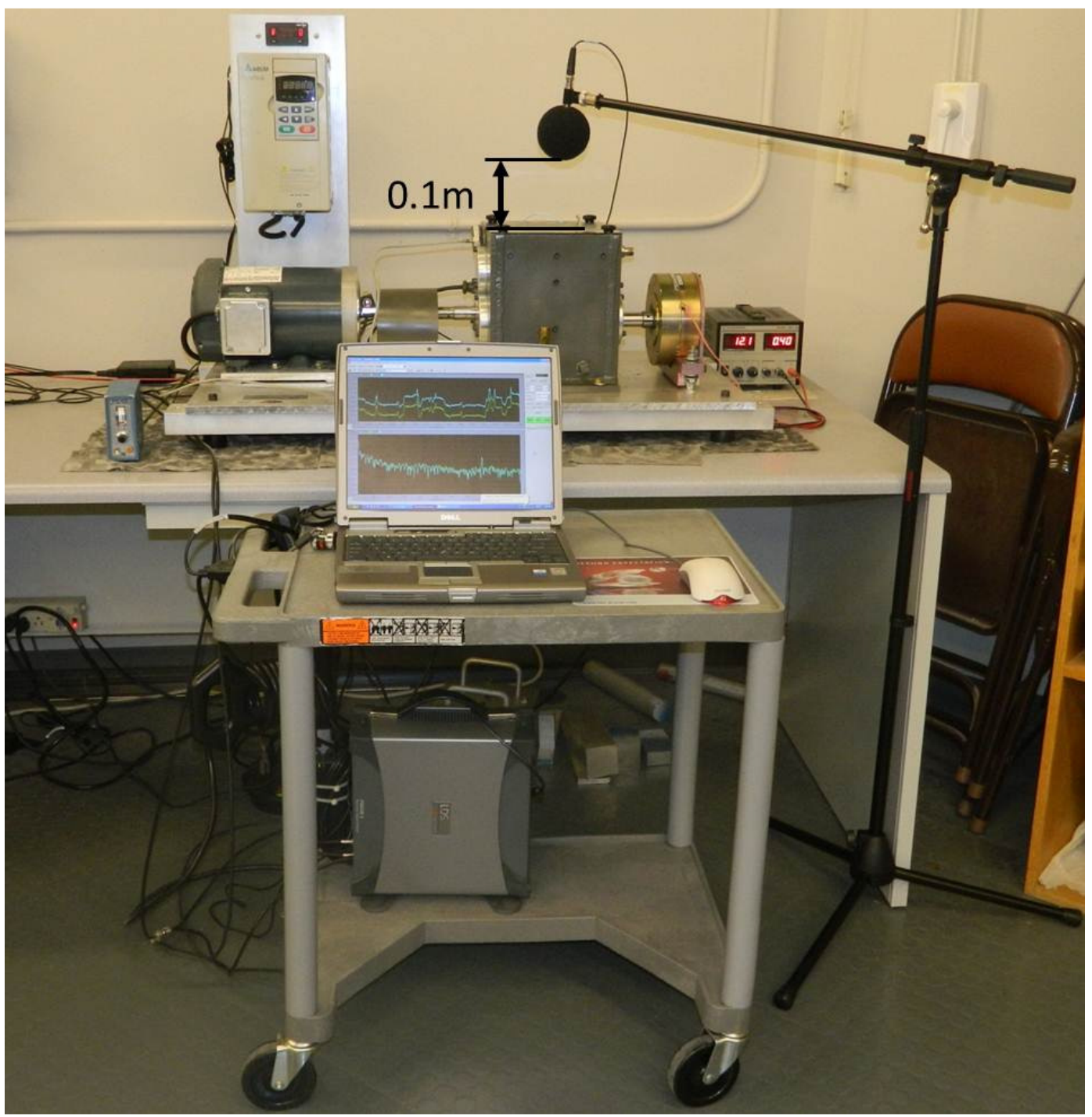

Figure 65. Set up of gear system with acoustic and vibration measurenment devices 


\subsubsection{Vibration measurement setup}

Data acquisition to measure gear vibration has several stages, shown in Figure 66.

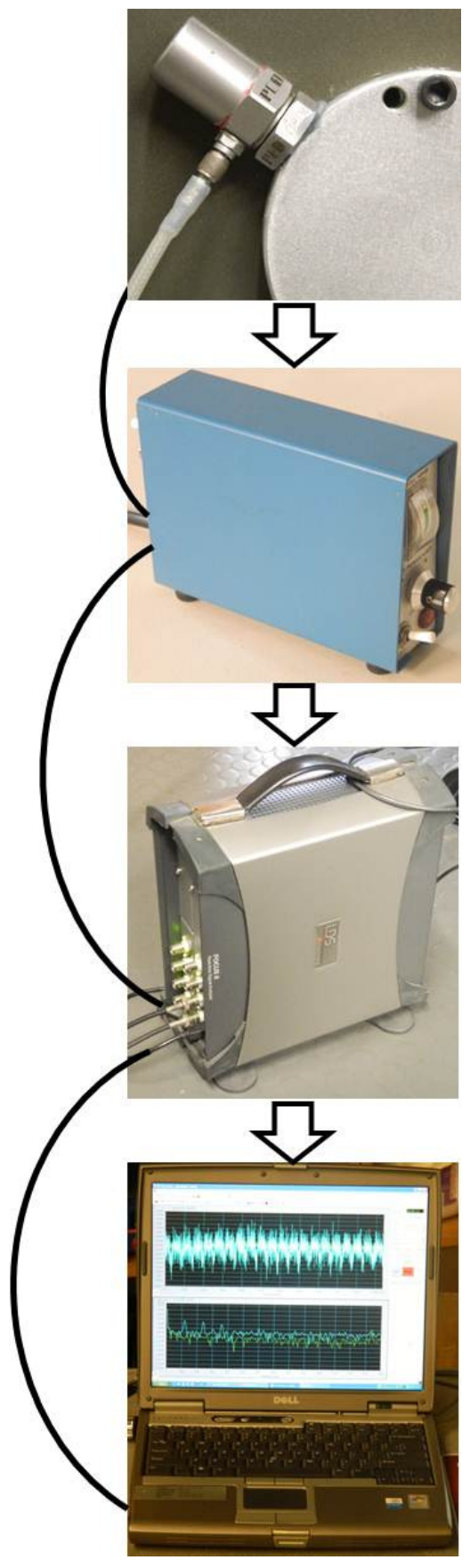

\section{Accelerometer:}

- $\quad$ PCB U3083 S/N 25066

- Const: $100.5 \mathrm{mV} / \mathrm{g}$

- Mass: $76.2 \mathrm{~g}$

- Resonance frequency: $29 \mathrm{kHz}$

Signal conditioner:

Provides specific voltage output.

\section{ME'scopeVES interface box:}

Spectrum analyzer is used to collect and analyze vibration signals from a system. It is flexible and can handle a broad range of data acquisition tasks.

\section{ADRE Sxp software}

Data acquisition equipment from Bently Nevada is used to measure and analyze vibration. ME'ScopeVES is a program which allows analyzing and collecting vibration signals.

Figure 66. Vibration measurement system 


\subsubsection{Placement of accelerometer}

James I. Taylor stated some helpful rules in "the Gear Analysis Handbook" [10] in order to measure accurate gear vibration. If the placement of the accelerometer is incorrect, useful data might be lost. Therefore, the correctly placing the accelerometer is important. According to James I. Taylor, the best signals are obtained by placing the accelerometer close to the bearings. More hints are listed below:

- The most accurate signal is obtained from a radial position.

- The closer the accelerometer is placed to vibrating gears, the better are results.

- The type of observed gear failure affects the accelerometer's location. Most gear failure in terms of spur gear has strong signals in radial direction.

- Thin plates are disadvantageous because they contain natural frequencies.

- Bolt heads yields the best results, because the threads on bolts don't attenuate the transmissibility of frequency.

- In order to get consistent results, data must be taken from the same location.

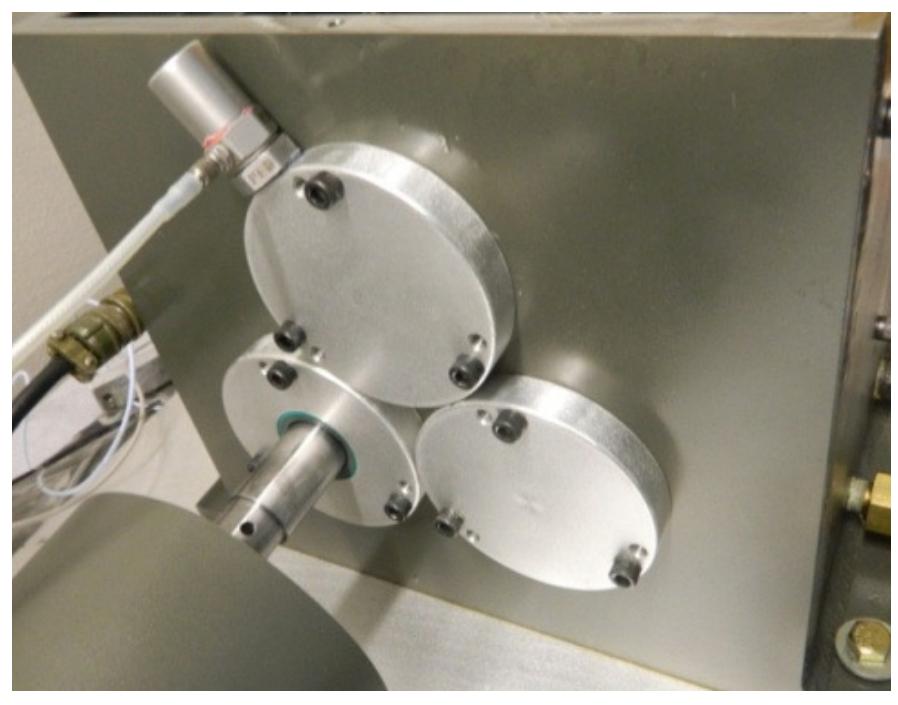

Figure 67. Sensor position on the GDS 


\subsubsection{Acoustic measurement setup}

Data acquisition to measure gear acoustics has several stages, shown in Figure 68.

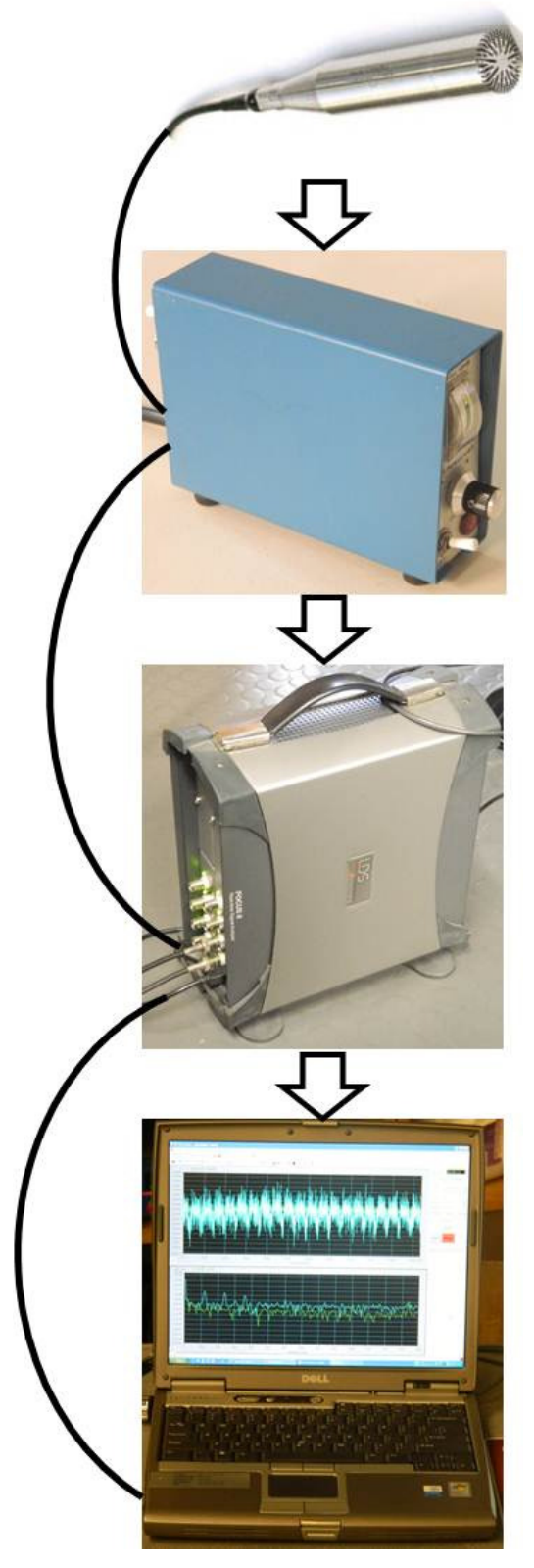

Figure 68. Acoustic measurement system

\section{Microphone:}

$1 / 2 "$ prepolarized random-incidence, condenser microphone $50 \mathrm{mV} / \mathrm{Pa}( \pm 1.5 \mathrm{~dB}), 3.15 \mathrm{~Hz}-12.5$ $\mathrm{kHz}( \pm 2 \mathrm{~dB})$ with $1 / 2$ " ICP preamplifier (426E01) and TEDS.

\section{Signal conditioner:}

Provides specific voltage output.

\section{ME'scopeVES interface box:}

Spectrum analyzer is used to collect and analyze vibration signals from a system. It is flexible and can handle a broad range of data acquisition tasks.

\section{ADRE Sxp software:}

Data acquisition equipment from Bently Nevada is used to measure and analyze vibration. ME'ScopeVES is a program which allows analyzing and collecting vibration signals. 


\subsubsection{Different types of microphones}

The type of microphones depends on the measured type of sound pressure and noise levels. A microphone is adjusted to each sound field and influences their design. Three different kinds of sound fields are distinguished: free field, pressure field, and random incidence, shown below. [28]

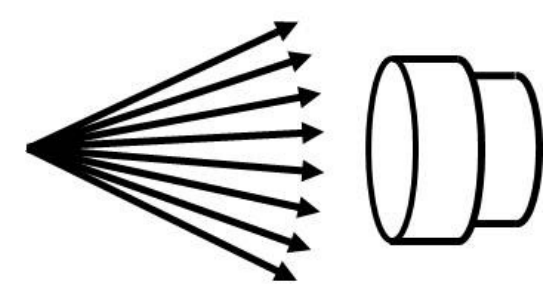

Figure 69. Free field

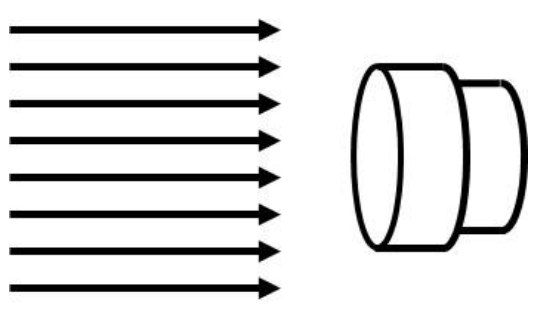

Figure 70. Pressure field

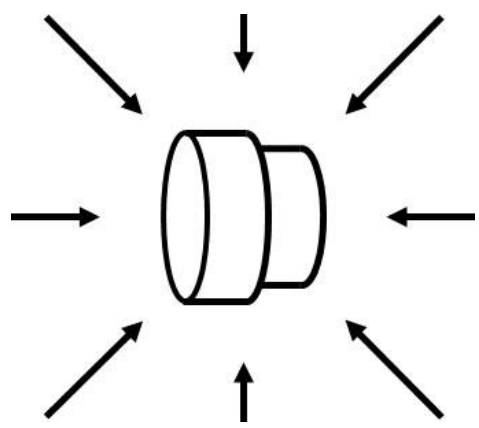

Figure 71. Random incidence noise
Free field measurement picks up sound pressure from a single source. It is designed to compensate its own disturbance.

Examples: free field with no reflective surfaces, like anechoic chamber or outdoor measurement.

Pressure field has the same magnitude and phase at any position in the sound field. Its presence affects the measurement in the field.

Examples: pressure exerted on walls, airplane wings, and general structures.

Random incidence noise arrives equally from all directions. Microphone compensates its own presence and disturbance.

Examples: closed system with reflective walls like cabins, casings, and reverberation room. 
Since the Gearbox Dynamic Simulator has several sources which creates a diffuse field inside the gearbox, a random incidence noise microphone is used to examine the acoustic of the gear system. Table 14 shows important performance, environmental and physical properties of the Condenser Microphone (model 378B20).

Table 14. Precision condenser Microphone (model 378B20) [28]

\section{Performance}

Nominal Microphone Diameter

$1 / 2 "$

Frequency response characteristic

Random incidence

Open Circuit Sensitivity (at $250 \mathrm{~Hz}$ )

$50 \mathrm{mV} / \mathrm{Pa}$

Frequency Range $( \pm 1 \mathrm{~dB})$

5 to $6300 \mathrm{~Hz}$

Frequency Range $( \pm 2 \mathrm{~dB})$

3.15 to $12.500 \mathrm{~Hz}$

Lower Limiting Frequency $(-3 \mathrm{~dB})$

1 to $2.4 \mathrm{~Hz}$

Resonant Frequency $\left(90^{\circ}\right.$ Phase Shift)

$12 \mathrm{kHz}$

Environmental

Temperature Range(Operating)

-40 to $+248{ }^{\circ} \mathrm{F}$

Temperature Coefficient of Sensitivity

$0.005 \mathrm{~dB} /{ }^{\circ} \mathrm{F}$

Static Pressure Coefficient (at $250 \mathrm{~Hz}$ )

$-0.01 \mathrm{~dB} / \mathrm{kPa}$

Influence of Humidity (0 to $100 \%$, non-condensing)

$<0.1 \mathrm{~dB}$

Physical

Housing Material

Nickel Alloy

Venting

Rear

Size (Diameter $x$ Height)(with grid)

0.52 in $\times 0.64$ in 


\subsection{Data Acquisition of physical experimental results}

In order to get reproducible results, the setup doesn't change for all measurements taken. Simultaneous record of acoustic and vibrating data acquisition ensures a comparison of both results. ADRE Sxp has the following setup for the Fast Fourier Analyzer: Lines $=25600$, Points $=65536, \operatorname{Span}=12800$, and Time $=30.5 \mu \mathrm{s}$. These values are chosen in order to get a high frequency resolution of $0.5 \mathrm{~Hz}$. Span and Lines are defined as:

$$
\Delta f=\frac{\text { Span }}{\text { Lines }}=\frac{12800}{25600}=0.5 \mathrm{~Hz}
$$

Another important value is the recorded time. In order to get reproducible results it is important to measure signals over a longer time. A signal length of 2 seconds turned out to be reproducible in magnitude and frequencies and is defined as:

$$
\Delta t=\text { points } * \text { time }=65536 * 30.5 \mu \mathrm{s}=2 \mathrm{sec}
$$

The torque of the brake system is important to compare results with Adams $\AA$. The highest current of the brake system is 0.4 ampere with a potential of 12 volts. According to Figure 62 and Table 12 torque can be determined with:

$$
75 \mathrm{LB} .-I N=30 * \frac{N}{0.22481} * 25.4 \mathrm{~mm}=3390 \mathrm{Nmm}
$$

The following figures show acoustic and vibration results normalized to compare results with the rigid-elastic model in Adams ${ }^{\circledR}$. 


\subsubsection{Vibration Data Acquisition}

Vibration data are introduced and compared with a tooth breakage of PinionS1224 of the first gear pair, shown in Figure 72. The time domain of the gear set without gear damage is shown in Figure 73.

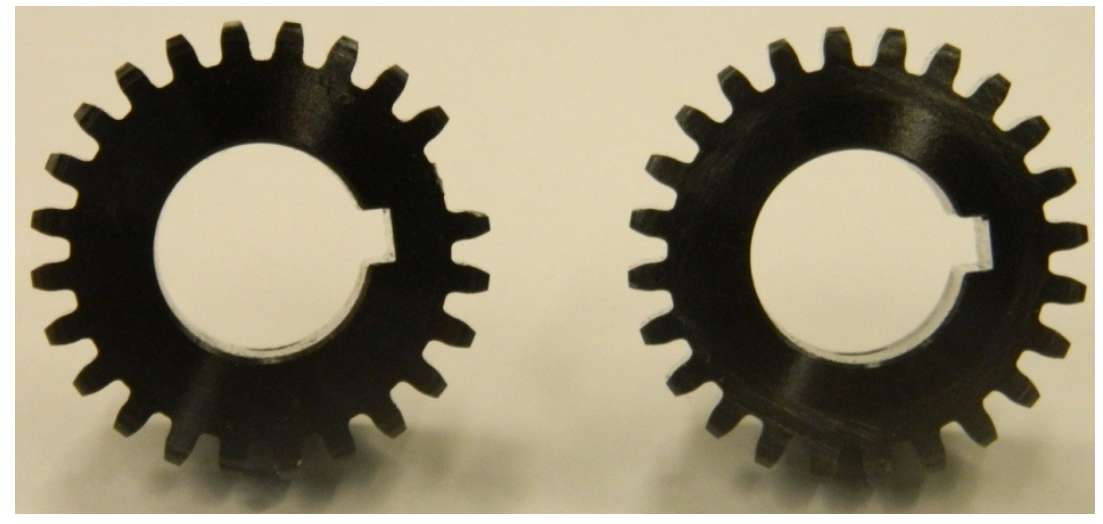

Figure 72. Tooth breakage of PinionS1224

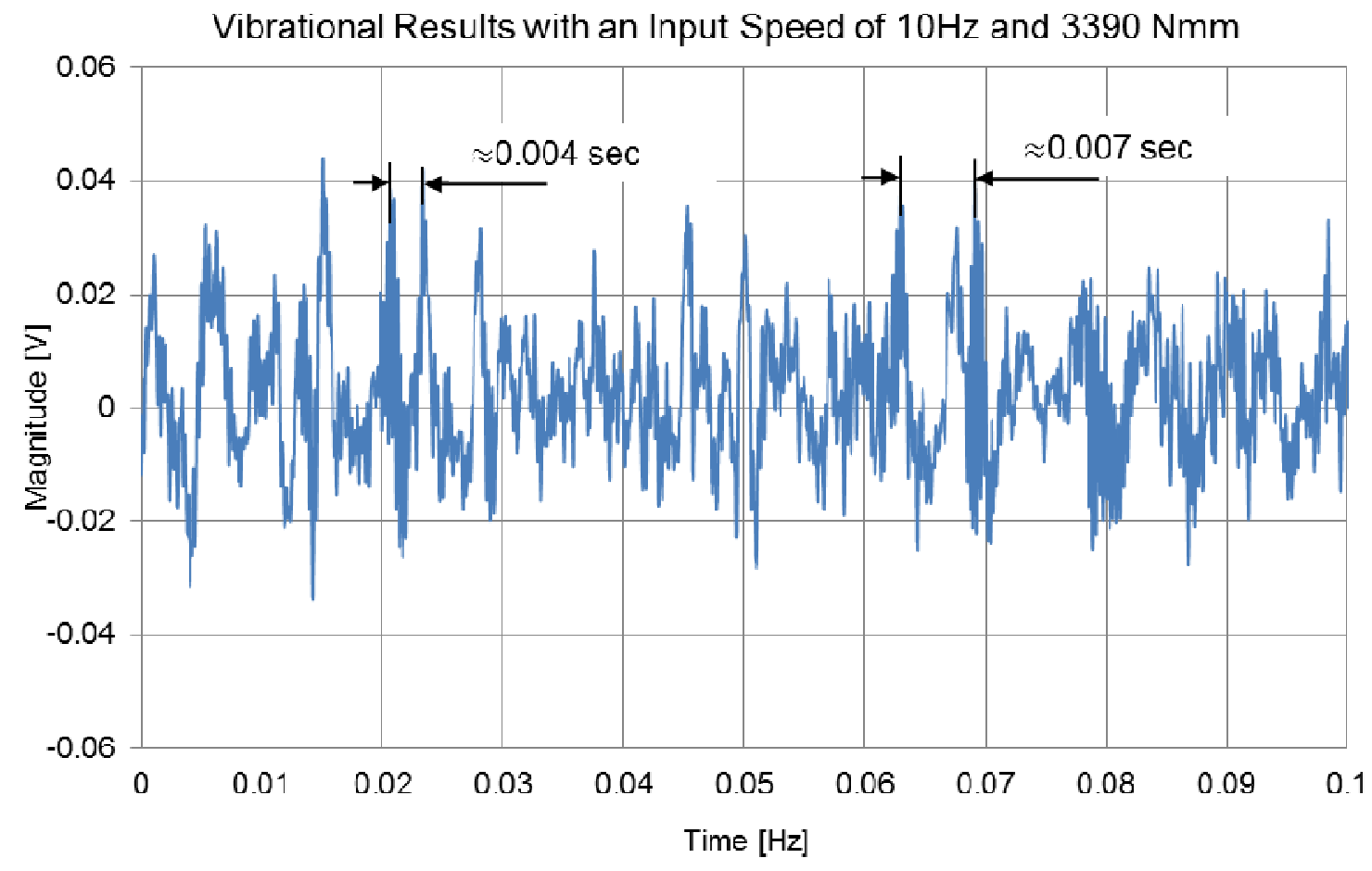

Figure 73. Time domain of GDS of accelerometer 
Harmonics show clearly the Gear Mesh Frequency of $240 \mathrm{~Hz}$ which correlates to 0.004 sec, and the seconds Gear Mesh Frequency of $144 \mathrm{~Hz}$ which correlates with 0.007 seconds. Higher frequencies are difficult to determine but shown in the frequency domain below in Figure 74.

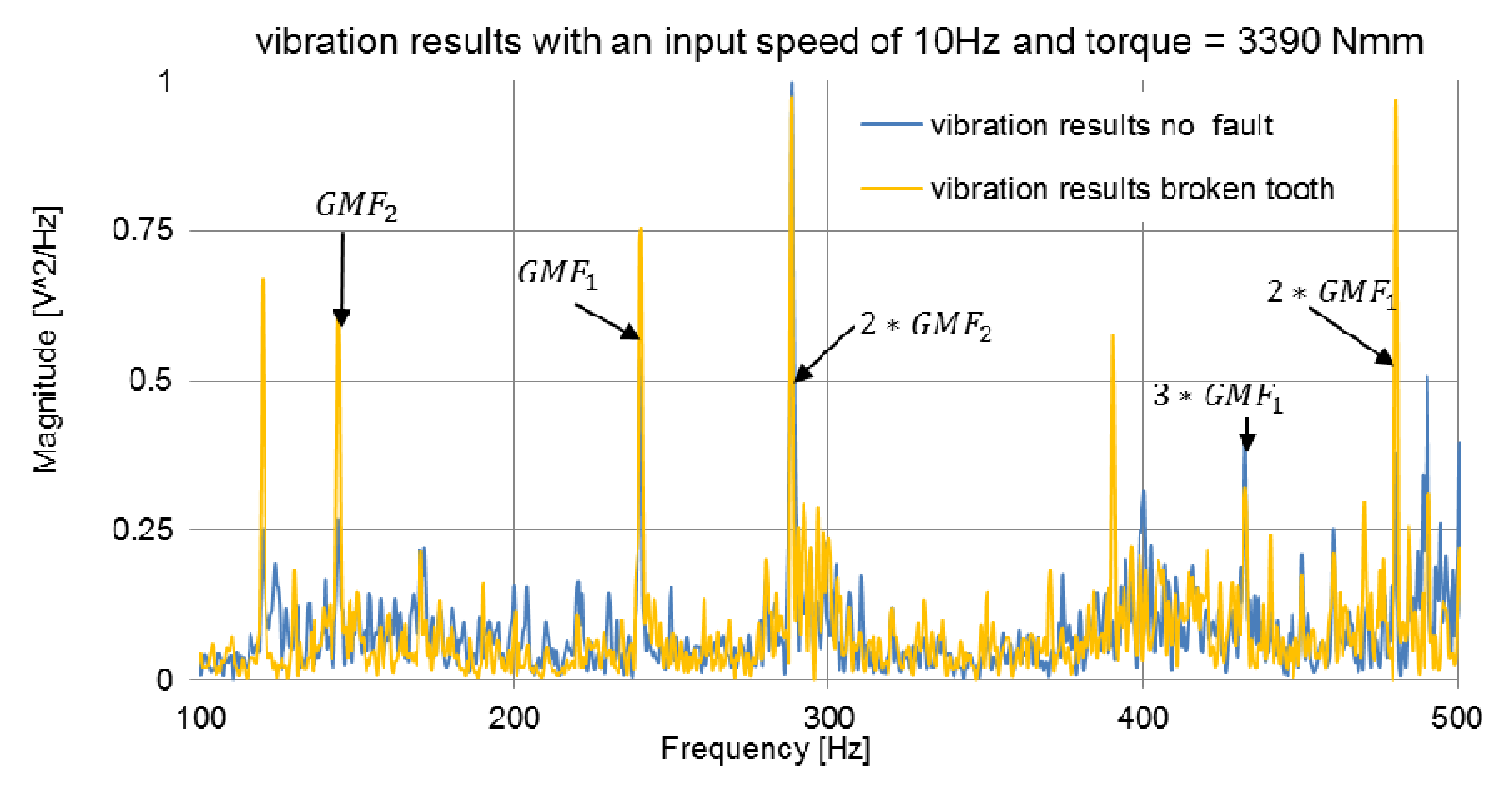

Figure 74. Frequency domain with Hanning Window of GDS with accelerometer

The Gear Mesh Frequencies match the calculated results clearly. Superhamonics are higher compared to the Gear Mesh Frequency.

Tooth breakage is implanted in the first gear pair. Magnitudes in the first Gear Mesh Frequency and the first superharmonic are clearly higher. Sidebands between Gear Mesh Frequencies are also slightly higher especially on the right side of the first superharmonic. Another typical characteristic of tooth breakage is the shaft speed of the broken tooth shown in Figure 75. 

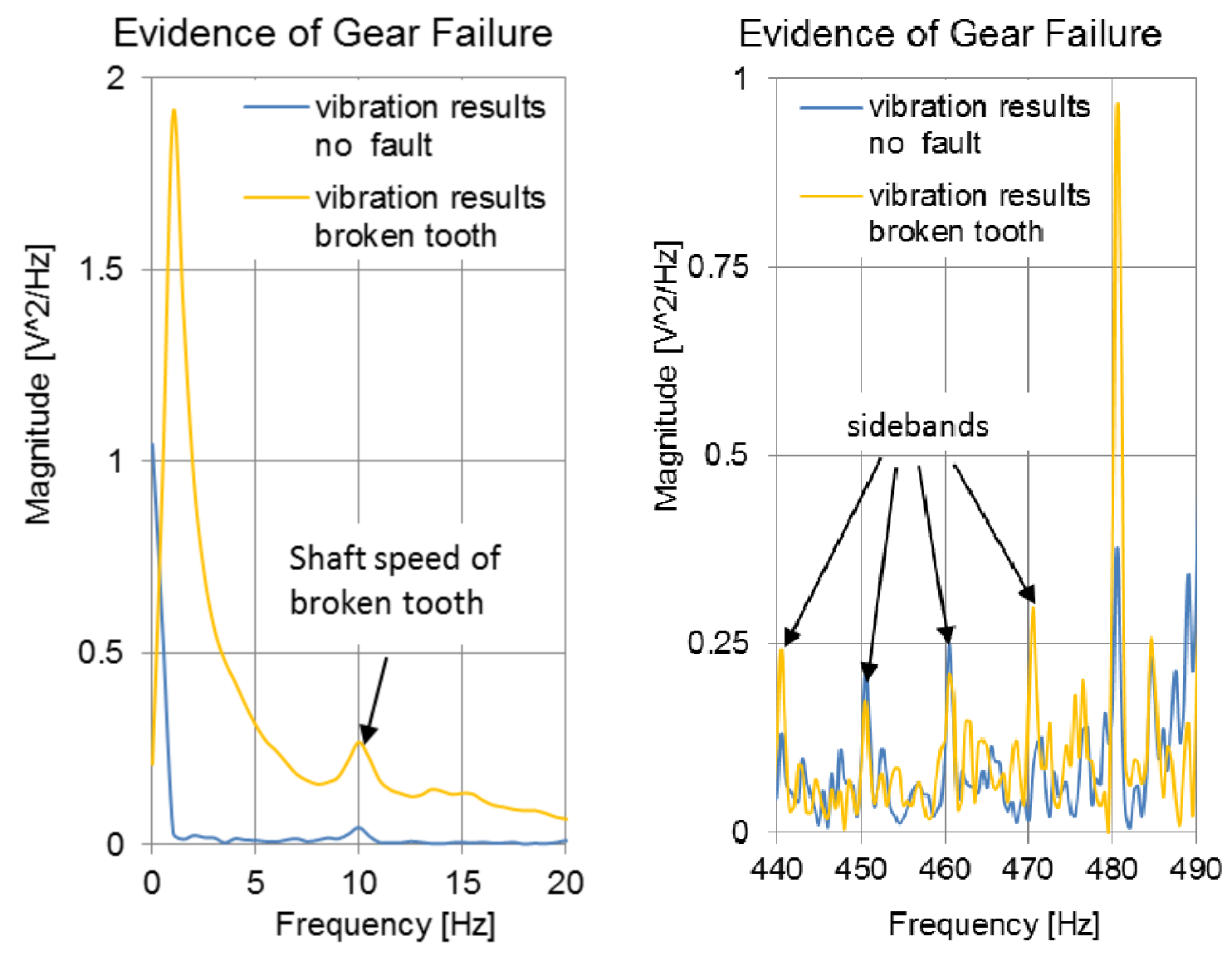

Figure 75. Evidence of tooth breakage

On the left hand side of Figure 75 the frequency of shaft speed is more than 5 times higher than the frequency of shaft speed. The lower the frequencies, the higher the magnitude of a tooth breakage.

On the right hand side of Figure 75 sidebands show up left to $2^{\star} \mathrm{GMF}$. This is also shonw in the rigid-elastic model of Figure 59. Therefore, the vibration experimental results match the predicted numerical results in Adams $®$. 


\subsubsection{Acoustic Data Acquisition}

Acoustic data is introduced and compared with the same tooth breakage as well. The time domain of the gear set without gear damage is shown in Figure 76.

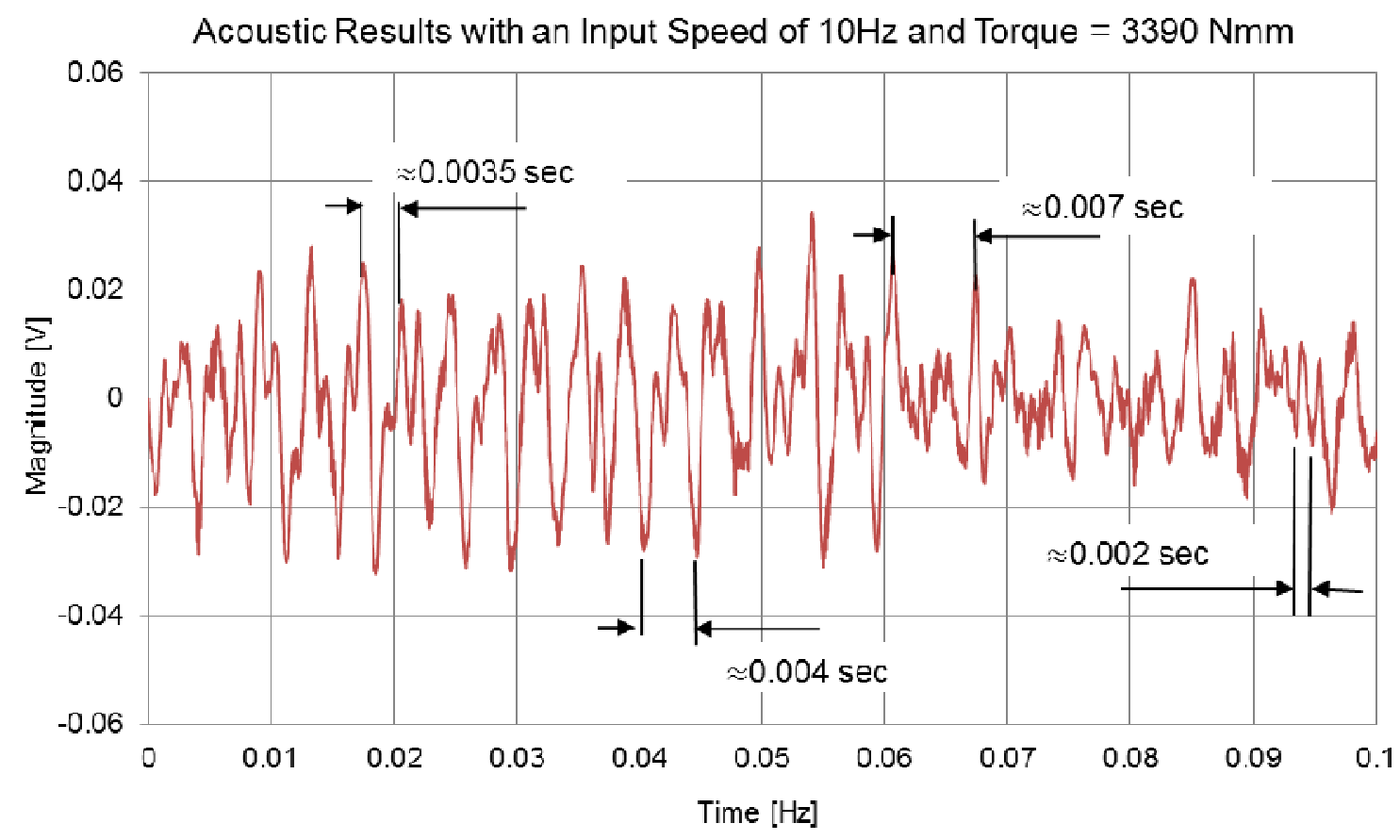

Figure 76. Time domain of GDS with microphone

Harmonics show clearly the Gear Mesh Frequency of $240 \mathrm{~Hz}$ which correlates to 0.004 sec, and the second Gear Mesh Frequency of $144 \mathrm{~Hz}$ which correlates with 0.007 sec. Even higher frequencies can also be detected, like the first superharmonic of the second gear pair with $288 \mathrm{~Hz}$ that correlates with 0.0035 seconds and the second superharmonic of the first gear pair with 480 Hertz that correlates with 0.002 seconds. These frequencies show up in the frequency domain shown below. 


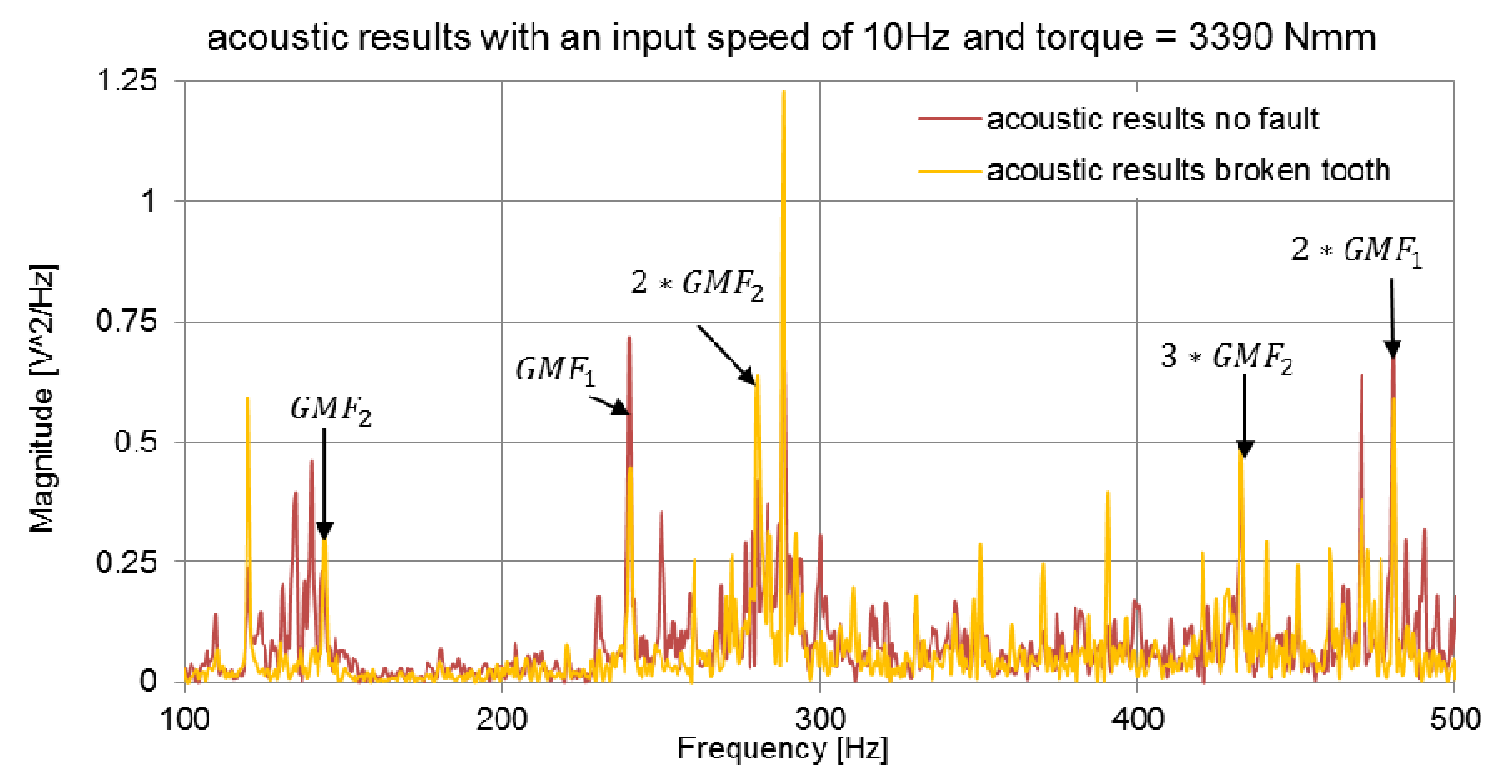

Figure 77. Frequency domain with Hanning Window of GDS with a microphone

Gear Mesh Frequencies and their superharmonics of first and second gear pair of time and frequency plot are clearly evident. Magnitudes of superharmonics are slightly higher than Gear Mesh Frequencies itself. Between Gear Mesh Frequencies a lot of frequencies show up and have to be identified with possible sub- or superharmonics of gear frequencies or bearing frequencies.

Compared to the frequency domain of the accelerometer in Figure 74, magnitudes of Gear Mesh Frequencies and their superharmonics are similar and show up in both frequency domain.

Gear breakage frequency magnitudes are lower compared to frequency magnitudes of gear with no fault. However, sidebands between first Gear Mesh Frequency and first superharmonic show up and are shown in Figure 78. 


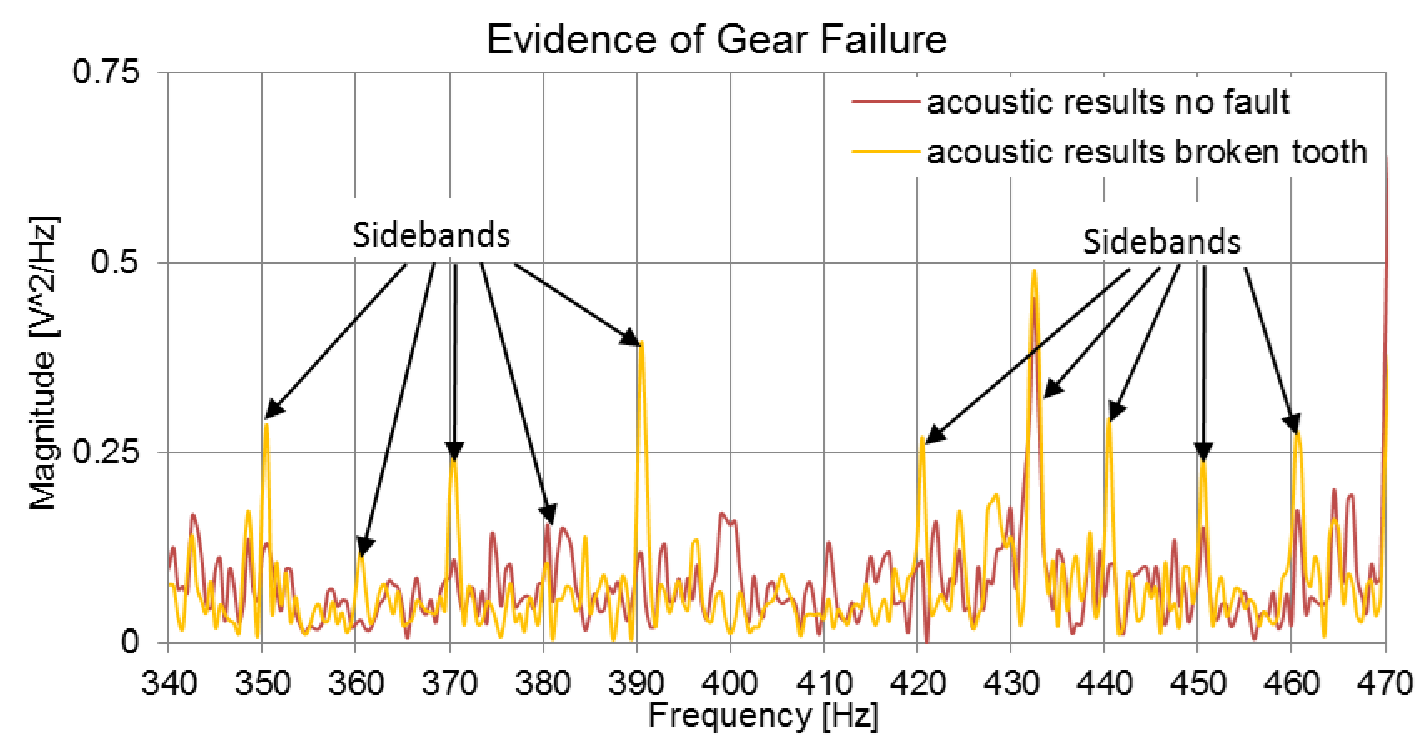

Figure 78. Sidebands between Gear Mesh Frequency and first superharmonic

In Figure 78, sidebands between the Gear Mesh Frequency and the first superharmonic are shown. All sidebands are clearly higher compared to the gear system with no fault. Fakher Chaari, Walid Baccar, Mohamed Slim Abbes, Mohamed Haddar observed "on a gearbox with a broken tooth the apparition of impulses on the time signals having the periodicity of the defected gear rotational period which will lead to a spectrum with sidebands around the gearmesh frequency and its harmonics." [29] Acoustic results show these effects clearly and might be a good method to detect sidebands between Gear Mesh Frequency and first superharmonic. 


\subsubsection{Experimental and Analytical result comparison}

Verifying experimental results is important to know what bearing and gear frequencies show up in experimental results. Table 15 shows frequencies according to the gear system without bearing.

Table 15. Calculated Frequencies compared with Experimental Results of the gear

\begin{tabular}{|c|c|c|c|c|c|c|c|}
\hline \multirow{3}{*}{\multicolumn{2}{|c|}{ Item }} & \multicolumn{3}{|c|}{ First Gear Pair } & \multicolumn{3}{|c|}{ Second Gear Pair } \\
\hline & & \multirow[t]{2}{*}{ Calc. $(\mathrm{Hz})$} & \multicolumn{2}{|c|}{ Exp. [Hz] } & \multirow{2}{*}{$\begin{array}{l}\text { Calc. } \\
\text { (Hz) }\end{array}$} & \multicolumn{2}{|c|}{ Exp. $(\mathrm{Hz})$} \\
\hline & & & vib. & ac. & & vib. & ac. \\
\hline \multicolumn{2}{|c|}{ Gear Mesh Frequency } & 240 & 240 & 240 & 144 & 144 & 144 \\
\hline \multirow{11}{*}{ 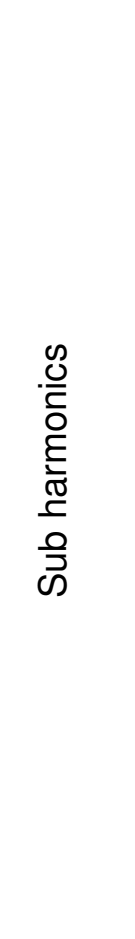 } & GMF $* 1 / 12$ & 20 & -- & -- & 12 & -- & -- \\
\hline & GMF $* 2 / 12$ & 40 & -- & -- & 24 & -- & -- \\
\hline & GMF $* 3 / 12$ & 60 & -- & -- & 36 & -- & -- \\
\hline & GMF $* 4 / 12$ & 80 & -- & -- & 48 & -- & -- \\
\hline & GMF $* 5 / 12$ & 100 & -- & -- & 60 & -- & -- \\
\hline & GMF $* 6 / 12$ & 120 & 120 & 120 & 72 & -- & -- \\
\hline & GMF $* 7 / 12$ & 140 & 140 & 140 & 84 & -- & -- \\
\hline & GMF $* 8 / 12$ & 160 & -- & -- & 96 & -- & -- \\
\hline & GMF $* 9 / 12$ & 180 & 180 & 180 & 108 & -- & -- \\
\hline & GMF $* 10 / 12$ & 200 & 200 & & 120 & 120 & 120 \\
\hline & GMF $* 11 / 12$ & 220 & -- & -- & 132 & -- & 132 \\
\hline \multirow{3}{*}{ 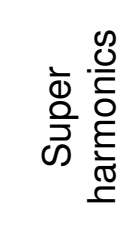 } & $\mathrm{GMF} * 2$ & 480 & 480 & 480 & 288 & 288 & 288 \\
\hline & $\mathrm{GMF} * 3$ & 720 & 720 & 720 & 432 & 432 & 432 \\
\hline & GMF $* 4$ & 960 & 960 & 960 & 576 & 576 & 576 \\
\hline
\end{tabular}


Table 16. Calculated Frequencies compared with Experimental Results of bearings

\begin{tabular}{|c|c|c|c|c|c|c|c|c|c|c|}
\hline & \multirow{3}{*}{ Item } & \multicolumn{3}{|c|}{ Input shaft } & \multicolumn{3}{|c|}{ Middle shaft } & \multicolumn{3}{|c|}{ Output shaft } \\
\hline & & \multirow{2}{*}{$\begin{array}{l}\text { Calc. } \\
(\mathrm{Hz})\end{array}$} & \multicolumn{2}{|c|}{ Exp. $(\mathrm{Hz})$} & \multirow{2}{*}{$\begin{array}{l}\text { Calc. } \\
(\mathrm{Hz})\end{array}$} & \multicolumn{2}{|c|}{ Exp. $(\mathrm{Hz})$} & \multirow{2}{*}{$\begin{array}{c}\text { Calc. } \\
(\mathrm{Hz})\end{array}$} & \multicolumn{2}{|c|}{ Exp. $(\mathrm{Hz})$} \\
\hline & & & vib. & ac. & & vib. & ac. & & vib. & ac. \\
\hline \multicolumn{2}{|c|}{ Shaft speed } & 10 & -- & -- & 4 & -- & -- & 3 & -- & -- \\
\hline \multirow{9}{*}{ 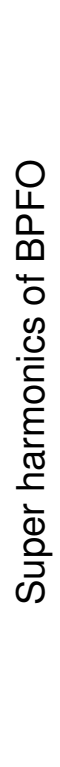 } & $\mathrm{BPFO} * 1$ & 68 & -- & -- & 27 & -- & -- & 21 & -- & -- \\
\hline & $\mathrm{BPFO} * 2$ & 137 & -- & -- & 55 & -- & -- & 41 & -- & -- \\
\hline & $\mathrm{BPFO} * 3$ & 205 & 204 & -- & 82 & 81.5 & -- & 62 & -- & -- \\
\hline & $\mathrm{BPFO} * 4$ & 273 & -- & -- & 109 & -- & 110 & 82 & -- & -- \\
\hline & $\mathrm{BPFO} * 5$ & 342 & -- & 342 & 137 & -- & -- & 103 & -- & -- \\
\hline & $\mathrm{BPFO} * 6$ & 410 & 408 & 410 & 164 & 163.5 & & 123 & -- & -- \\
\hline & $\mathrm{BPFO} * 7$ & 479 & 480 & -- & 191 & -- & -- & 144 & 144 & 144 \\
\hline & $\mathrm{BPFO} * 8$ & 547 & -- & -- & 219 & -- & -- & 164 & -- & -- \\
\hline & $\mathrm{BPFO} * 9$ & 615 & -- & -- & 246 & -- & -- & 185 & -- & -- \\
\hline \multirow{9}{*}{ 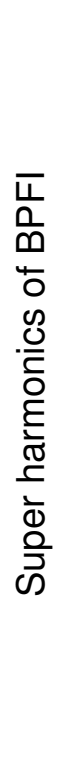 } & $\mathrm{BPFO} * 1$ & 92 & -- & -- & 37 & -- & -- & 27 & -- & -- \\
\hline & BPFO $* 2$ & 183 & -- & -- & 73 & -- & -- & 55 & -- & -- \\
\hline & BPFO $* 3$ & 275 & -- & -- & 110 & & 110 & 82 & -- & -- \\
\hline & $\mathrm{BPFO} * 4$ & 367 & -- & -- & 147 & -- & -- & 110 & -- & 110 \\
\hline & BPFO $* 5$ & 458 & 640 & -- & 183 & -- & -- & 137 & -- & -- \\
\hline & $\mathrm{BPFO} * 6$ & 550 & -- & 550 & 220 & 220 & -- & 165 & -- & -- \\
\hline & $\mathrm{BPFO} * 7$ & 641 & -- & -- & 257 & -- & -- & 192 & -- & -- \\
\hline & BPFO $* 8$ & 733 & -- & -- & 293 & 294 & 291 & 220 & 220 & 220 \\
\hline & $\mathrm{BPFO} * 9$ & 825 & -- & -- & 330 & -- & 330 & 247 & -- & -- \\
\hline
\end{tabular}




\subsubsection{Comparison between Adams ${ }^{\circledR}$ results and experimental results}

Acoustic and vibration results with torque of $3390 \mathrm{Nmm}$ compared with a rigid elastic model in $A d a m s \circledast$ with input speed of

$10 \mathrm{~Hz}$ and torque at output shaft of $10,000 \mathrm{Nmm}$

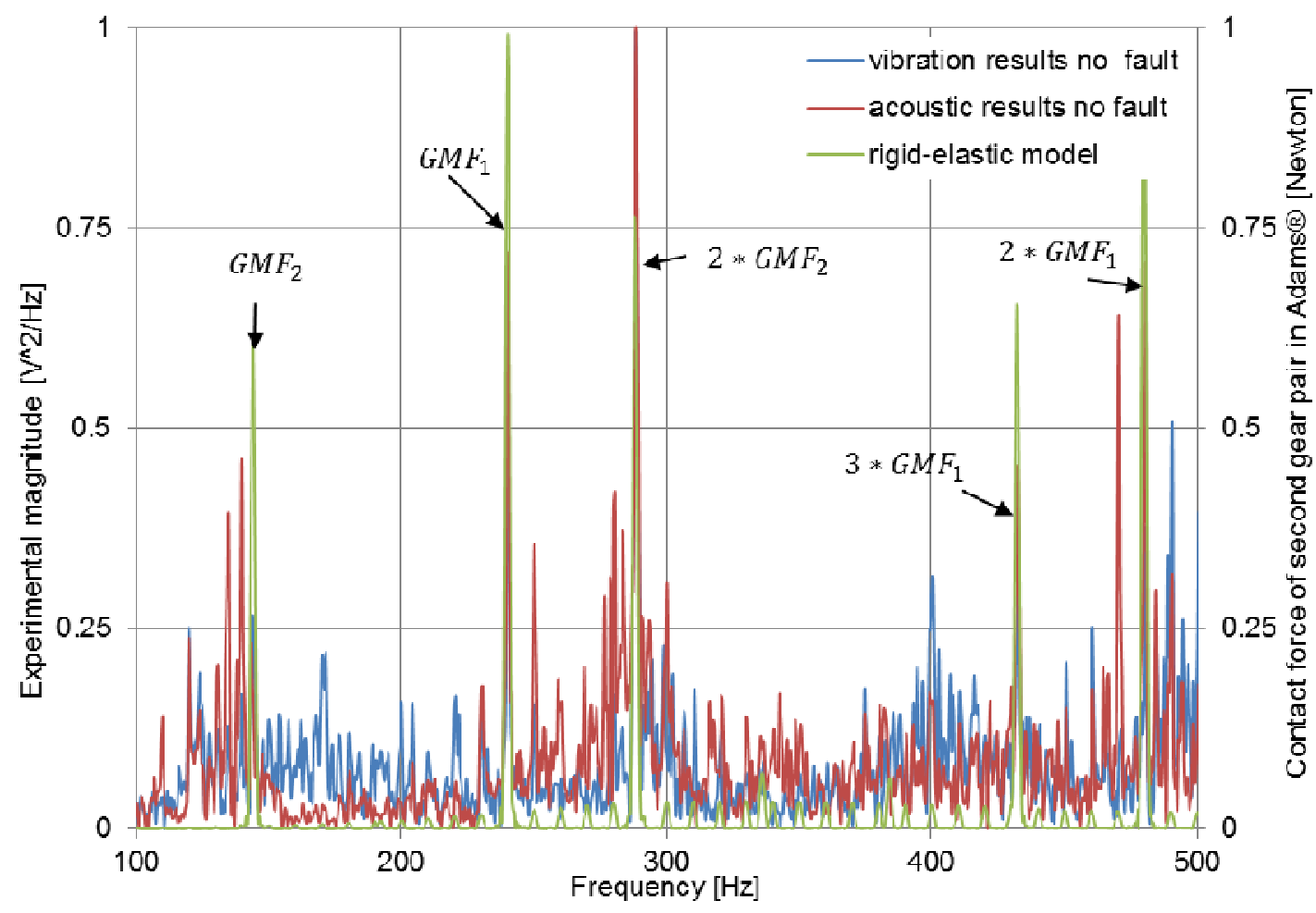

Figure 79. Frequency domain of experimental results and rigid-elastic results

Experimental results are measured in square voltage divided with Hertz and shown on the "Primary Vertical Axis Title" on the left side of Figure 79. Numerical contact forces in Adams ${ }^{\circledR}$ are measured in Newton and shown on the "Secondary Vertical Axis Title" on the right side of Figure 79. The Gear Mesh Frequencies of the first and second gear pair with the first two superharmonics are clearly evident in all cases. Sidebands between Gear Mesh Frequencies are generated from the gear and bearing system listed in Table 15 and Table 16. The rigid-elastic model in Adams $®$ has a frequency modulation of $10 \mathrm{~Hz}$ and correlates with input shaft speed. Gear Mesh Frequencies of both gear pairs are shown in Figure 80. 

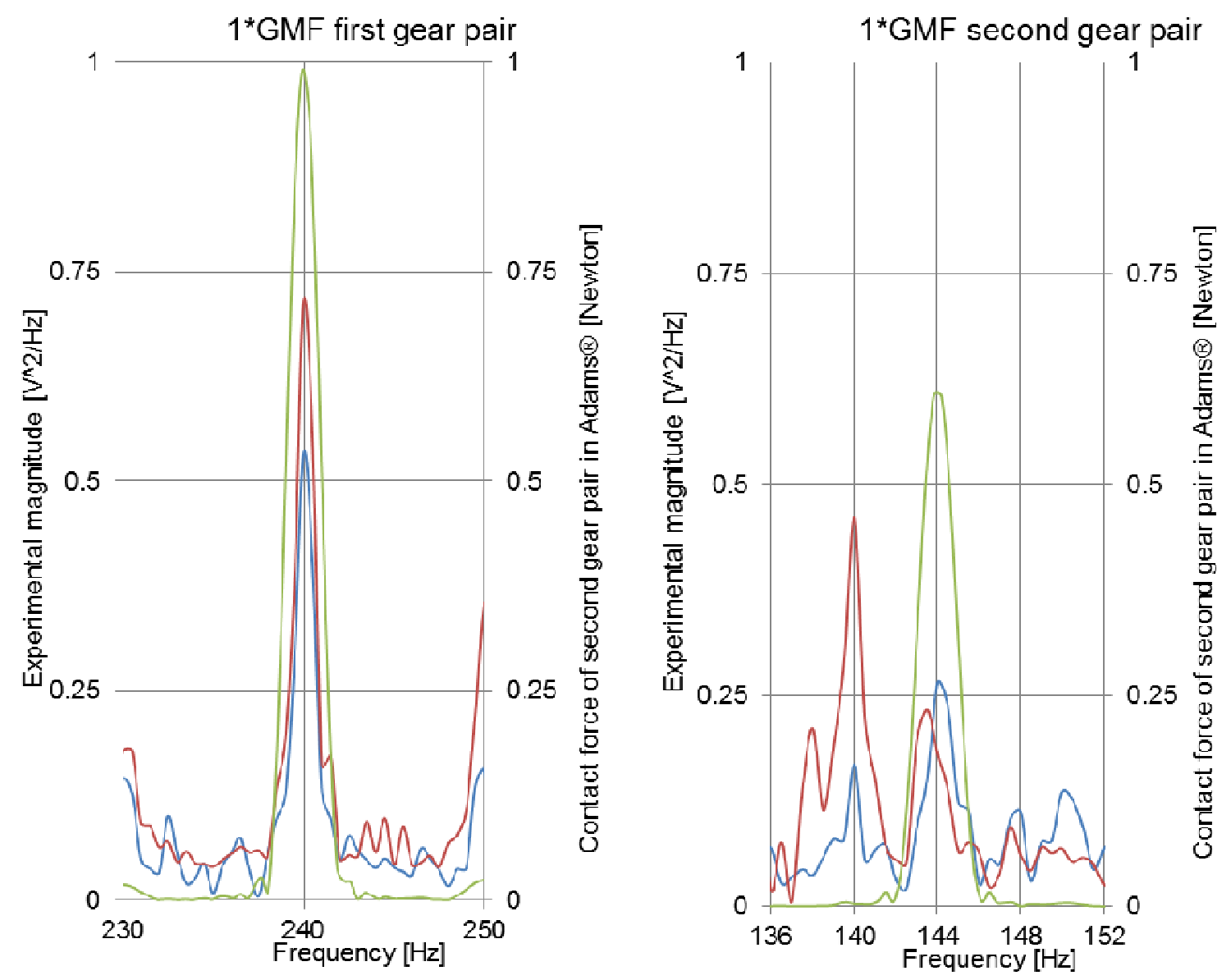

Figure 80. First superharmonic of Figure 79. Legend follows Figure 79.

All three Gear Mesh Frequencies are clearly evident. The second gear pair has lower magnitudes in vibration, acoustic and rigid-elastic model in Adams ${ }^{\circledR}$ compared to the first gar pair. The vibration Frequencies has sidebands with a higher magnitude than the Gear Mesh Frequency itself with $140 \mathrm{~Hz}$ and correlates with one subharmonic of the first gear pair. The Magnitudes of acoustic results is half high compared to vibration results of the first gear pair. However, the magnitudes in the second gear pair are as high as acoustic magnitudes. The second Gear Mesh Frequencies of both gear pairs are shown in Figure 81 below. 

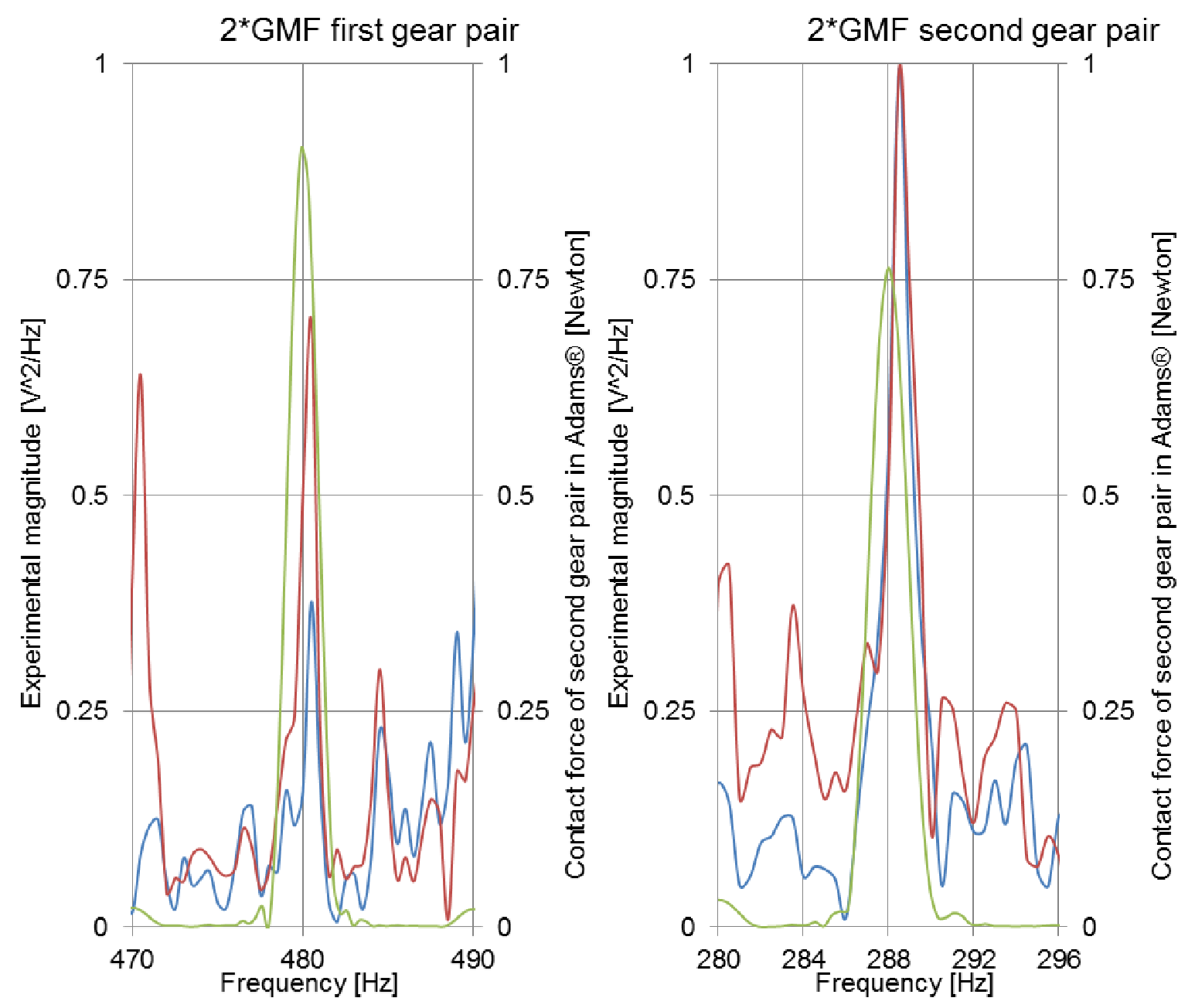

Figure 81. Second superharmonic of Figure 79. Legend follows Figure 79.

Experimental vibration response shows unknown sidebands of $280.5 \mathrm{~Hz} 283.5 \mathrm{~Hz}$, $290 \mathrm{~Hz}$, and $293.5 \mathrm{~Hz}$ that don't relate to any shaft speed. Second Gear Mesh Frequency magnitudes of acoustic and vibration are higher compared to the rigid-elastic model results. However, magnitudes in Adams ${ }^{\circledR}$ are higher in the first gear pair. 


\section{Conclusion}

\subsection{Force distribution along the line of contact}

It has been shown that contact forces along the line of tooth contact can be developed in Adams ${ }^{\circledR}$. Loads along the Roll Angle are important to judge Tip Relief and further the health of gear action. It is possible to recognize and adjust the shape of Tip Relief profile loads along the Roll Angle, shown in Figure 82.

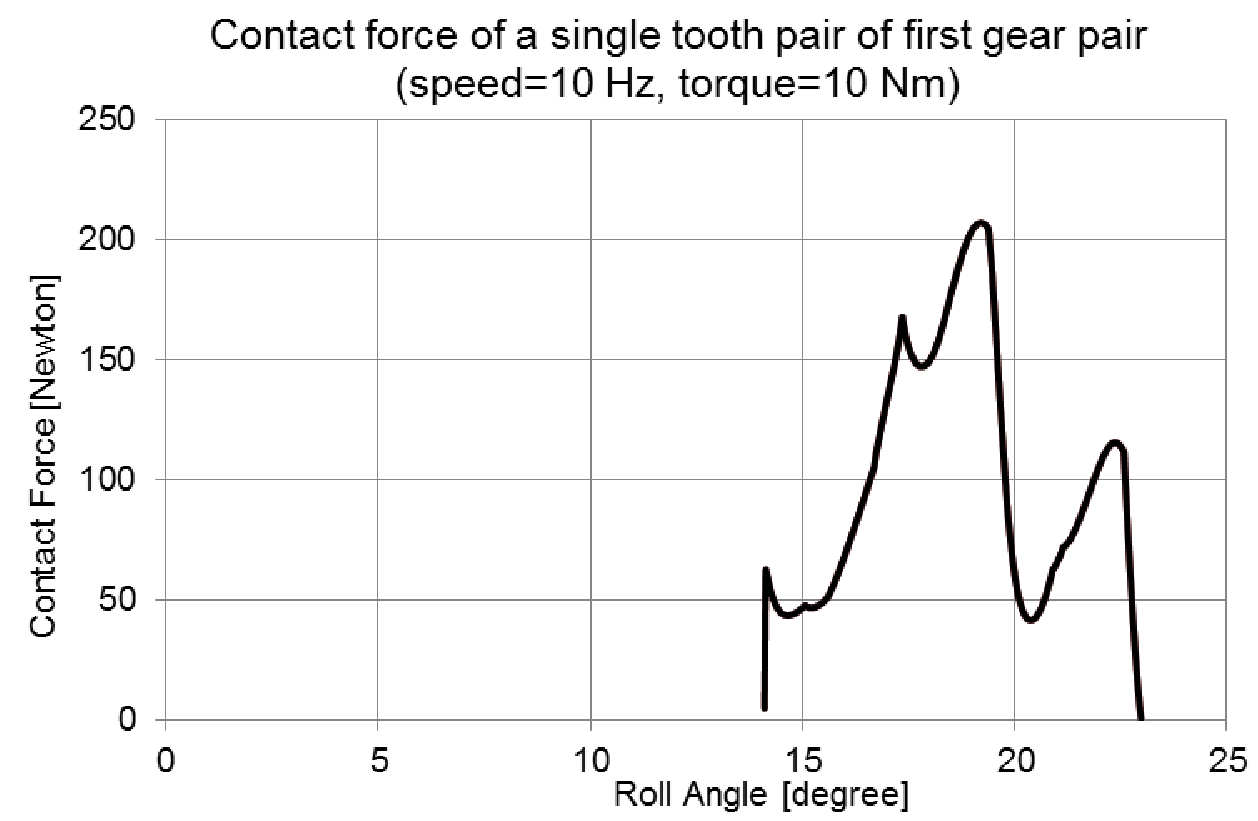

Figure 82. Contact forces along the Roll Angle with a rigid-elastic model in Adams ${ }^{\circledR}$

Research with the rigid-elastic model in Admas $\AA^{\circledR}$ have shown that gear action is highly sensitive to speed, torque, gear profile, and especially contact forces. Contact forces with damping coefficient, gear mesh stiffness, and force exponent have to be chosen and determined very carefully in order to get decent results. 


\subsection{Gear action with acoustic and rigid-elastic modeling}

Acoustic and vibration results matched the major gear contact frequencies in analytical and numerical results. Implanted tooth breakage in the Gearbox Dynamic Simulator matched results from the rigid-elastic model in Adams $\AA^{\circledR}$ and confirmed with literature. Further gear failure modeled in Adams $\AA$ matched expected results and is therefore a suitable software product to model and simulate gear failure. Figure 83 compares acoustic, vibration, and rigid-elastic model results.

Acoustic and vibration results with torque of $3390 \mathrm{Nmm}$ compared with a rigid elastic model in Adams $(3)$ with input speed of

$10 \mathrm{~Hz}$ and torque at output shaft of $10,000 \mathrm{Nmm}$

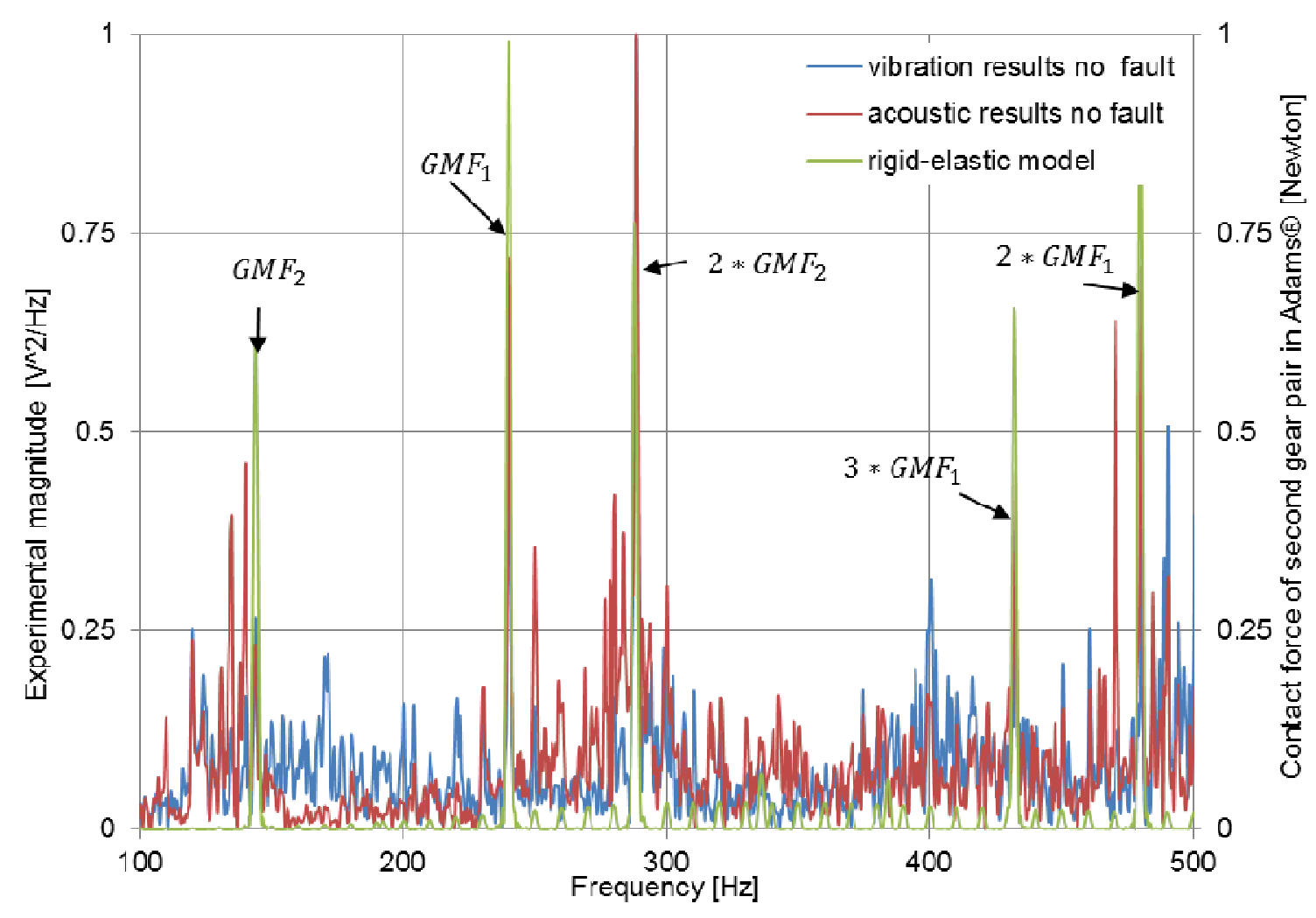

Figure 83. Contact forces in Adams ${ }^{\circledR}$ and experimental data of an eccentric gear 


\section{Bibliography}

1. Lester E. Alban: "Systematic Analysis of Gear Failure." (1985).

ISBN: 0-87170-200-

2. J. Derek Smith: "Gear and their Vibration" (1983)

(a basic approach to understanding gear noise.)

ISBN 0-8247-1759-7.

3. P. S. Houghton C. Eng., M. I. Mech. E., M. I. B. F. "Gears"

Spur, Helical, Bevel, Internal, Epicyclic and Worm. (1960).

4. J.R. Davis \& Associates: "Gear Materials, Properties, and Manufacture" ISBN 0-87170-815-9

5. G. Niemann and H. Winter: „Getriebeschaeden und Abhilfe, Entwicklungstendenzen, Maschinen-elemente, Vol 2, 2nd ed. s.I. Springer-Verlag (Berlin), 1983.

6. E.E. Shipley: "Failure Modes in Gears," 19 Oct 1973 (Detroit), American Society of Mechanical Engineers

7. American national standard: "Appearance of Gear Teeth -Terminology of Wear and Failure ANSI/AGMA." American National Standards Institute/American Gear Manufacturers Assiciation. 1010-E95.

ISBN: 1--55589--665--0

8. D.W. Dudley, Gear Wear, Wear Control Handbook M. Peterson and W. Winter, Ed. American society of Mechanical Engineering 
9. Raymond J. Drago: "Fundamentals of Gear Design"

ISBN 0-409-90127-X

10. James I.Taylor: "The Gear Analysis Handbook"

ISBN 0-9640517-1-0

11. Richard H. Ewert: "Gears and Gear Manufacture- The Fundamentals" ISBN 0-412-10611-6

12. J.R. Colbourne: "The Geometry of Involute Gears" ISBN 3-540-96522-X Springer Verlag Berline Heidelberg New York

13. Naim Baydar and Andrew Ball: "A Comparative Study of Acoustic and Vibration Signals in Detection of Gear Failures using Wigner-Ville Distribution" Article Received 1 March 2000, and in final form 24 August 2000

14. Prof. K.Gopinath \& Prof. M.M.Mayuram Machine Design II "Module 2 - GEARS Lecture 6-gear failure"

15. Bob Errichello, Jane Muller: "How to Analyze Gear Failures" http://www.machinerylubrication.com/Read/150/gear-failures

16. Jacks Transmissions: "Gear Work and Strengthening" http://www.jackstransmissions.com/pages/gear-work-and-strengthening

17. Rotating Machinery - Consultancy Services: "Gear tooth Fracture Caused by Subcase Fatigue Failure Below the Carburized Layer" http://www.dnv.com.ar/industry/maritime/servicessolutions/ consulting/technicalconsulting/rotatingmachinery/tiff.asp 
18. AMERICAN NATIONAL STANDARD

Appearance of Gear Teeth -Terminology of Wear and Failure http://www.scribd.com/doc/47032508/ANSI-AGMA-1010-E95

19. James I. Taylor: "The Vibration Analysis Handbook" http://www.scribd.com/doc/20986108/Vibration-Analysis-Handbook-James-Taylor

20. Rothe Erde- ThyssenKrupp http://www.rotheerde.com/GB/TG/Kopfflankenruecknahme.shtm

21. Prof. M. Beghini, Dott. F. Presicce, Dott. C. Santus: "Proposal for Tip Relief Modification to Reduce Noise in Spur Gears and Sensitivity to Meshing Conditions" Dipartimento di Ingegneria Meccanica, Nucleare e della Produzione http://www.dimnp.unipi.it/santus/Pubblicazioni/Articoli/2005_3.pdf

22. A Comparison of Gear Mesh Stiffness Modeling Strategies Jim Meagher, Xi Wu, Dewen Kong, and Chun Hung Lee

23. System Health Monitoring and Prognostics - a review of current paradigms and practices

Ranganath Kothamasu, Samuel H. Huang, William H. VerDuin

24 Simulation of acoustic and Vibroacoustic Problems in LS-Dyna® using Boundary Element Method.

Yun Hang, Mhamed Souli, Rogelio Perez. (2008)

Livermore Software Technology Corporation USA [61] 
25. Learn material for Spectrum interpretation

http://www.vibrationschool.com/mans/Speclnter/Speclnter45.htm

26. Assessment of Gear Damage Monitoring Techniques using Vibration Measurement

Wilson Q. Wang, Fathy Ismail and M. Farid Golnaraghi

27. Observation of Acoustic Emission Activity during Gear Defect Diagnosis

Tim Toutountzakis and David Mba

28. PCB Piezotronics, Inc.

Website: www.pcb.com

29. Effect of spalling or tooth breakage on gearmesh stiffnessand dynamic response of a one-stage spur gear transmission

Fakher Chaari, Walid Baccar, Mohamed Slim Abbes, Mohamed Haddar (2007) 